\title{
A Comprehensive Review of the Ethnotraditional Uses and Biological and Pharmacological Potential of the Genus Mimosa
}

\author{
Ismat Majeed ${ }^{1}$, Komal Rizwan ${ }^{2}$, Ambreen Ashar ${ }^{1}\left({ }^{1}\right.$, Tahir Rasheed ${ }^{3}{ }^{\oplus}$, Ryszard Amarowicz ${ }^{4, *}$, \\ Humaira Kausar ${ }^{5}$, Muhammad Zia-Ul-Haq ${ }^{6}$ and Luigi Geo Marceanu ${ }^{7}$ (D) \\ 1 Department of Chemistry, Government College Women University, Faisalabad 38000, Pakistan; \\ ismatmajeed123@gmail.com (I.M.); ambreenashar2013@gmail.com (A.A.) \\ 2 Department of Chemistry, University of Sahiwal, Sahiwal 57000, Pakistan; komal.rizwan45@yahoo.com \\ 3 School of Chemistry and Chemical Engineering, Shanghai Jiao Tong University, Shanghai 200240, China; \\ masil@sjtu.edu.cn \\ 4 Department of Chemical and Physical Properties of Food, Institute of Animal Reproduction and Food \\ Research, Polish Academy of Sciences, Tuwima Street 10, 10-748 Olsztyn, Poland \\ 5 Department of Chemistry, Lahore College for Women University, Lahore 54000, Pakistan; \\ humairakausar1@gmail.com \\ 6 Office of Research, Innovation \& Commercialization, Lahore College for Women University, \\ Lahore 54000, Pakistan; ahirzia@gmail.com \\ 7 Faculty of Medicine, Transilvania University of Brasov, 500019 Brasov, Romania; marceanu@gmail.com \\ * Correspondence: amaro@pan.olsztyn.pl; Tel.: +48-89-523-4627
}

Citation: Majeed, I.; Rizwan, K.; Ashar, A.; Rasheed, T.; Amarowicz, R.; Kausar, H.; Zia-Ul-Haq, M.; Marceanu, L.G. A Comprehensive Review of the Ethnotraditional Uses and Biological and Pharmacological Potential of the Genus Mimosa. Int. J. Mol. Sci. 2021, 22, 7463. https:// doi.org/10.3390/ijms22147463

Academic Editors: Raffaele Capasso, Rafael Cypriano Dutra and Elisabetta Caiazzo

Received: 14 June 2021

Accepted: 7 July 2021

Published: 12 July 2021

Publisher's Note: MDPI stays neutral with regard to jurisdictional claims in published maps and institutional affiliations.

Copyright: (c) 2021 by the authors. Licensee MDPI, Basel, Switzerland. This article is an open access article distributed under the terms and conditions of the Creative Commons Attribution (CC BY) license (https:/ / creativecommons.org/licenses/by/ $4.0 /)$.

\begin{abstract}
The Mimosa genus belongs to the Fabaceae family of legumes and consists of about 400 species distributed all over the world. The growth forms of plants belonging to the Mimosa genus range from herbs to trees. Several species of this genus play important roles in folk medicine. In this review, we aimed to present the current knowledge of the ethnogeographical distribution, ethnotraditional uses, nutritional values, pharmaceutical potential, and toxicity of the genus Mimosa to facilitate the exploitation of its therapeutic potential for the treatment of human ailments. The present paper consists of a systematic overview of the scientific literature relating to the genus Mimosa published between 1931 and 2020, which was achieved by consulting various databases (Science Direct, Francis and Taylor, Scopus, Google Scholar, PubMed, SciELO, Web of Science, SciFinder, Wiley, Springer, Google, The Plant Database). More than 160 research articles were included in this review regarding the Mimosa genus. Mimosa species are nutritionally very important and several species are used as feed for different varieties of chickens. Studies regarding their biological potential have shown that species of the Mimosa genus have promising pharmacological properties, including antimicrobial, antioxidant, anticancer, antidiabetic, wound-healing, hypolipidemic, anti-inflammatory, hepatoprotective, antinociceptive, antiepileptic, neuropharmacological, toxicological, antiallergic, antihyperurisemic, larvicidal, antiparasitic, molluscicidal, antimutagenic, genotoxic, teratogenic, antispasmolytic, antiviral, and antivenom activities. The findings regarding the genus Mimosa suggest that this genus could be the future of the medicinal industry for the treatment of various diseases, although in the future more research should be carried out to explore its ethnopharmacological, toxicological, and nutritional attributes.
\end{abstract}

Keywords: Mimosa; genus; Fabaceae; pharmacology; nutrition; leaves

\section{Introduction}

The Mimosa genus belongs to the Fabaceae family of legumes (subfamily: Mimosoideae) and consists of almost 400 species of shrubs and herbs [1]. The species are distributed mainly in Bangladesh, Indonesia, Malaysia, Japan, India, Pakistan, Sri Lanka, China, Cambodia, Taiwan, Africa (Nigeria, Mauritius, and Reunion Island), Australia, Brazil, Venezuela, Mexico, Philippines, Cuba, northern Central America, Paraguay, Argentina, Uruguay, Thailand, several Pacific Islands, Papua New Guinea, and North America [2-11]. 
Figure 1 presents the ethnogeographical distribution of the Mimosa species in different countries of the world. Almost 20-25 species of this genus are well known to the world, including Mimosa tenuiflora (Wild.) pior, Mimosa pudica L., Mimosa pigra L., Mimosa caesalipiniifolia Benth., Mimosa hamata Willd., Mimosa diplotricha Sauvalle, Mimosaa xanthocentra Mart., Mimosa artemisiana Heringer and Paula, Mimosa invisa Mart. ex Colla, Mimosa scabrella Benth., Mimosa somnians Humb. and Bonpl. ex Willd., Mimosa bimucronata (DC.) Kuntze, Mimosa verrucosa Benth., Mimosa arenosa (Willd.) Poir., Mimosa humilis Willd., Mimosa rubicaulis Lam., Mimosa linguis, and M. albida Willd. Mimosa ophthalmocentra Mart. ex Benth. (http:/ / mpns.kew.org/MPNS.kew.org 2018; www.theplantlist.org 2017) (Accessed on 18 May 2021). Leaves of this genus may be bipinnate or binate, compound or branched, with one or two pairs of branchlets or much larger branched leaves. Some species have the ability to fold their leaves when touched, with M. pudica being one common example. The flowers may be pink and globular in the form of clusters and with prickles or may be white and grouped in dense heads 3-6.5 mm long. The fruit are lance-shaped with 2-6 articulations. The fruit wall is compressed between the seeds. Huge amounts of starch and calcium oxalate crystals are present in the bark [12]. Some species are prickly leguminous shrubs [13]. The plants of this genus usually grow across roadsides, walkways, marshes, and hillsides, and on margins of rivers and lakes on wet soil, where several individuals can form dense aggregations [14]. The plants are commonly used for ornamental purposes. They also serve as sleeping shelters for animals [15]. Economically, their wood is used for fence posts, firewood, coal, plywood, particle board, and lightweight containers, and more recently has been introduced in furniture and flooring [16]. Leaves of the plants are used for poultry diets [17]. In the food industry, the leaves are used as additives, while in the leather and textile industry they are used as colorants $[18,19]$. The plants provide wood for market purposes and add nitrogen in warm-climate silvopasture systems [20]. This genus has remarkable economic importance in the cosmetics industry [21]. Traditionally, species of this genus are used in folklore medicines for the treatment of various ailments, including head colds, wounds, toothaches, jaundice, eye problems, fever, weak heart, skin burns, asthma, diarrhea, piles, gastrointestinal ailments, liver disorders (such as hepatitis and diuresis), and respiratory [22-26] disorders. They are also used as coagulants and in tonics for urinary complaints. The genus Mimosa has been demonstrated to possess various pharmacological activities, including antiseptic, antimicrobial [27,28], antioxidant [29-34], anticonvulsant [35], antifertility [36], antigout [37], anti-inflammatory [38-40], antinociceptive [41,42], antiulcer [43], antimalarial [44], antiparasitic [45], antidiabetic [46,47], anticancer [48,49], antidepressant [50], antidiarrheal [51,52], antihistamic [53], wound-healing [54], antispasmolytic [55], hypolipidemic [56], hepatoprotective [57], hypolipidiemic [58], antivenom [40], antiproliferative [59], antiviral [60], and aphrodisiac activities [61]. Phytochemicals studies of plants have revealed the presence of secondary metabolites, such as alkaloids, tannins, flavonoids, terpenoids, saponins, steroids [62,63], and coumarins [64]. The green synthesis of nanoparticles is cheap, simple, comparatively and reproducible, resulting in the production of more stable and useful materials [65]. The Mimosa genus has been used in the green synthesis of pharmacologically important gold [66], silver [67], iron [68], cadmium [69], platinum [70], and zinc oxide [71]based nanoparticles; however, data regarding all species of the Mimosa genus have not been compared and organized to date in proper review form (to the best knowledge of the authors). Our research group is currently working on compiling data regarding bioactive constituents isolated from the genus Mimosa and their pharmacological effectiveness. 


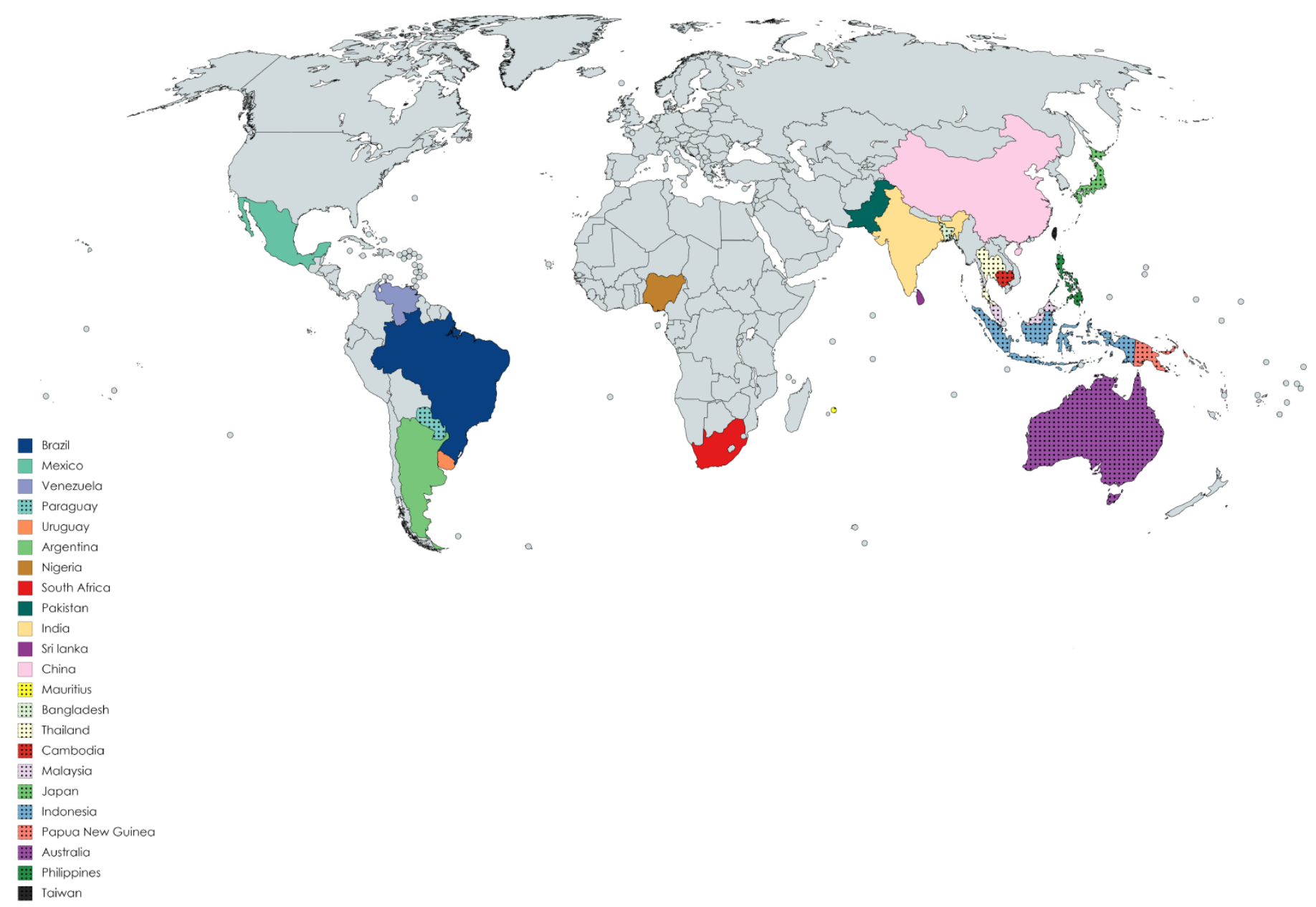

Figure 1. Ethnogeographical distribution of Mimosa species.

\section{Materials and Methods}

A detailed bibliographic study that included papers published from 1931 to 2020 was carried out. Several databases (Science Direct, Francis and Taylor, Scopus, Google Scholar, PubMed, SciELO, Web of Science, SciFinder, Wiley, Springer, Google, and The Plant Database) were explored in order to collect information on this genus. Various books, full text manuscripts, and abstracts were consulted. The genus name and the synonyms and scientific names of Mimosa species were used as keywords. The scientific names of all plants of the genus Mimosa and their synonyms were validated using a standard database (http:/ / mpns.kew.org/MPNS.kew.org 2018; www.theplantlist.org 2017) (accessed on 15 May 2021).

\section{Nutritional Potential of Genus Mimosa}

Nworgu and Egbunike [17] reported on the nutritional potential of M. invisa leaves by preparing meals for different varieties of cockerel chicks, cockerel growers, broiler starters, and finishers within the years 2004-2009. The diets were formulated for cockerel chicks, broiler starters, and finishers. Leaves were found to be rich in crude protein $(23.34 \%)$, ash $(4.25 \%)$, dry matter $(89.99 \%)$, crude fiber $(11.29 \%)$, nitrogen-free extract $(58.74 \%)$, oxalate $(0.065 \%)$, phytate $(0.37 \%)$, and tannins $(1.57 \%)$. High mineral elements were found in M. invisa leaves, including zinc ( $40.00 \%$ of DM), iron (10.11\% of DM), potassium $(1.60 \%$ of DM), calcium ( $1.26 \%$ of DM), phosphorus $(0.38 \%$ of DM), and magnesium $(0.24 \%$ of $\mathrm{DM})$. Inclusion of more than $20 \mathrm{~g} / \mathrm{kg}$ M. invisa leaf meal to the diets of cockerel chicks and cockerel growers resulted in decreased feed intake, weight gain, and feed conversion ratio. Dietary inclusion of leaf meal in broiler starters and finishers resulted in significant 
reductions in feed, weight gain, and feed conversion ratio. These results were found to be progressive and comparable within different chicken types. A schematic illustration of the nutritional value of the Mimosa genus is presented in Figure 2.

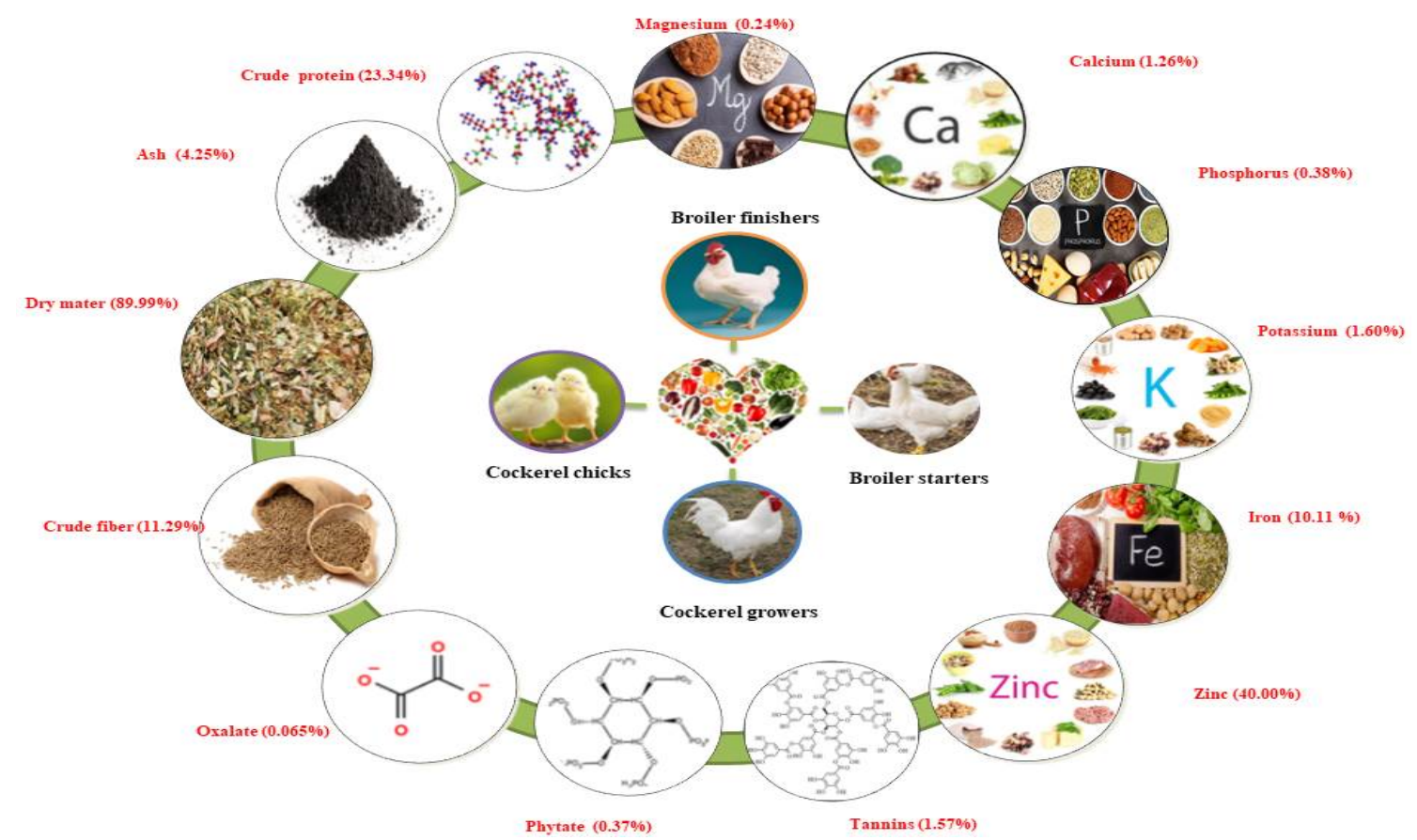

Figure 2. Schematic presentation of the nutritional value of the Mimosa genus. Note: \% represents percentage of dry matter content.

Rajan et al. [72] measured trace elements present in M. pudica leaves with the help of the proton-induced X-ray emission (PIXE) technique. PIXE analysis revealed that trace elements of $\mathrm{Fe}=308.467 \mathrm{mg} / \mathrm{L}, \mathrm{Mn}=65.664 \mathrm{mg} / \mathrm{L}, \mathrm{Zn}=18.209 \mathrm{mg} / \mathrm{L}, \mathrm{Cu}=10.707 \mathrm{mg} / \mathrm{L}$, $\mathrm{Co}=2.025 \mathrm{mg} / \mathrm{L}$, and $\mathrm{V}=0.059 \mathrm{mg} / \mathrm{L}$ were present in M. pudica leaves. These trace elements are used for curing skin diseases, especially infections on the legs and between the fingers, and are also taken orally. Yongpisanphop et al. [73] estimated lead contamination levels in M. pudica roots. The lead contamination level found to be in the root sample was $826 \mathrm{mg} / \mathrm{kg}$, as compared to $496 \mathrm{mg} / \mathrm{kg}$ in the soil sample. There are no reports available regarding the trace elements and mineral compositions of other Mimosa species.

\section{Ethno-Traditional Uses of Genus Mimosa}

Various species of Mimosa, including M. tenuiflora, M. pudica, M. pigra, M. caesalpiniifolia, M. hamata, M. rubicaulis, M. somnians, M. bimucronata, M. linguis, M. humilis, $M$. invisa, $M$. arenosa, $M$. ophthalmocentra, $M$. verrucosa, and $M$. albida, have been reported to be used in traditional medicine for the treatment of various ailments (Figure 3). Due to their potential benefits in phytomedicines, all parts of this genus are used in traditional systems of medicine in Mexico, Brazil, India, Bangladesh, China, Indonesia, Madagascar, South America, and tropical Africa for countless ailments, including toothaches, head colds, and eye problems. M. tenuiflora is a perennial shrub or tree commonly known as skin tree or Jurema-preta in many parts of the world. In Northeastern Brazil, the bark of M. tenuiflora is used in a religious drink called Yurema [74,75], while the leaves, stem, and flowers are used to relieve fever, menstrual colic, headache, hypertension, bronchitis, and coughs [41,55,76-81]. In Mexico, its stem bark is used to treat skin burns, lesions, and inflammation [24]. 


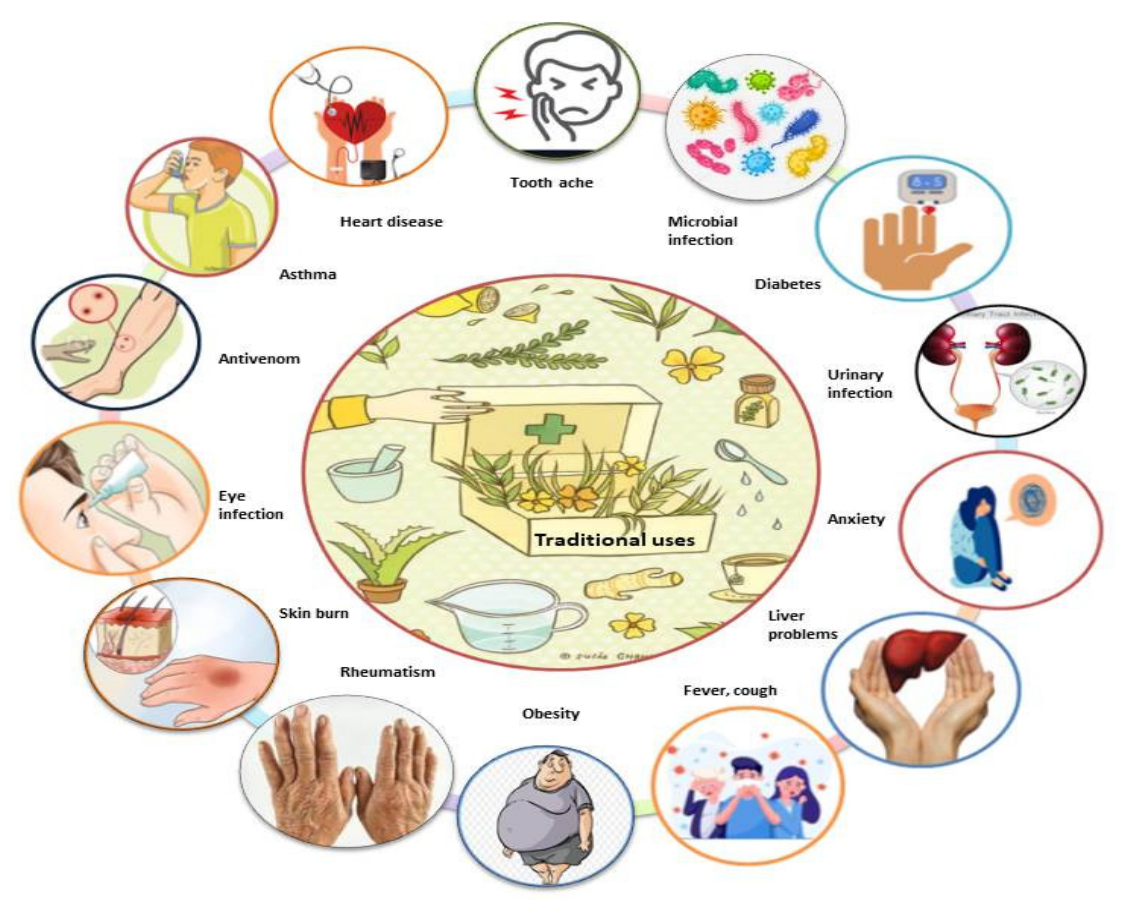

Figure 3. Schematic illustration of the traditional uses of the genus Mimosa.

M. pudica is a creeping perennial or annual flowering plant and is the most famous plant of this genus; it is commonly known as touch-me-not, sensitive plant, or shy plant. In Mexico, M. pudica is used for the treatment of depression, anxiety, premenstrual syndrome, menorrhagia, skin wounds, diarrhea, and rheumatoid arthritis [50,82-85]. Ayurveda and Unani are the two main medical systems in India, in which M. pudica leaves and roots are used for prevention of vaginal and uterine infections [86], ulcers, bile, leprosy, fever, small pox, jaundice, and piles $[87,88]$. The seeds are combined with sugar and used to control skin and venereal diseases [72]. Indians use it for the removal of kidney stone (vesicle calculi) myalgia, rheumatism, uterus tumors, and odema-type disorders [89]. The leaves are commonly used in Bangladesh as one of the ingredients to control piles, diarrhea, persistent dysentery, and convulsion of children [90]; additionally, the root extracts have antivenomic properties [91]. In China, women use its herbal paste in the form of a solution to narrow their vaginas [92], and it is also used as a dental powder to treat gingiva and bad breath [93]. M. pigra is a leguminous shrub known as giant sensitive tree and bashful plant. The people of Africa, the America, Indonesia, and Mexico use M. pigra to deal with several health disorders, such as liver ailments, hepatitis and respiratory disorders [94], and snakebite [95]. It is also used for mouthwash to treat toothaches and in eye medicines [96]. Additionally, the leaves are used by the local people of Bangladesh to lower their blood sugar [97], while Indonesian people use the roasted ground leaves to stabilize a weak heart or weak pulse $[98,99]$.

M. caesalpiniifolia is a spiny, deciduous tree or shrub with white flowers that is commonly found in Brazil. Its bark and flowers are used as an effective remedy to prevent skin infections, injuries [100], and hypertension [77].

$M$. hamata is a flowering shrub found in India that is known as Jinjani, which is used as animal feed. The roots and leaves are used in customary medications for the treatment of numerous health ailments, such as jaundice, diarrhea, coagulant, fever, wounds, piles, gastrointestinal and liver disorders (such as hepatitis), and respiratory issues [3], as well as being used in tonics for urinary complaints. A paste made from the leaves is applied to reduce glandular swelling, piles, sinus issues, and sores [101,102]. The seed extract is used as a blood purifier $[33,103]$.

M. albida is a leguminous shrub commonly found in rain forests. In Brazil, roots are used for cardiovascular and renal system disorders [104], as well as inflammation of 
the uterus [105]. In Mexico, the leaves are used for treatment of chronic pain [106]. In Honduras, women use its roots in abortifacient agents [107]. Different species of Mimosa are known by different names in different countries. Ethnobotanical information for this genus based on their geographic distribution, along with the plant parts and their corresponding medicinal properties, are listed in Table 1.

Table 1. Ethnotraditional uses of different species of the genus Mimosa.

\begin{tabular}{|c|c|c|c|c|c|}
\hline Plant & Plant Parts & Country & Common Names in Different Languages & Uses & References \\
\hline \multirow{6}{*}{ M. tenuiflora } & Stem bark & Mexico & Tepescohuite & $\begin{array}{l}\text { Used for to treat cutaneous } \\
\text { wounds, burns, and } \\
\text { inflammations }\end{array}$ & {$[9,24,108-111]$} \\
\hline & $\begin{array}{l}\text { Stem bark, leaves, } \\
\text { flowers }\end{array}$ & $\begin{array}{c}\text { Northeastern } \\
\text { Brazil, Venezuela }\end{array}$ & Skin tree, jurema-preta, calumbi & $\begin{array}{l}\text { Used for injury, odontalgia, } \\
\text { inflammations, fever, } \\
\text { menstrual colic, headache, } \\
\text { hypertension, bronchitis, } \\
\text { cough, external ulcers }\end{array}$ & {$[41,55,76-81]$} \\
\hline & Root bark & $\begin{array}{l}\text { Northeastern } \\
\text { Brazil }\end{array}$ & Jurema preta, black jurema, Vinho de jurema & $\begin{array}{c}\text { Used for Jurema, a } \\
\text { psychoactive beverage } \\
\text { consumed for } \\
\text { medicoreligious purposes }\end{array}$ & {$[74,75]$} \\
\hline & Bark & NortheasternBrazil & & $\begin{array}{c}\text { Some indigenous tribes } \\
\text { use it as a miraculous } \\
\text { drink }\end{array}$ & {$[55,112]$} \\
\hline & & Italy & & Used for eczema & [113] \\
\hline & Whole plant & Mexico & & $\begin{array}{l}\text { Used for hallucinogenic } \\
\text { compounds }\end{array}$ & [114] \\
\hline \multirow{6}{*}{ M. pudica } & Whole plant & $\begin{array}{l}\text { Cameroon, } \\
\text { Mexico }\end{array}$ & $\begin{array}{c}\text { English—“Touch me not”; Urdu-Chhimui; } \\
\text { Punjabi-Lajan; } \\
\text { Hindi-Lajauni, Chhuimui; } \\
\text { Marathi-Lajalu; } \\
\text { Gujrati-Lajavanti, Risamani, Lajamani; } \\
\text { Bengali-Lajjavanti, Lajaka; } \\
\text { Telugu_-Mudugudamara; Tamil- Tottavadi, } \\
\text { Tottalchurungi; } \\
\text { Oriya-Lajakuri; } \\
\text { Kannada-Lajjavati, Muttidasenui, } \\
\text { Machikegida; } \\
\text { Sanskrit-Namaskari, Samanga, Varakranta; } \\
\text { Malayalam-Thottavati }\end{array}$ & $\begin{array}{c}\text { Used for to treat } \\
\text { headaches, insomnia, } \\
\text { depression, anxiety, } \\
\text { premenstrual syndrome, } \\
\text { hemorrhoids, skin } \\
\text { wounds, menorrhagia, } \\
\text { diarrhea, rheumatoid } \\
\text { arthritis }\end{array}$ & {$[50,82-85]$} \\
\hline & Roots & India & & $\begin{array}{l}\text { Used for to treat fever, } \\
\text { dysentery, piles, jaundice, } \\
\text { uterine and vaginal } \\
\text { illnesses, burning } \\
\text { sensation, leucoderma, } \\
\text { asthma, inflammations, } \\
\text { leprosy, fatigue, blood } \\
\text { infections }\end{array}$ & [86] \\
\hline & Stem & & Touch-me-not & $\begin{array}{c}\text { Aphrodisiac properties, } \\
\text { antivenom activities, } \\
\text { antihepatotoxic effect, } \\
\text { diuretic effect, } \\
\text { hyperglycemic effect, } \\
\text { wound-healing effect }\end{array}$ & [115] \\
\hline & Leaves & Bangladesh & & $\begin{array}{l}\text { Used for to treat piles, } \\
\text { diarrhea, persistent } \\
\text { dysentery, convulsion of } \\
\text { children }\end{array}$ & [90] \\
\hline & & Philippines & $\begin{array}{l}\text { Iloko-Bain bain; } \\
\text { Tagalog-Makahiya }\end{array}$ & & {$[116,117]$} \\
\hline & Leaves and roots & India & Namaskari, Lajjalu & $\begin{array}{l}\text { In Unani and Ayurvedic } \\
\text { methods of medication, } M \text {. } \\
\text { Pudica is used for } \\
\text { treatment of ulcers, bile, } \\
\text { leprosy, fever, small pox, } \\
\text { jaundice, piles, ulcers, } \\
\text { inflammation, burning } \\
\text { sensations, asthma, } \\
\text { hemorrhoids, spasmodic } \\
\text { fistula, strangury, } \\
\text { hydrocele, scrofula, } \\
\text { conjunctivitis, wounds, } \\
\text { hemorrhages }\end{array}$ & {$[87-89,118]$} \\
\hline
\end{tabular}


Table 1. Cont.

\begin{tabular}{|c|c|c|c|c|c|}
\hline Plant & Plant Parts & Country & Common Names in Different Languages & Uses & References \\
\hline \multirow{7}{*}{ M. pudica } & Whole plant & & & $\begin{array}{l}\text { Used internally to treat } \\
\text { vesicle calculi and } \\
\text { externally to treat myalgia, } \\
\text { rheumatism, uterus } \\
\text { tumors, odema-type } \\
\text { disorders }\end{array}$ & [89] \\
\hline & Roots & Bangladesh & & Antivenom effects & [91] \\
\hline & Bark & China & & $\begin{array}{l}\text { Treatment of traumatic } \\
\text { injury to dissipate blood } \\
\text { stasis }\end{array}$ & [93] \\
\hline & Herb & China & & $\begin{array}{l}\text { In women is used in } \\
\text { vagina-narrowing solution }\end{array}$ & [92] \\
\hline & Paste & China & & $\begin{array}{l}\text { Used in dental powder to } \\
\text { treat gingiva and bad } \\
\text { breath }\end{array}$ & [93] \\
\hline & Seeds +5 g sugar & India & Chunimui & Venereal diseases & \\
\hline & Leaves & & & $\begin{array}{l}\text { Used to cure skin } \\
\text { infections }\end{array}$ & [72] \\
\hline \multirow{6}{*}{ M. pigra } & Shrub & Africa & & $\begin{array}{l}\text { Used for asthma, } \\
\text { respiratory diseases, } \\
\text { diarrhea, typhoid fever, } \\
\text { genitourinary tract } \\
\text { infections }\end{array}$ & [94] \\
\hline & $\begin{array}{l}\text { Roots, leaves, } \\
\text { stem }\end{array}$ & $\begin{array}{l}\text { Madagascar, } \\
\text { tropical Africa, } \\
\text { South America, } \\
\text { Indonesia }\end{array}$ & & $\begin{array}{l}\text { Used for head colds, } \\
\text { mouthwash for toothaches, } \\
\text { eye medicines }\end{array}$ & [96] \\
\hline & Leafy stem fruits & Africa & & Antivenom effects & [95] \\
\hline & Leaves & Mexico & & $\begin{array}{l}\text { Used in Mayan medicine } \\
\text { for treatment of diarrhea }\end{array}$ & [23] \\
\hline & & Bangladesh & & $\begin{array}{l}\text { Used to lower blood sugar } \\
\text { in diabetic patients and for } \\
\text { the treatment of pain }\end{array}$ & [97] \\
\hline & $\begin{array}{l}\text { Roasted and } \\
\text { ground leaves }\end{array}$ & Indonesia & $\begin{array}{l}\text { English name-bashful plant; } \\
\text { vernacular name-Alfas }\end{array}$ & $\begin{array}{l}\text { Used to treat a weak heart } \\
\text { or weak pulse }\end{array}$ & {$[98,99]$} \\
\hline $\begin{array}{l}\text { M. caesalipini- } \\
\quad \text { ifolia }\end{array}$ & Bark and flowers & $\begin{array}{l}\text { Northeastern } \\
\text { Brazil }\end{array}$ & Cascudo, sabia & $\begin{array}{l}\text { Used for bronchitis, skin } \\
\text { infections, injuries, } \\
\text { inflammation, } \\
\text { hypertension, cough, } \\
\text { gastritis }\end{array}$ & $\begin{array}{l}{[27,77,100,105} \\
\quad 119-121]\end{array}$ \\
\hline \multirow{3}{*}{ M. hamata } & Whole plant & \multirow{3}{*}{ India } & \multirow{3}{*}{ Jinjani, hooked } & $\begin{array}{l}\text { Used to treat jaundice, } \\
\text { diarrhea, coagulant, fever, } \\
\text { dysentery, wounds. Used } \\
\text { as a blood-purifier and as a } \\
\text { tonic for urinary } \\
\text { complaints and piles }\end{array}$ & [3] \\
\hline & Leaves & & & $\begin{array}{l}\text { Used for treatment of } \\
\text { burns, glandular swelling, } \\
\text { sores, piles. Used as a } \\
\text { sinus dressing and } \\
\text { contraceptive }\end{array}$ & {$[101,102]$} \\
\hline & Seeds & & & Blood purifier & {$[33,103]$} \\
\hline M. rubicaulis & Whole plant & India & $\begin{array}{l}\text { Commonly known as Mimosa himalayan; } \\
\text { korinda, putta korinda in Telugu }\end{array}$ & $\begin{array}{l}\text { Used to treat leucoderma, } \\
\text { leprosy, chronic diarrhea, } \\
\text { rheumatism, treatment of } \\
\text { snake bite, fungal } \\
\text { infections, cuts and } \\
\text { wounds }\end{array}$ & [122] \\
\hline M. somnians & Whole plant & Central America & Dormidera, sensitive plant & & [104] \\
\hline $\begin{array}{c}M . \\
\text { bimucronata }\end{array}$ & Leaves & Brazil & & $\begin{array}{c}\text { Cardiovascular, renal } \\
\text { system, diuresis, and } \\
\text { saluresis treatment in rats }\end{array}$ & {$[123,124]$} \\
\hline M. linguis & Whole plant & & & Diuretic & \multirow{2}{*}{ [26] } \\
\hline M. humilis & Whole plant & & & Rheumatism treatment & \\
\hline M. invisa & Leaves & Nigeria & Idon zakara, Nila grass & $\begin{array}{c}\text { Used to treat bronchitis, } \\
\text { and asthma and to relieve } \\
\text { tooth pain, has antidiabetic } \\
\text { properties }\end{array}$ & [125-128] \\
\hline
\end{tabular}


Table 1. Cont.

\begin{tabular}{|c|c|c|c|c|c|}
\hline Plant & Plant Parts & Country & Common Names in Different Languages & Uses & References \\
\hline M. arenosa & Bark & Brazil & & Used for asthma & \\
\hline $\begin{array}{l}\text { M. ophthalmo- } \\
\text { centra }\end{array}$ & Bark & Brazil & Jurema & Used for bronchitis, cough & [77] \\
\hline M. verrucosa & Stem bark & Brazil & Jurema-preta & $\begin{array}{l}\text { Used for gastritis, ulcer, } \\
\text { asthma, inflammation of } \\
\text { the uterus }\end{array}$ & {$[77,105]$} \\
\hline \multirow[t]{2}{*}{ M. albida } & $\begin{array}{l}\text { Roots, leaves and } \\
\text { flowers }\end{array}$ & Mexico & & $\begin{array}{l}\text { Used for pain and anxiety, } \\
\text { chronic pain }\end{array}$ & [106] \\
\hline & Roots & Honduras & & Used for abortion & [107] \\
\hline
\end{tabular}

\section{Pharmacological Activities of Genus Mimosa}

During the past decades, the genus Mimosa has been extensively studied for its broad biological and pharmacological potential. Different preparations and extracts from this genus have demonstrated multiple health benefits and pharmacological effects, including antimicrobial, antioxidant, anticancer, wound-healing, hypolipidemic, anti-inflammatory, hepatoprotective, antinociceptive, antiepileptic, neuropharmacological, toxicological, antiallergic, antihyperurisemic, larvicidal, antiparasitic, molluscicidal, antimutagenic, genotoxic-teratogenic, antispasmolytic, antiviral, and antivenom activities. These pharmacological effects have been studied through in vitro and in vivo assays. These activities are presented in detail in this review article (Table 2).

Table 2. Pharmacological studies of different species of the genus Mimosa.

\begin{tabular}{|c|c|c|c|c|c|c|c|}
\hline Activities & Plant & Plant Part & $\begin{array}{l}\text { Extract/ } \\
\text { Fraction }\end{array}$ & Assay & Model & Results/Outcome/Response & References \\
\hline \multirow{9}{*}{$\begin{array}{l}\text { Antimicro- } \\
\text { bialactivity }\end{array}$} & \multirow{9}{*}{$\begin{array}{l}\text { M. } \\
\text { tenuiflora }\end{array}$} & $\begin{array}{l}\text { Bark and } \\
\text { chitosan }\end{array}$ & $\begin{array}{l}\text { Biocomposite } \\
\quad \text { film }\end{array}$ & $\begin{array}{l}\text { Turbidimetry } \\
\text { method }\end{array}$ & E. coli, M. lysodeikticus & $\begin{array}{c}\text { Chitosan/M. Tenuiflora film } \\
\text { showed potent antibacterial } \\
\text { activity }\end{array}$ & [129] \\
\hline & & Wood & $\begin{array}{l}\text { Pyroligneous } \\
\text { acid }\end{array}$ & $\begin{array}{l}\text { Agar } \\
\text { diffusion } \\
\text { method }\end{array}$ & $\begin{array}{c}\text { E. coli, C. albicans, } \\
\text { P. aeruginosa, S. aureus, C. } \\
\text { neoformans }\end{array}$ & $\begin{array}{l}\text { Significant inhibition obtained at } \\
\text { all concentrations }\end{array}$ & [130] \\
\hline & & \multirow{7}{*}{ Bark } & $\begin{array}{c}\mathrm{HyOH} \\
\text { extracts }\end{array}$ & $\begin{array}{l}\text { Agar } \\
\text { diffusion } \\
\text { method }\end{array}$ & $\begin{array}{c}\text { E. coli, S. aureus, E. } \\
\text { aerogenes, K. pneumoniae, } \\
\text { Providencia, P. aeruginosa, P. } \\
\text { Mirabilis, S. sonnei, S. } \\
\text { pyogenes, Staphylococcus } \\
\text { spp. }\end{array}$ & $\begin{array}{c}\text { Actively inhibited the growth of } \\
\text { bacteria }\end{array}$ & [131] \\
\hline & & & $\mathrm{EtOH}$ & $\begin{array}{l}\text { Agar dilution } \\
\text { method, } \\
\text { time-kill } \\
\text { assay }\end{array}$ & S. aureus & Bactericidal effect was observed & {$[132]$} \\
\hline & & & EtOH 95\% & $\begin{array}{l}\text { Disc diffusion } \\
\text { method }\end{array}$ & $\begin{array}{l}\text { E. coli, B. subtilis, } \\
\text { M. luteus, P. oxalicum }\end{array}$ & $\begin{array}{c}\text { Significant results obtained. } \\
\text { Active doses of extract: } E \text {. } \\
\text { coli }=5.0 \mathrm{ug} / \text { disk; } B . \\
\text { subtilis }=10.0 \mathrm{ug} / \text { disk; } M \\
\text { luteus }=20.0 \mathrm{ug} / \mathrm{disk} ; P . \\
\text { oxalicum }=10.0 \mathrm{ug} / \text { disk }\end{array}$ & {$[133]$} \\
\hline & & & EtOH 95\% & $\begin{array}{l}\text { Minimum } \\
\text { inhibitory } \\
\text { concentration } \\
\quad(\mathrm{MIC})\end{array}$ & $\begin{array}{c}\text { S. epidermidis, } A . \\
\text { calcoaceticus, S. aureus, M. } \\
\text { luteus, E. coli, K. pneumonia, } \\
\text { P. aeruginosa, C. albicans }\end{array}$ & $\begin{array}{l}\text { Active doses of extract } S \text {. } \\
\text { epidermidis, A. calcoaceticus }=\mathrm{MIC} \\
>10.0 \mu \mathrm{g} / \mathrm{mL}, S . \text { aureus, } M . \text { luteus } \\
\mathrm{MIC}=10.0 \mu \mathrm{g} / \mathrm{mL}, \text { E. coli, K. } \\
\text { pneumonia } \mathrm{MIC}=20.0 \mu \mathrm{g} / \mathrm{mL}, C \text {. } \\
\text { albicans } \mathrm{MIC}=70.0 \mu \mathrm{g} / \mathrm{mL}\end{array}$ & {$[134]$} \\
\hline & & & $\mathrm{BuOH}$ & \multirow{3}{*}{$\begin{array}{l}\text { Well diffusion } \\
\text { method }\end{array}$} & S. aureus, E. coli & $\begin{array}{l}\text { Active doses of extract: } S . \\
\text { aureus }=5.0 \mathrm{mg} / \text { well; } E . \\
\text { coli }=15.0 \mathrm{mg} / \text { well }\end{array}$ & \multirow{3}{*}[135]{} \\
\hline & & & $\mathrm{MeOH}$ & & S. aureus, E. coli & $\begin{array}{l}\text { Active doses of extract: } S \text {. } \\
\text { aureus }=5.0 \mathrm{ug} / \text { well; } E \text {. } \\
\text { coli }=30.0 \mathrm{ug} / \text { well }\end{array}$ & \\
\hline & & & EtOAc & & E. coli, C. albicans & $\begin{array}{l}\text { Active doses of extract: } E \text {. } \\
\text { coli }=10.0 \mathrm{mg} / \text { well; } C \text {. } \\
\text { albicans }=30.0 \mathrm{mg} / \text { / well }\end{array}$ & \\
\hline
\end{tabular}


Table 2. Cont.

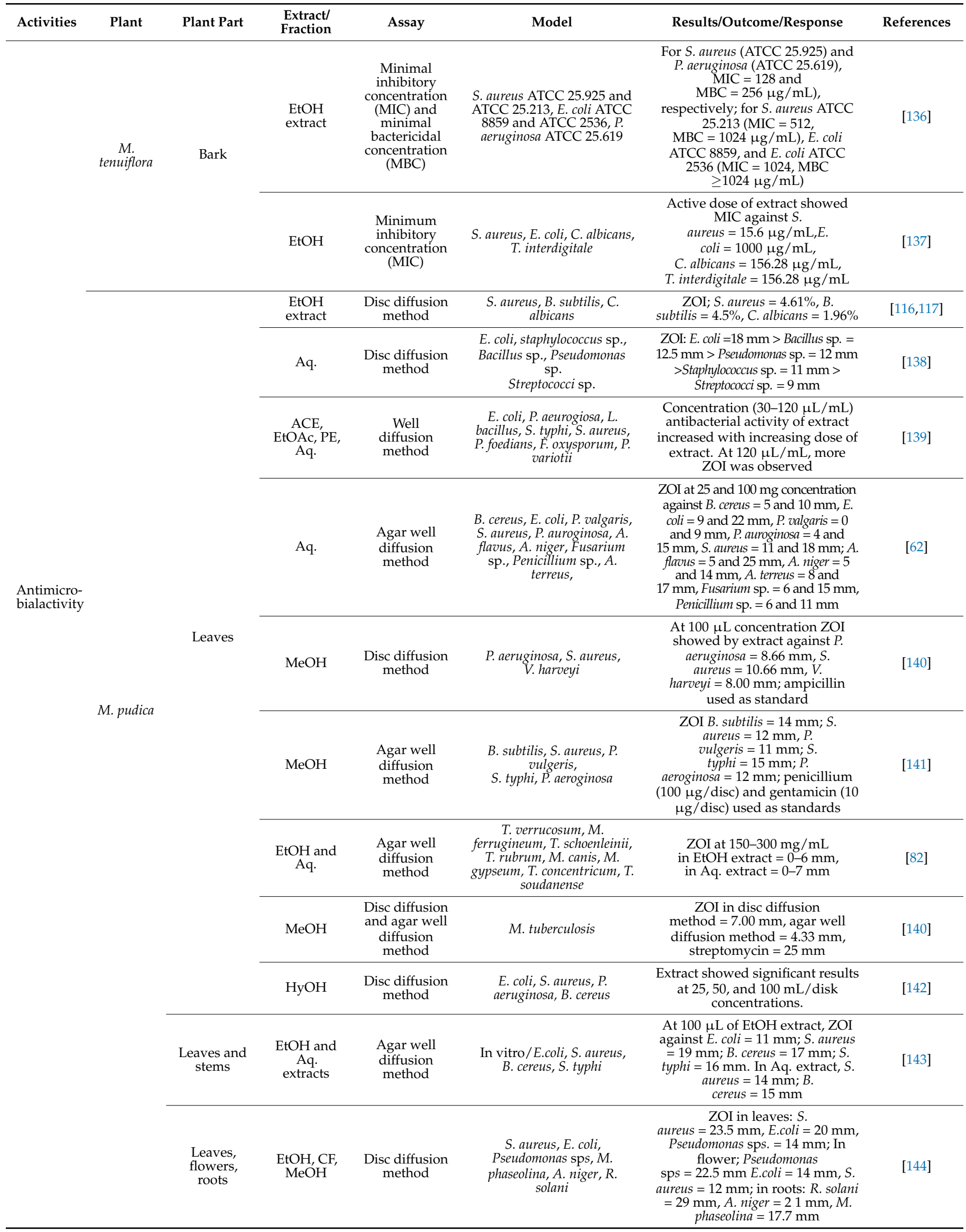


Table 2. Cont.

\begin{tabular}{|c|c|c|c|c|c|c|c|}
\hline Activities & Plant & Plant Part & $\begin{array}{l}\text { Extract/ } \\
\text { Fraction }\end{array}$ & Assay & Model & Results/Outcome/Response & References \\
\hline \multirow{10}{*}{$\begin{array}{l}\text { Antimicro- } \\
\text { bialactivity }\end{array}$} & \multirow[t]{2}{*}{ M. pudica } & \multirow[t]{2}{*}{$\begin{array}{l}\text { Whole } \\
\text { plant }\end{array}$} & EtOH 98\% & $\begin{array}{l}\text { Disc } \\
\text { Diffusion } \\
\text { method }\end{array}$ & $\begin{array}{l}\text { S. aureus, E. faecalis, } P \text {. } \\
\text { aeroginosa, E. coli, } M \text {. } \\
\text { smegmatis }\end{array}$ & $\begin{array}{c}\text { ZOI at } 25 \mathrm{mg} / \mathrm{mL} \text { concentration; } \\
\text { S. aureus }=3.5 \mathrm{mg} / \mathrm{mL} ; P . \\
\text { aeroginosa }=12.0 \mathrm{mg} / \mathrm{mL} ; \text { E. coli }= \\
5.5 \mathrm{mg} / \mathrm{mL} \text {. At } 100 \mathrm{mg} / \mathrm{mL} \\
\text { concentration S. aureus }= \\
9.8 \mathrm{mg} / \mathrm{mL} ; \text { P. aeroginosa }= \\
18.0 \mathrm{mg} / \mathrm{mL} ; \text { E. coli }= \\
14.0 \mathrm{mg} / \mathrm{mL} . \text { Standard } \\
\text { chloramphenicol at } 100 \mathrm{mg} / \mathrm{mL} \\
\text { showed significant results }\end{array}$ & [145] \\
\hline & & & $\begin{array}{l}\text { Absolute } \\
\text { EtOH }\end{array}$ & $\begin{array}{l}\text { Disc diffusion } \\
\text { method }\end{array}$ & $\begin{array}{l}\text { A. flavus, } \\
\text { T. rubrum }\end{array}$ & $\begin{array}{c}\text { ZOI at } 100 \mathrm{mg} / \mathrm{mL} \text { concentration } \\
\text { of extract against } A \text {. flavus }= \\
22 \mathrm{~mm} ; \text {. rubrum }=17 \mathrm{~mm} \text {. At } \\
25 \mathrm{mg} / \mathrm{mL} \text { concentration of } \\
\text { extract: } A \text {. flavus }=13 \mathrm{~mm} ; T . \\
\text { rubrum } 11 \mathrm{~mm}\end{array}$ & [146] \\
\hline & \multirow{4}{*}{ M pigra } & \multirow{4}{*}{ Leaves } & $\begin{array}{l}\mathrm{MeOH} \text { and } \\
\text { Aq. extract }\end{array}$ & $\begin{array}{l}\text { Agar well } \\
\text { diffusion } \\
\text { method }\end{array}$ & $\begin{array}{l}\text { S. aureus, E. coli, A. niger, } P . \\
\text { aeruginosa, } B \text {. subtilis, C. } \\
\text { albicans }\end{array}$ & $\begin{array}{c}\text { Plant was found to be active } \\
\text { against all strains except } E \text {. coli, } A \text {. } \\
\text { niger }\end{array}$ & [23] \\
\hline & & & $\mathrm{MeOH} 60 \%$ & $\begin{array}{l}\text { Broth } \\
\text { microdilution } \\
\text { method }\end{array}$ & $\begin{array}{c}\text { In vitro: T. mentagrophytes, } \\
\text { E. floccosum, } M . \text { gypseum, T. } \\
\text { rubrum }\end{array}$ & $\begin{array}{l}\text { All strains showed antifungal } \\
\text { activity except } E \text {. floccosum }\end{array}$ & \multirow[b]{2}{*}{ [147] } \\
\hline & & & $\begin{array}{l}\text { MeOH } \\
60 \%, \mathrm{Hex} \\
\text { DCM, } \\
\text { EtOAc } \\
\text { fractions }\end{array}$ & $\begin{array}{l}\text { Minimal } \\
\text { inhibitory } \\
\text { concentration } \\
\text { (MIC) }\end{array}$ & & $\begin{array}{l}\text { Significant results were observed } \\
\text { against strains }\end{array}$ & \\
\hline & & & $\begin{array}{l}\text { Crude } \\
\text { MeOH } \\
\text { extract }\end{array}$ & $\begin{array}{l}\text { Agar tube } \\
\text { diffusion } \\
\text { method }\end{array}$ & $\begin{array}{l}\text { B. subtilis, } A \text {. niger, } P \text {. } \\
\text { aeruginosa, E. coli, } K . \\
\text { pneumonia, A. flavus. }\end{array}$ & $\begin{array}{c}\text { Potent activity was obtained } \\
\text { against bacteria, while no activity } \\
\text { was found against fungi }\end{array}$ & [5] \\
\hline & \multirow[b]{2}{*}{$\begin{array}{c}\text { M. } \\
\text { hamata }\end{array}$} & $\begin{array}{l}\text { Whole } \\
\text { plant and } \\
\text { callus } \\
\text { tissue }\end{array}$ & $\begin{array}{l}\text { EtOH } \\
\text { extract and } \\
\text { its fractions } \\
(\mathrm{Aq}, \mathrm{CF}, \mathrm{PE} \text {, } \\
\quad \mathrm{BZ})\end{array}$ & $\begin{array}{l}\text { Disc diffusion } \\
\text { method }\end{array}$ & $\begin{array}{l}\text { E. coli, } K \text {. pneumoniae, } A \text {. } \\
\text { flavus, P. aeruginosa, } P \text {. } \\
\text { vulgaris, S. aureus, } F \text {. } \\
\text { moniliforme, } R \text {. bataticola }\end{array}$ & $\begin{array}{c}\text { EtOH extract and Aq. fraction } \\
\text { showed significant activity } \\
\text { against all tested strains } \\
\text { PE found to be active against } \\
\text { fungi }\end{array}$ & {$[60]$} \\
\hline & & $\begin{array}{l}\text { Whole } \\
\text { plant }\end{array}$ & $\begin{array}{l}\text { Crude Hex, } \\
\text { MeOH } \\
\text { extracts }\end{array}$ & & $\begin{array}{l}\text { B. cereus, C. diphteriae, E. } \\
\text { coli, A. niger, T. simii, } \\
\text { P. aeroginosa, M. canis M. } \\
\text { phaseolina, P. boydii, } M . \\
\text { canis, F. Solani, T. } \\
\text { schoenleinii, S. sonii, S. typhi, } \\
\text { S. pyogenes, T. longifuses, } P \text {. } \\
\text { mirabillis, S. boydii, S. } \\
\text { aureus, S. pyogenes, } R . \\
\text { solani, C. albicans }\end{array}$ & 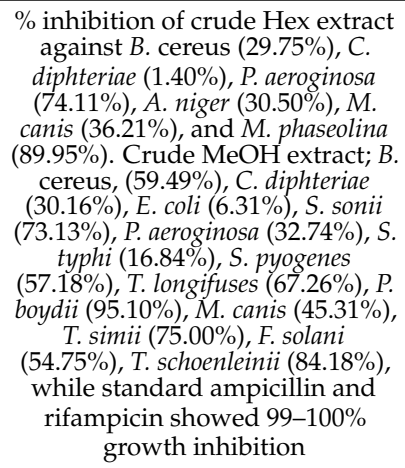 & [148] \\
\hline & $\begin{array}{l}M . \\
\text { verrucosa }\end{array}$ & Barks & $\mathrm{EtOH}$ & $\begin{array}{l}\text { Minimum } \\
\text { inhibitory } \\
\text { concentration } \\
\quad(\mathrm{MIC})\end{array}$ & $\begin{array}{l}\text { S. aureus, } \\
\text { E. coli, } \\
\text { C. albicans, } \\
\text { T. interdigitale }\end{array}$ & $\begin{array}{c}\text { Active dose of extract showed } \\
\text { MIC against } S \text {. aureus }= \\
250 \mu \mathrm{g} / \mathrm{mL} \\
\text { E. coli }=1000 \mu \mathrm{g} / \mathrm{mL} \\
\text { C. albicans }=1250 \mu \mathrm{g} / \mathrm{mL} \\
\text { T. interdigitale }=78.13 \mu \mathrm{g} / \mathrm{mL}\end{array}$ & [137] \\
\hline & $\begin{array}{l}\text { M. pteridi- } \\
\text { folia }\end{array}$ & Barks & $\mathrm{EtOH}$ & $\begin{array}{l}\text { Minimum } \\
\text { inhibitory } \\
\text { concentration } \\
\quad(\mathrm{MIC})\end{array}$ & $\begin{array}{c}\text { S. aureus, } \\
\text { E. coli, } \\
\text { C. albicans, } \\
\text { T. interdigitale }\end{array}$ & $\begin{array}{l}\text { Active dose of extract showed } \\
\text { MIC against } S \text {. } \\
\text { aureus }=500 \mu \mathrm{g} / \mathrm{mL} \\
\text { E. coli }=1000 \mu \mathrm{g} / \mathrm{mL} \\
\text { C. albicans }=625 \mu \mathrm{g} / \mathrm{mL} \\
\text { T. interdigitale }=312.5 \mu \mathrm{g} / \mathrm{mL}\end{array}$ & [137] \\
\hline $\begin{array}{l}\text { Antioxidant } \\
\text { activity }\end{array}$ & $\begin{array}{l}\text { M. } \\
\text { tenuiflora }\end{array}$ & $\begin{array}{c}\text { Leaves, } \\
\text { twigs, } \\
\text { barks, roots }\end{array}$ & $\begin{array}{l}\text { EtOH } \\
\text { extract and } \\
\text { fractions } \\
\text { (Hex, DCM, } \\
\text { EtOAc, } \\
\text { HyOH }\end{array}$ & $\begin{array}{l}\text { DPPH radical } \\
\text { and ABTS } \\
\text { radical cation } \\
\text { scavenging } \\
\text { assay }\end{array}$ & & $\begin{array}{c}\text { In EtOH extract: DPPH } \\
\left(\mathrm{EC}_{50}\right)=132.99 \mu \mathrm{g} / \mathrm{mL} ; \mathrm{ABTS} \\
\left(\mathrm{EC}_{50}\right)=189.14 \mu \mathrm{g} / \mathrm{mL} . \text { EtOAc } \\
\text { fraction: DPPH }\left(\mathrm{EC}_{50}\right) \\
=141.20 \mu \mathrm{g} / \mathrm{mL} ; \mathrm{ABTS} \\
\left(\mathrm{EC}_{50}\right)=273.00 \mu \mathrm{g} / \mathrm{mL}\end{array}$ & [149] \\
\hline
\end{tabular}


Table 2. Cont.

\begin{tabular}{|c|c|c|c|c|c|c|c|}
\hline Activities & Plant & Plant Part & $\begin{array}{l}\text { Extract/ } \\
\text { Fraction }\end{array}$ & Assay & Model & Results/Outcome/Response & References \\
\hline \multirow{12}{*}{$\begin{array}{l}\text { Antioxidant } \\
\text { activity }\end{array}$} & $\begin{array}{l}\text { M. } \\
\text { tenuiflora }\end{array}$ & Bark & $\mathrm{EtOH}$ & $\begin{array}{l}\text { DPPH radical } \\
\text { and ABTS } \\
\text { radical cation } \\
\text { scavenging } \\
\text { assay }\end{array}$ & & $\begin{aligned} \text { DPPH }\left(\mathrm{IC}_{0}\right) & =17.21 \mu \mathrm{g} / \mathrm{mL} \\
\text { ABTS }\left(\mathrm{IC}_{50}\right) & =3.75 \mu \mathrm{g} / \mathrm{mL}\end{aligned}$ & [137] \\
\hline & \multirow{9}{*}{ M. pudica } & \multirow{5}{*}{ Leaves } & $n$-Hex & $\begin{array}{l}\text { DPPH, OH, } \\
\text { NO, and } \\
\text { superoxide } \\
\text { radical } \\
\text { scavenging } \\
\text { assays }\end{array}$ & & $\begin{array}{c}n \text {-Hex at } 5-25 \mathrm{mM} \text { concentration } \\
\text { showed DPPH }\left(\mathrm{IC}_{50}=20.83 \mathrm{mM}\right) \\
\mathrm{OH}\left(\mathrm{IC}_{50}=19.37 \mathrm{mM}\right) ; \mathrm{NO} \\
\left(\mathrm{IC}_{50}=21.62 \mathrm{mM}\right), \mathrm{O}_{2}^{-} \\
\left(\mathrm{IC}_{50}=22.19 \mathrm{mM}\right) ; \mathrm{BHT} \text { and } \\
\text { vitamin } \mathrm{C} \text { used as standards }\end{array}$ & [30] \\
\hline & & & $\begin{array}{l}\text { ACE-Aq- } \\
\text { AA }(8.0 \mathrm{~mL} \\
70: 29.5: 0.5)\end{array}$ & $\begin{array}{l}\text { ORAC assay, } \\
\text { DPPH free } \\
\text { radical } \\
\text { scavenging } \\
\text { activity }\end{array}$ & & $\begin{array}{c}\text { ORAC }=1187.9 \mu \mathrm{mol} \mathrm{TE} \mathrm{g} \\
\text { FW) } \\
\text { DPPH EC } 50=243.2 \mathrm{mg} / \mathrm{kg}) \\
\text { vitamin C content }=259.1 \mu \mathrm{g} / \mathrm{g} \\
\text { FW) }\end{array}$ & [150] \\
\hline & & & Aq. $1.0 \%$ & $\begin{array}{l}\text { Hydrogen } \\
\text { peroxide } \\
\text { scavenging, } \\
\text { reducing } \\
\text { power assays }\end{array}$ & & $\begin{array}{c}\mathrm{H}_{2} \mathrm{O}_{2} \text { scavenging for } 0.2 \text { and } \\
1.0 \% \text { extract concentration }=34.6 \\
\text { and } 58.3 \% \text {, respectively. } \\
\text { Reducing power for } 0.2 \text { and } 1.0 \% \\
\text { extract }=59.8 \text { and } 94.7 \% \text { activity, } \\
\text { respectively; while standard } \\
\text { thiobarbitaric acid extract at } 0.2 \\
\text { and } 1.0 \%=59.7 \text { and } 86.3 \% \\
\text { activity, respectively }\end{array}$ & {$[62]$} \\
\hline & & & $\mathrm{MeOH}$ & $\begin{array}{l}\text { DPPH free } \\
\text { radical } \\
\text { scavenging } \\
\text { assay }\end{array}$ & & $\begin{array}{c}\text { DPPH scavenging; } \\
\mathrm{IC}_{50}=126.71 \mu \mathrm{g} / \mathrm{mL} \text {, ascorbic } \\
\text { acid; } \mathrm{IC}_{50}=20.13 \mu \mathrm{g} / \mathrm{mL} \text {; total } \\
\text { antioxidant capacity of } \\
\text { extract }=5.038 \mathrm{mg}(\mathrm{mg} \text { AAE } / \mathrm{g})\end{array}$ & [151] \\
\hline & & & $\begin{array}{l}\text { PE, EtOAc, } \\
\text { EtOH, Aq. } \\
\text { extract }\end{array}$ & ABTS assay & & $\begin{array}{c}\text { PE; } \mathrm{EC}_{50}=40.6 \mu \mathrm{g} / \mathrm{mL}, \mathrm{EtOAc} ; \\
\mathrm{EC}_{50}=27.2 \mu \mathrm{g} / \mathrm{mL} ; \mathrm{EtOH} ; \\
\mathrm{EC}_{50}=73.8 \mu \mathrm{g} / \mathrm{mL} ; \mathrm{Aq} . ; \\
\mathrm{EC}_{50}=13.2 \mu \mathrm{g} / \mathrm{mL}, \text { ascorbic } \\
\text { acid; } \mathrm{EC}_{50}=11.5 \mu \mathrm{g} / \mathrm{mL}\end{array}$ & [152] \\
\hline & & \multirow{3}{*}{$\begin{array}{l}\text { Whole } \\
\text { plant }\end{array}$} & $\begin{array}{l}\text { HyEtOH } \\
\text { extract and } \\
\text { L- } \\
\text { Mimosine } \\
\text { compound }\end{array}$ & $\begin{array}{l}\text { DPPH radical } \\
\text { scavenging } \\
\text { assay }\end{array}$ & & $\begin{array}{c}\text { At concentration } \\
31.25-250 \mu \mathrm{g} / \mathrm{mL}, \mathrm{HyEtOH} \\
\text { extract }\left(\mathrm{IC}_{50}=103.88 \mu \mathrm{g} / \mathrm{mL}\right) \\
\text { L-mimosine }\left(\mathrm{IC}_{50}=233.06 \mu \mathrm{M}\right)\end{array}$ & {$[31]$} \\
\hline & & & $\begin{array}{l}\text { Isolated } \\
\text { flavonoids } \\
\text { from } \\
\text { EtOAc- } \\
\text { soluble } \\
\text { fractions of } \\
\text { MeOH }\end{array}$ & $\begin{array}{l}\text { DPPH free } \\
\text { radical, OH } \\
\text { radical } \\
\text { scavenging } \\
\text { assays }\end{array}$ & & $\begin{array}{c}\mathrm{DPPH}=\% \text { inhibition at } \\
20-140 \mu \mathrm{g} / \mathrm{mL}, \text { standard } \\
\text { ascorbic acid at } 0-100 \mu \mathrm{g} / \mathrm{mL} \text {, } \\
\text { OH radical scavenging at } \\
240-1000 \mu \mathrm{g} / \mathrm{mL} ; \text { quercetin } \\
\text { standard at } 0-300 \mu \mathrm{g} / \mathrm{mL} \\
\text { showed significant results }\end{array}$ & [153] \\
\hline & & & $\mathrm{EtOH}$ & $\begin{array}{l}\text { Hydrogen } \\
\text { peroxides } \\
\text { and } \\
\text { superoxide } \\
\text { scavenging } \\
\text { assay }\end{array}$ & & $\begin{array}{c}\mathrm{H}_{2} \mathrm{O}_{2} \text { assay; extract } \\
\left(\mathrm{IC}_{50}=19 \mathrm{mg} / \mathrm{mL}\right) \\
\text { ascorbic acid; } \mathrm{IC}_{50}=5.2 \mathrm{mg} / \mathrm{mL}, \\
\mathrm{O}_{2}^{-} \text {assay; extract } \\
\left(\mathrm{IC}_{50}=80.4 \mathrm{mg} / \mathrm{mL}\right), \text { gallic acid; } \\
\mathrm{IC}_{50}=50.10 \mathrm{mg} / \mathrm{mL}\end{array}$ & [154] \\
\hline & & Aerial parts & $\begin{array}{l}\mathrm{MeOH} \\
\text { extract and } \\
\text { fractions } \\
\text { (Hex, } \\
\text { EtOAc, } \\
\text { ACE, and } \\
\text { MeOH) }\end{array}$ & $\begin{array}{l}\text { DPPH free } \\
\text { radical } \\
\text { scavenging } \\
\text { activity }\end{array}$ & & $\begin{array}{c}\text { DPPH assay; } \mathrm{MeOH} \\
\text { extract }=\left(\mathrm{IC}_{50} 7.18 \mu \mathrm{g} / \mathrm{mL}\right) \\
\text { Fractions; } \mathrm{MeOH}=\left(\mathrm{IC}_{50}\right. \\
158.4 \mu \mathrm{g} / \mathrm{mL}) ; \mathrm{Hex}=\left(\mathrm{IC}_{50}\right. \\
92.30 \mu \mathrm{g} / \mathrm{mL}) ; \mathrm{EtOAc}=\left(\mathrm{IC}_{50}\right. \\
49.59 \mu \mathrm{g} / \mathrm{mL}) ; \mathrm{ACE}=\left(\mathrm{IC}_{50}\right. \\
45.63 \mu \mathrm{g} / \mathrm{mL}) . \text { Ascorbic } \\
\text { acid }=\mathrm{IC} \mathrm{C}_{50} 20.13 \mu \mathrm{g} / \mathrm{mL}\end{array}$ & [46] \\
\hline & $\begin{array}{l}\text { M. } \\
\text { caesalpi- } \\
\text { niifolia }\end{array}$ & Leaves & $\begin{array}{l}\text { EtOH and } \\
\text { EtOAc } \\
\text { fractions }\end{array}$ & $\begin{array}{l}\text { DPPH free } \\
\text { radical } \\
\text { scavenging } \\
\text { assay }\end{array}$ & & $\begin{array}{c}\text { EtOH extract }=35.3 \mathrm{~g} \text { vitamin } \\
\text { C.eq } / \mathrm{kg} ; \text { EtOAc fraction }=65.3 \mathrm{~g} \\
\text { vitamin C eq } / \mathrm{kg}\end{array}$ & [32] \\
\hline & M. pigra & Leaves & $\mathrm{HyMeOH}$ & $\begin{array}{l}\text { DPPH free } \\
\text { radical } \\
\text { scavenging } \\
\text { activity, } \\
\text { oxygen } \\
\text { radical } \\
\text { absorbance } \\
\text { capacity } \\
\text { (ORAC) }\end{array}$ & & $\begin{array}{c}\text { DPPH }=1268 \mu \mathrm{mol} \mathrm{TE} / \mathrm{g} ; \\
\text { ORAC }=2287 \mu \mathrm{mol} \mathrm{TE} / \mathrm{g} ; \\
\text { chlorogenic acid (reference drug), } \\
\text { DPPH = } 2927 \mu \mathrm{mol} \mathrm{TE} / \mu \mathrm{mol} ; \\
\text { ORAC }=11.939 \mu \mathrm{mol} \mathrm{TE} / \mu \mathrm{mol} ; \\
\text { quercetin (reference drug); } \\
\text { DPPH }=6724 \mu \mathrm{mol} \mathrm{TE} / \mu \mathrm{mol} ; \\
\text { ORAC }=22,218 \mu \mathrm{mol} \mathrm{TE} / \mu \mathrm{mol}\end{array}$ & [155] \\
\hline
\end{tabular}


Table 2. Cont.

\begin{tabular}{|c|c|c|c|c|c|c|c|}
\hline Activities & Plant & Plant Part & $\begin{array}{l}\text { Extract/ } \\
\text { Fraction }\end{array}$ & Assay & Model & Results/Outcome/Response & References \\
\hline & & $\begin{array}{l}\text { Whole } \\
\text { plant }\end{array}$ & $\begin{array}{l}\text { Crude } \\
\text { EtOH } \\
\text { extract and } \\
\text { sub- } \\
\text { fraction } \\
\text { (EtOAc and } \\
\text { diethyl } \\
\text { ether) }\end{array}$ & $\begin{array}{l}\text { DPPH radical } \\
\text { scavenging, } \\
\text { hydrogen } \\
\text { peroxide } \\
\text { scavenging } \\
\text { assay }\end{array}$ & & $\begin{array}{c}\text { \% inhibition at } 100 \mu \mathrm{g} / \mathrm{mL} ; \\
\text { DPPH scavenging; crude EtOH } \\
\text { extract }=76.01 \% \text { EtOAc, } \\
\text { diethyl ether } \\
\text { sub-fraction }=96.63 \% ; \\
\text { ascorbic acid = } 93.52 \% ; \mathrm{H}_{2} \mathrm{O}_{2} \\
\text { scavenging; extract }=67.81 \% \\
\text { EtOAc, } \\
\text { diethyl ether } \\
\text { sub-fraction }=88.43 \% ; \\
\text { ascorbic acid }=86.87 \% \\
\text { scavenging activity }\end{array}$ & [29] \\
\hline & $\begin{array}{c}\text { M. } \\
\text { hamata }\end{array}$ & Stem & $\begin{array}{l}\text { MeOH, } \\
\text { cycloHex, } \\
\text { and EtOAc }\end{array}$ & $\begin{array}{l}\text { DPPH free } \\
\text { radical } \\
\text { scavenging } \\
\text { assay, } \\
\text { ABTS } \\
\text { scavenging } \\
\text { assay }\end{array}$ & In vitro & $\begin{array}{c}\text { DPPH radical scavenging assay } \\
\mathrm{IC}_{50} ; \mathrm{MeOH}=0.70 \mu \mathrm{g} / \mathrm{mL}, \\
\text { EtOAc }=0.85 \mu \mathrm{g} / \mathrm{mL}, \\
\text { cycloHex }=0.95 \mu \mathrm{g} / \mathrm{mL}, \text { ascorbic } \\
\text { acid }=0.60 \mu \mathrm{g} / \mathrm{mL} ; \\
\text { ABTS assay } \mathrm{IC}_{50} ; \\
\mathrm{MeOH}=0.35 \mu \mathrm{g} / \mathrm{mL}, \\
\text { EtOAc }=0.37 \mu \mathrm{g} / \mathrm{mL} ; \\
\text { cycloHex }=0.40 \mu \mathrm{g} / \mathrm{mL} ; \text { ascorbic } \\
\text { acid }=0.32 \mu \mathrm{g} / \mathrm{mL}\end{array}$ & {$[33]$} \\
\hline & & $\begin{array}{c}\text { Leaves, } \\
\text { stems, } \\
\text { roots, seeds }\end{array}$ & $\begin{array}{l}\text { PE, CF, } \\
\text { BuOH, and } \\
\text { Aq. }\end{array}$ & $\begin{array}{l}\text { DPPH free } \\
\text { radical } \\
\text { scavenging } \\
\text { assay }\end{array}$ & & $\begin{array}{c}\mathrm{IC}_{50} ; \\
\text { leaves }=51.30-56.50 \mu \mathrm{g} / \mathrm{mL} \\
\text { stems }=51.80-61.80 \mu \mathrm{g} / \mathrm{mL} \\
\text { roots }=26.33-73.16 \mu \mathrm{g} / \mathrm{mL} \\
\text { seeds }=16.60-51.16 \mu \mathrm{g} / \mathrm{mL}\end{array}$ & [156] \\
\hline \multirow[t]{4}{*}{$\begin{array}{l}\text { Antioxidant } \\
\text { activity }\end{array}$} & M. albida & $\begin{array}{l}\text { Whole } \\
\text { fresh plant }\end{array}$ & Aq. & $\begin{array}{c}\text { DPPH } \\
\text { radical, ferric } \\
\text { reducing } \\
\text { antioxidant } \\
\text { power } \\
\text { (FRAP), } \\
\text { Trolox- } \\
\text { equivalent } \\
\text { antioxidant } \\
\text { capacity } \\
\text { (TEAC), } \\
\text { oxygen } \\
\text { radical } \\
\text { absorption } \\
\text { capacity } \\
\text { (ORAC), } \\
\text { low-density } \\
\text { lipoprotein } \\
\text { (LDL) assays }\end{array}$ & & $\begin{array}{c}\text { DPPH }=1540 \mu \mathrm{mol} \mathrm{TE} / \mathrm{g} \\
\text { FRAP }=1070 \mu \mathrm{mol} \mathrm{TE} / \mathrm{g} \\
\text { TEAC }=1770 \mu \mathrm{mol} \mathrm{TE} / \mathrm{g} \\
\text { ORAC }=1870 \mu \mathrm{mol} \mathrm{TE} / \mathrm{g} \\
\mathrm{LDL}=50 \% \text { inhibition }\end{array}$ & [157] \\
\hline & M. invisa & Leaves & Aq. Extract & $\begin{array}{l}\text { DPPH radical } \\
\text { scavenging } \\
\text { assay }\end{array}$ & In vitro & $\begin{array}{c}\text { Aq. extract } \mathrm{IC}_{50}=0.119 \mathrm{mg} / \mathrm{mL} \\
\text { Ascorbic acid } \\
\mathrm{IC}_{50}=0.058 \mathrm{mg} / \mathrm{mL}\end{array}$ & [127] \\
\hline & $\begin{array}{c}\text { M. } \\
\text { verrucosa }\end{array}$ & Bark & $\mathrm{EtOH}$ & $\begin{array}{l}\text { DPPH radical } \\
\text { and ABTS } \\
\text { radical cation } \\
\text { scavenging } \\
\text { assay }\end{array}$ & - & $\begin{array}{c}\text { DPPH }\left(\mathrm{IC}_{50}\right)=33.22 \mu \mathrm{g} / \mathrm{mL} \\
\text { ABTS }\left(\mathrm{IC}_{50}\right)=4.91 \mu \mathrm{g} / \mathrm{mL}\end{array}$ & [137] \\
\hline & $\begin{array}{l}\text { M. } \\
\text { pteridifo- } \\
\text { lia }\end{array}$ & Bark & $\mathrm{EtOH}$ & $\begin{array}{l}\text { DPPH radical } \\
\text { and ABTS } \\
\text { radical cation } \\
\text { scavenging } \\
\text { assay }\end{array}$ & & $\begin{array}{c}\mathrm{DPPH}\left(\mathrm{IC}_{50}\right)=51.82 \mu \mathrm{g} / \mathrm{mL} \\
\text { ABTS }\left(\mathrm{IC}_{50}\right)=4.88 \mu \mathrm{g} / \mathrm{mL}\end{array}$ & [137] \\
\hline \multirow{2}{*}{$\begin{array}{l}\text { Anticancer } \\
\text { activity }\end{array}$} & \multirow{2}{*}{$\begin{array}{l}\text { M. } \\
\text { tenuiflora }\end{array}$} & $\begin{array}{l}\text { Biofilm of } \\
\text { cortex and } \\
\text { chitosan }\end{array}$ & $\begin{array}{l}\text { Biocomposite } \\
\quad \text { film }\end{array}$ & $\begin{array}{l}\text { (3T3) } \\
\text { fibroblast by } \\
\text { MTT assays }\end{array}$ & & $\begin{array}{l}\text { Cells decreased significantly in } \\
\text { the } 90: 10 \text { and } 80: 20 \text { chitosan/M. } \\
\text { tenuiflora films. Cytotoxicity } \\
\text { increased in high-concentration } \\
\text { M. tenuiflora (70:30) and chitosan } \\
\text { films (100:0) }\end{array}$ & [129] \\
\hline & & Bark & $\mathrm{EtOH}$ & MTT assay & $\begin{array}{c}\text { Human tumor cell lines } \\
\text { HL-60 (acute myeloid } \\
\text { leukemia), HCT-116 } \\
\text { (Colorectal carcinoma), } \\
\text { PC-3 (prostate } \\
\text { adenocarcinoma), SF-295 } \\
\text { (glioblastoma) }\end{array}$ & $\begin{array}{c}\text { Extract displayed } \mathrm{IC}_{50} \geq \\
50 \mu \mathrm{g} / \mathrm{mL} \text { against all cell lines, } \\
\text { while no activity was observed } \\
\text { against HCT-116 }\end{array}$ & [137] \\
\hline
\end{tabular}


Table 2. Cont

\begin{tabular}{|c|c|c|c|c|c|c|c|}
\hline Activities & Plant & Plant Part & $\begin{array}{l}\text { Extract/ } \\
\text { Fraction }\end{array}$ & Assay & Model & Results/Outcome/Response & References \\
\hline \multirow{10}{*}{$\begin{array}{l}\text { Anticancer } \\
\text { activity }\end{array}$} & \multirow[t]{2}{*}{ M. pudica } & Leaves & $\begin{array}{l}\text { PE, EtOAc, } \\
\text { EtOH, } \\
\text { Aq. extract }\end{array}$ & MTT assay & $\begin{array}{l}\text { In vitro: Human cancer } \\
\text { cell lines from lungs } \\
\text { (CHAGO), } \\
\left.\text { liver (HepG }{ }_{2}\right), \text { colon } \\
(\text { SW620) }\end{array}$ & $\begin{array}{c}\text { CHAGO cell; absolute EtOAc } \\
\left(\mathrm{IC}_{50}=29.74 \mu \mathrm{M}\right), \\
\text { SW620 cell; EtOAc } \\
\left(\mathrm{IC} \mathrm{C}_{50}=11.12 \mu \mathrm{M}\right) \text { and absolute } \\
\text { EtOH }\left(\mathrm{IC}_{50}=5.85 \mu \mathrm{M}\right) ; \mathrm{HepG}_{2} \\
\text { cell; EtOAc }\left(\mathrm{IC}_{50}=229.81 \mu \mathrm{M}\right) \\
\text { and absolute EtOH } \\
\left(\mathrm{IC}_{50}=10.11 \mu \mathrm{M}\right)\end{array}$ & [152] \\
\hline & & $\begin{array}{l}\text { Whole } \\
\text { plant }\end{array}$ & $\begin{array}{l}\text { HyEtOH } \\
\text { extract and } \\
\text { L- } \\
\text { mimosine } \\
\text { compound }\end{array}$ & MTT assay & In vitro: Daudi cell line & $\begin{array}{c}\text { At concentration of } \\
12.5-400 \mu \mathrm{g} / \mathrm{mL} ; \text { Extract showed } \\
\mathrm{IC}_{50}=201.65 \mu \mathrm{g} / \mathrm{mL} \text { and } \mathrm{L}- \\
\text { Mimosine }\left(\mathrm{IC}_{50}=86.61 \mu \mathrm{M}\right)\end{array}$ & [31] \\
\hline & \multirow[t]{2}{*}{ M. pigra } & Leaves & $\mathrm{HyMeOH}$ & MTT assay & $\begin{array}{l}\text { In vitro: Male Wistar rats, } \\
\text { endothelial and aortic } \\
\text { smooth muscle cell }\end{array}$ & $\begin{array}{l}\text { Extract }(0.01-1 \mathrm{mg} / \mathrm{mL}) \text { showed } \\
\text { no significant effect on cellular } \\
\text { viability/proliferation }\end{array}$ & [155] \\
\hline & & Fruit & & & Intake orally & Active against tumor & [98] \\
\hline & \multirow[b]{2}{*}{$\begin{array}{l}\text { M. } \\
\text { caesalpi- } \\
\text { niifolia }\end{array}$} & Leaves & $\mathrm{EtOH}$ & SRB assay & $\begin{array}{l}\text { Human breast cancer cell } \\
\text { line MCF-7 }\end{array}$ & $\begin{array}{l}\text { Extract showed maximum effect } \\
\text { at } 320.0 \mu \mathrm{g} / \mathrm{mL} .\end{array}$ & {$[158]$} \\
\hline & & Stems, bark & $\begin{array}{l}\text { EtOH } \\
\text { extract, } \\
n \text {-Hex, } \\
\text { DCM, } \\
\text { EtOAc, Aq. } \\
\text { fractions }\end{array}$ & MTT assay & $\begin{array}{l}\text { HCT-116 (colon), } \\
\text { OVCAR-8 (ovarian), } \\
\text { SF-295 (glioblastoma) } \\
\text { tumor cell lines }\end{array}$ & $\begin{array}{l}\text { EtOAc and Aq. fractions showed } \\
\text { minimum inhibition of cell } \\
\text { proliferation while EtOH } \\
\text { showed }=69.5-84.8 \%, n-\mathrm{Hex} \\
\text { fraction }=65.5-86.4 \% \text {, DCM } \\
\text { fraction and betulinic acid } \leq \\
86.5 \% \text {, doxorubicin } \geq 83.0 \%\end{array}$ & [49] \\
\hline & \multirow[b]{2}{*}{$\begin{array}{l}\text { M. } \\
\text { rubicauli- } \\
\text { slam }\end{array}$} & \multirow[b]{2}{*}{ Stems } & \multirow[b]{2}{*}{$\mathrm{MeOH}$} & $\begin{array}{l}\text { Hematological } \\
\text { parameters } \\
\text { (hemoglobin } \\
\text { content, RBC, } \\
\text { WBC, PCV) }\end{array}$ & $\begin{array}{l}\text { Ehrlich ascites carcinoma } \\
\text { (EAC) tumor model, Swiss } \\
\text { albino mice }\end{array}$ & $\begin{array}{l}\text { At a dose of } 400 \mathrm{mg} / \mathrm{kg} \text {, the level } \\
\text { of WBC increased, with decreases } \\
\text { in RBC, PCV as compared to } \\
\text { standard drug } 5 \text {-FU } 20 \mathrm{mg} / \mathrm{kg}, i P\end{array}$ & \multirow[b]{2}{*}[122]{} \\
\hline & & & & $\begin{array}{l}\text { XTT assay } \\
\text { (EAC, MCF-7, } \\
\text { MDA-MB } \\
\text { 435S cell lines }\end{array}$ & In vivo: Swiss albino mice & $\begin{array}{c}\text { At dose of } 200 \mathrm{mg} / \mathrm{kg} ; \mathrm{IC}_{50} \\
\text { values of extract; } \\
\text { EAC }=72.326 \mu \mathrm{g} / \mathrm{mL}, \\
\mathrm{MCF}-7=69.692 \mu \mathrm{g} / \mathrm{mL}, \\
\text { MDA-MB } 435 \mathrm{~S}=80.565 \mu \mathrm{g} / \mathrm{mL} ; \\
\mathrm{IC}_{50} \text { tamoxifen }(\text { stranded) } \\
\text { EAC }=22.42 \mu \mathrm{g} / \mathrm{mL}, \\
\text { MCF-7 }=20.7 \mu \mathrm{g} / \mathrm{mL}, \mathrm{MDA}-\mathrm{MB} \\
435 \mathrm{~S}=20.87 \mu \mathrm{g} / \mathrm{mL}\end{array}$ & \\
\hline & $\begin{array}{c}\text { M. } \\
\text { verrucosa }\end{array}$ & Barks & $\mathrm{EtOH}$ & MTT assay & $\begin{array}{l}\text { Human tumor cell lines } \\
\text { HL-60 (acute myeloid } \\
\text { leukemia), HCT-116 } \\
\text { (colorectal carcinoma), } \\
\text { PC-3 (prostate } \\
\text { adenocarcinoma), SF-295 } \\
\text { (glioblastoma) }\end{array}$ & $\begin{array}{c}\text { Extract displayed } \mathrm{IC}_{50} \geq \\
50 \mu \mathrm{g} / \mathrm{mL} \text { against all cell lines }\end{array}$ & {$[137]$} \\
\hline & $\underset{\text { pteridifo- }}{\text { lia }}$ & Barks & $\mathrm{EtOH}$ & MTT assay & $\begin{array}{l}\text { Human tumor cell lines } \\
\text { HL-60 (acute myeloid } \\
\text { leukemia), HCT-116 } \\
\text { (colorectal carcinoma), } \\
\text { PC-3 (prostate } \\
\text { adenocarcinoma), SF-295 } \\
\text { (glioblastoma) }\end{array}$ & $\begin{array}{c}\text { Extract displayed } \mathrm{IC}_{50} \geq \\
50 \mu \mathrm{g} / \mathrm{mL} \text { against all cell lines }\end{array}$ & [137] \\
\hline \multirow{2}{*}{$\begin{array}{l}\text { Antidiabetic } \\
\text { activity }\end{array}$} & \multirow{2}{*}{ M. pudica } & Aerial parts & $\begin{array}{l}\mathrm{MeOH} \\
\text { extract and } \\
\text { fractions } \\
\text { (Hex, } \\
\text { EtOAc, } \\
\text { ACE, and } \\
\text { MeOH) }\end{array}$ & $\begin{array}{l}\alpha \text {-Amylase } \\
\text { inhibitory } \\
\text { assay, } \\
\alpha- \\
\text { glucosidase } \\
\text { inhibitory } \\
\text { assay }\end{array}$ & In vitro & $\begin{array}{c}\% \text { inhibition in } \alpha \text { - amylase and } \\
\alpha \text {-glucosidase inhibitory assays } \\
\text { showed by MeOH extract }=33.86 \\
\text { and } 95.65 \% \text { (fractions; } \\
\text { Hex }=10.583 \& 0.884 \% \text {, } \\
\text { EtOAc }=18.65 \text { and } 51.87 \% \text {, } \\
\text { ACE }=15.64 \text { and } 16.04 \%, \text { MeOH= } \\
27.21 \text { and } 4.83 \% \text { ), respectively. } \\
\text { Standard acarbose = } 28.24 \text { and } \\
36.93 \%\end{array}$ & [46] \\
\hline & & $\begin{array}{l}\text { Whole } \\
\text { plant }\end{array}$ & $80 \% \mathrm{EtOH}$ & $\begin{array}{l}\text { Oral glucose } \\
\text { tolerance test } \\
\text { (OGTT) and } \\
\text { fasting blood } \\
\text { glucose test }\end{array}$ & $\begin{array}{c}\text { Streptozotocin } \\
\text { (STZ)-induced diabetic } \\
\text { male albino Wistar rats }\end{array}$ & $\begin{array}{c}\text { Extract } 500 \mathrm{mg} / \mathrm{kg} \text { bw did not } \\
\text { decrease blood glucose in } \\
\text { STZ-induced diabetic rats as } \\
\text { compared to } 0.5 \mathrm{mg} / \mathrm{kg} \text { bw. After } \\
1 \text { week, blood glucose reduction } \\
\text { shown by extract }(500 \mathrm{mg} / \mathrm{kg} \\
\text { bw })=421.00 \mathrm{mg} / \mathrm{dL}, \\
\text { glybenclamide }(0.5 \mathrm{mg} / \mathrm{kg} \\
\text { bw })=572.67 \mathrm{mg} / \mathrm{dL}\end{array}$ & {$[159]$} \\
\hline
\end{tabular}


Table 2. Cont.

\begin{tabular}{|c|c|c|c|c|c|c|c|}
\hline Activities & Plant & Plant Part & $\begin{array}{l}\text { Extract/ } \\
\text { Fraction }\end{array}$ & Assay & Model & Results/Outcome/Response & References \\
\hline \multirow{6}{*}{$\begin{array}{l}\text { Antidiabetic } \\
\text { activity }\end{array}$} & \multirow[t]{2}{*}{ M. pudica } & $\begin{array}{l}\text { Whole } \\
\text { plant }\end{array}$ & $\begin{array}{l}\text { Aq. and } \\
\text { HyEtOH } \\
\text { extracts }\end{array}$ & $\begin{array}{l}\text { Fasting blood } \\
\text { glucose test } \\
\text { (FBG) }\end{array}$ & $\begin{array}{l}\text { Streptozotocin } \\
\text { (STZ)-induced diabetic } \\
\text { male albino Wistar rats }\end{array}$ & $\begin{array}{c}\text { Significantly decreased FBG } \\
\text { levels } \\
\text { At } 250 \mathrm{mg} / \mathrm{kg} \text { bw concentration } \\
\text { of Aq. }=517 \mathrm{mg} / \mathrm{dL}, \\
\mathrm{Hy}-\mathrm{EtOH}=484.00 \mathrm{mg} / \mathrm{dL} \text {. At } \\
500 \mathrm{mg} / \mathrm{kg} \text { bw concentration } \\
\mathrm{Aq} .=309.88 \mathrm{mg} / \mathrm{dL} \\
\mathrm{HyEtOH}=484.00 \mathrm{mg} / \mathrm{dL} \\
\text { glibenclamide }(0.5 \mathrm{mg} / \mathrm{kg} \\
\text { bw })=419.00 \mathrm{mg} / \mathrm{dL}\end{array}$ & {$[160]$} \\
\hline & & Leaves & $\begin{array}{l}\text { ACE-Aq.- } \\
\text { AA }(8.0 \mathrm{~mL} \\
70: 29.5: 0.5)\end{array}$ & $\begin{array}{l}\alpha \text {-Amylase } \\
\text { and } \alpha- \\
\text { glucosidase } \\
\text { inhibitory } \\
\text { assay }\end{array}$ & In vitro & $\begin{array}{l}\alpha \text {-Amylase }=189.3 \mu \mathrm{mol} \mathrm{AE} / \mathrm{g} ; \\
\alpha \text {-glucosidase }=6.6 \mu \mathrm{mol} \mathrm{AE} / \mathrm{g} . \\
\text { Acarbose was used as the } \\
\text { positive control. }\end{array}$ & {$[150]$} \\
\hline & \multirow{4}{*}{ M. pigra } & \multirow[t]{2}{*}{$\begin{array}{l}\text { Aq. } \\
\text { extracts }\end{array}$} & \multirow[t]{2}{*}{ Leaves } & \multirow[t]{2}{*}{$\begin{array}{l}\text { Fasting blood } \\
\text { glucose (FBG) }\end{array}$} & $\begin{array}{l}\text { Normoglycemic male ICR } \\
\text { mice }\end{array}$ & $\begin{array}{c}\text { Significant FBG reduction in aq. } \\
\text { extract } \\
(200 \mathrm{mg} / \mathrm{kg} / \mathrm{bw})=14.84 \% \\
(100 \mathrm{mg} / \mathrm{kg} \mathrm{bw})=16.60 \% \\
(400 \mathrm{mg} / \mathrm{kg} \mathrm{bw})=9.28 \%, \text { insulin } \\
(0.5 \mathrm{IU} / \mathrm{kg})=54.05 \% \\
\text { glibenclamide } \\
(1 \mathrm{mg} / \mathrm{kg})=31.39 \%\end{array}$ & \multirow[t]{2}{*}[127]{} \\
\hline & & & & & Diabetic male ICR mice & $\begin{array}{c}\text { Extract }(100 \mathrm{mg} / \mathrm{kg} \mathrm{bw})=25.01 \%, \\
\text { insulin }(0.5 \mathrm{IU} / \mathrm{kg})=56.62 \% \\
\text { glibenclamide } \\
(1 \mathrm{mg} / \mathrm{kg})=18.51 \%\end{array}$ & \\
\hline & & Stems & $\mathrm{MeOH}$ & $\begin{array}{l}\text { Glucose } \\
\text { oxidase } \\
\text { method }\end{array}$ & Swiss albino male mice & $\begin{array}{l}\text { Significant blood glucose } \\
\text { reduction by extract at } \\
400 \mathrm{mg} / \mathrm{kg} / \mathrm{bw}=50.50 \% \\
\text { glibenclamide }(10 \mathrm{mg} / \\
\mathrm{kg} / \mathrm{bw})=56.33 \%\end{array}$ & [97] \\
\hline & & Roots & $\mathrm{EtOH}$ & $\begin{array}{l}\text { Fasting blood } \\
\text { glucose (FBG) }\end{array}$ & Albino rats & $\begin{array}{c}\text { Significant blood glucose } \\
\text { reduction in acute study extract } \\
(250 \text { and } 500 \mathrm{mg} / \mathrm{kg})=360.00 \\
\text { and } 391.80 \mathrm{mg} / \mathrm{dL} \text { respectively; } \\
\text { glibenclamide } \\
(10 \mathrm{~mL} / \mathrm{kg})=485.8 \mathrm{mg} / \mathrm{dL} \text {. In } \\
\text { prolonged study, extract }(250 \text { and } \\
500 \mathrm{mg} / \mathrm{kg})=140.00 \text { and } \\
125.00 \mathrm{mg} / \mathrm{dL} \text {, respectively. } \\
\mathrm{Glibenclamide} \\
(10 \mathrm{~mL} / \mathrm{kg})=273.60 \mathrm{mg} / \mathrm{dL}\end{array}$ & {$[161]$} \\
\hline \multirow{5}{*}{$\begin{array}{l}\text { Wound- } \\
\text { healing } \\
\text { effects }\end{array}$} & \multirow{5}{*}{$\begin{array}{l}\text { M. } \\
\text { tenuiflora }\end{array}$} & Leaves & $\begin{array}{l}\text { Herbal mix } \\
\text { of leaf } \\
\text { extract } \\
(20 \%) \text { and } \\
\text { A. Vulgaris } \\
(20 \%)\end{array}$ & $\begin{array}{l}\text { In vitro/scratch } \\
\text { assay }\end{array}$ & $\begin{array}{l}\text { In vivo: Human } \\
\text { keratinocyte (HaCaT) and } \\
\text { umbilical vein endothelial } \\
\text { cells (HUVECs), mouse } \\
\text { fibroblast 3T3-L1 cells }\end{array}$ & Rapid wound healing observed & {$[162]$} \\
\hline & & Bark & $\begin{array}{c}\text { Aq. } \\
\text { extracts, } \\
\text { EtOH- } \\
\text { precipitated } \\
\text { com- } \\
\text { pounds } \\
\text { (EPC) }\end{array}$ & $\begin{array}{l}\text { Mitochondrial } \\
\text { activity (MTT, } \\
\text { WST-1), } \\
\text { proliferation } \\
\text { (BrdU incor- } \\
\text { poration), } \\
\text { necrosis } \\
\text { (LDH) }\end{array}$ & $\begin{array}{l}\text { In vitro: Human primary } \\
\text { dermal fibroblasts and } \\
\text { HaCaT keratinocytes }\end{array}$ & $\begin{array}{l}\text { Aq. extract }(10 \text { and } 100 \mu \mathrm{g} / \mathrm{mL}) \\
\text { loss of cell viability was observed } \\
\text { proliferation in dermal } \\
\text { fibroblasts. EPC }(10 \mu \mathrm{g} / \mathrm{mL}) \text { only } \\
\text { stimulated mitochondrial activity } \\
\text { and proliferation of dermal } \\
\text { fibroblasts. EPC at } 100 \mu \mathrm{g} / \mathrm{mL} \\
\text { showed minor stimulation of } \\
\text { human kerationocytes }\end{array}$ & [108] \\
\hline & & $\begin{array}{l}\text { Whole } \\
\text { plant }\end{array}$ & $\begin{array}{l}10 \% \text { con- } \\
\text { centration }\end{array}$ & & Adult human external use & Significant results observed & {$[50]$} \\
\hline & & $\begin{array}{l}\text { Whole } \\
\text { plant }\end{array}$ & $\mathrm{MeOH}$ & $\begin{array}{l}\text { Chorioallantoic } \\
\text { membrane } \\
\text { (CAM) model }\end{array}$ & $\begin{array}{c}\text { Ex vivo: Fertilized chick } \\
\text { eggs }\end{array}$ & Significant results observed & [163] \\
\hline & & & $\begin{array}{l}\text { Crude } \\
\text { EtOH } \\
\text { cortex } \\
\text { extract stan- } \\
\text { dardized in } \\
\text { its tannin } \\
\text { concentra- } \\
\text { tion } \\
(1.8 \%)\end{array}$ & $\begin{array}{l}\text { Double-blind, } \\
\text { randomized, } \\
\text { placebo- } \\
\text { controlled } \\
\text { clinical trial }\end{array}$ & $\begin{array}{c}\text { Patients diagnosed } \\
\text { withvenous leg ulceration } \\
\text { (VLU) }\end{array}$ & Ulcer size was reduced by $92 \%$ & {$[24]$} \\
\hline
\end{tabular}


Table 2. Cont

\begin{tabular}{|c|c|c|c|c|c|c|c|}
\hline Activities & Plant & Plant Part & $\begin{array}{l}\text { Extract/ } \\
\text { Fraction }\end{array}$ & Assay & Model & Results/Outcome/Response & References \\
\hline \multirow[t]{2}{*}{$\begin{array}{l}\text { Hypolipide- } \\
\text { mic } \\
\text { activity }\end{array}$} & \multirow[t]{2}{*}{ M. pudica } & $\begin{array}{l}\text { Whole } \\
\text { plant }\end{array}$ & $80 \% \mathrm{EtOH}$ & $\begin{array}{l}\text { TC, TG, HDL, } \\
\text { LDL }\end{array}$ & $\begin{array}{l}\text { Streptozotocin } \\
\text { (STZ)-induced diabetic } \\
\text { male albino Wistar rats }\end{array}$ & $\begin{array}{c}\text { Extract at } 500 \mathrm{mg} / \mathrm{kg} \text { bw } \\
\text { increased HDL } \\
\text { level }=46.33 \mathrm{mg} / \mathrm{dL} \text { but } \\
\text { decreased } \mathrm{TC}=111.67 \mathrm{mg} / \mathrm{dL}, \\
\mathrm{TG}=121.67 \mathrm{mg} / \mathrm{dL} \\
\mathrm{LDL}=41.00 \mathrm{mg} / \mathrm{dL} \text { in the } \\
\text { diabetic rats as compared to } \\
\text { standard glybenclamide } \\
(0.5 \mathrm{mg} / \mathrm{kg} b w)\end{array}$ & [159] \\
\hline & & Leaves & $\mathrm{EtOH}$ & $\begin{array}{l}\text { TG, TC, } \\
\text { VLDL, LDL, } \\
\text { HDL }\end{array}$ & $\begin{array}{l}\text { Wistar albino rats, induced } \\
\text { hepatic injury by }\left(\mathrm{CCl}_{4}\right)\end{array}$ & $\begin{array}{c}\text { Extract at the dose of } 400 \mathrm{mg} / \mathrm{kg} \\
\text { showed significant decreases in } \\
\text { TG } \\
96.8 \mathrm{mg} / \mathrm{dL}, \mathrm{TC}=98.7 \mathrm{mg} / \mathrm{dL} \\
\text { VLDL }=26.9 \mathrm{mg} / \mathrm{dL} \\
\mathrm{LDL}=37.4 \mathrm{mg} / \mathrm{dL} \\
\mathrm{HDL}=34.3 \mathrm{mg} / \mathrm{dL}\end{array}$ & [58] \\
\hline \multirow{7}{*}{$\begin{array}{l}\text { Anti- } \\
\text { infla- } \\
\text { mmatory } \\
\text { and } \\
\text { hepato- } \\
\text { protective } \\
\text { activities }\end{array}$} & $\begin{array}{l}\text { M. } \\
\text { tenuflora }\end{array}$ & Bark & $\begin{array}{l}\mathrm{MeOH} / \mathrm{NaOH} \\
\text { and EtOH } \\
\text { precipita- } \\
\text { tion } \\
\text { polysac- } \\
\text { cride }\end{array}$ & $\begin{array}{l}\text { Edematogenic } \\
\text { effect }\end{array}$ & $\begin{array}{l}\text { Wistar rats of acute } \\
\text { inflammation (paw edema } \\
\text { and peritonitis) }\end{array}$ & $\begin{array}{c}\text { Edematogenic effect at } \\
1 \mathrm{mg} / \mathrm{kg}^{-} \text {concentration of } \\
\text { polysaccharides extracted from } \\
\text { M. tenuiflora bark was }=40 \mathrm{x} \text { as } \\
\text { compared to saline, while } \\
\text { inhibited by L-NAME }=52 \% \text {, } \\
\text { dexamethasone }=26 \%\end{array}$ & [164] \\
\hline & \multirow{3}{*}{ M. pudica } & Leaves & Aq. & $\begin{array}{l}\text { Bovine serum } \\
\text { albumin, } \\
\text { egg }\end{array}$ & In vitro & $\begin{array}{c}\text { Reduced activity of extract in } \\
\text { serum albumin at } 0.2 \text { and } 1.0 \% \\
\text { concentration }=59.7 \text { and } 83.7 \% \text {, } \\
\text { respectively; while drug } \\
\text { diclofenac sodium }=51.5 \% \text {; In } \\
\text { egg at } 0.2 \text { and } 1.0 \% \text { conc }=39.6 \\
\text { and } 76.7 \% \text {, respectively. Standard } \\
\text { drug diclofenac sodium }=42.5 \%\end{array}$ & {$[62]$} \\
\hline & & Leaves & Aq. & $\begin{array}{l}\text { Sperm } \\
\text { motility, } \\
\text { sperm } \\
\text { morphology, } \\
\text { sperm count }\end{array}$ & $\begin{array}{l}\text { Adult male } \\
\text { Sprague-Dawley rats, } \\
\text { cadmium-induced } \\
\text { testicular damage }\end{array}$ & $\begin{array}{l}\text { (1) Significant activation of sperm } \\
\text { motility shown by extract at } \\
250 \mathrm{mg} / \mathrm{kg}=13.00 \% \text {; } \\
500 \mathrm{mg} / \mathrm{kg}=9.00 \% \text {, control } \\
\text { group (Aq.) }=15.00 \% \text {. } \\
\text { (2) Both doses showed significant } \\
\text { effects on sperm morphology. } \\
\text { (3) Sperm counts were } \\
\text { significantly increased at } \\
250 \mathrm{mg} / \mathrm{kg}=4.18 \times 10^{6} / \mathrm{cc} ; \\
500 \mathrm{mg} / \mathrm{kg}=2.54 \times 10^{6} / \mathrm{cc} ; \\
\text { control group }=12.78 \times 10^{6} / \mathrm{cc}\end{array}$ & [165] \\
\hline & & $\begin{array}{l}\text { Whole } \\
\text { plant }\end{array}$ & $\begin{array}{l}\text { Crude } \\
\text { powder }\end{array}$ & $\begin{array}{l}\text { ALP, ACP, } \\
\text { LPO, } \gamma-G T \\
\text { AST, ALT. }\end{array}$ & $\begin{array}{l}\text { Male albino rats, induced } \\
\text { jaundice by }\left(\mathrm{CCl}_{4}\right)\end{array}$ & $\begin{array}{l}100 \mathrm{mg} / \mathrm{kg} \text { dose of extract } \\
\text { significantly reduced the levels of } \\
\text { all parameters and protected the } \\
\text { hepatic cells }\end{array}$ & [57] \\
\hline & $\begin{array}{l}\text { M. } \\
\text { caesalpi- } \\
\text { niifolia }\end{array}$ & Leaves & $\begin{array}{l}\text { HyOH } \\
\text { extract, } \\
\text { EtOAc } \\
\text { fraction }\end{array}$ & $\begin{array}{l}\text { Histopathologic } \\
\text { analysis }\end{array}$ & $\begin{array}{l}\text { alIn vivo: Adult male Wistar } \\
\text { rats }\end{array}$ & $\begin{array}{c}\mathrm{HyOH} \text { extract (125 and } \\
250 \mathrm{mg} / \mathrm{kg}), \text { EtOAc fraction ( } 25 \\
\text { and } 50 \mathrm{mg} / \mathrm{kg} \text { ) were effective }\end{array}$ & [166] \\
\hline & \multirow[b]{2}{*}{ M. pigra } & \multirow[b]{2}{*}{ Leaves } & \multirow[b]{2}{*}{$\mathrm{HyMeOH}$} & $\begin{array}{l}\text { TNF } \alpha- \\
\text { induced }\end{array}$ & $\begin{array}{l}\text { In vitro: male Wistar rats, } \\
\text { endothelial cells }\end{array}$ & $\begin{array}{c}\text { Extract }(0.01-1 \mathrm{mg} / \mathrm{mL}) \text { inhibited } \\
90 \% \text { and pyrrolidine } \\
\text { dithiocarbamate }(200 \mathrm{mM}) \\
\text { inhibited } 98 \% \mathrm{TNF} \alpha\end{array}$ & [155] \\
\hline & & & & $\begin{array}{c}\text { Chronic } \\
\text { hypoxic PAH }\end{array}$ & In vivo: Male Wistar rats & $\begin{array}{c}\text { Decreased pulmonary arterial } \\
\text { pressure }=22.3 \% \text {, pulmonary } \\
\text { artery }=20.0 \% \text {, cardiac } \\
\text { remodeling }=23.9 \% \text { was } \\
\text { observed }\end{array}$ & [155] \\
\hline
\end{tabular}


Table 2. Cont.

\begin{tabular}{|c|c|c|c|c|c|c|c|}
\hline Activities & Plant & Plant Part & $\begin{array}{l}\text { Extract/ } \\
\text { Fraction }\end{array}$ & Assay & Model & Results/Outcome/Response & References \\
\hline \multirow[t]{3}{*}{$\begin{array}{l}\text { Antinoci- } \\
\text { ceptive } \\
\text { activity }\end{array}$} & M. pudica & Leaves & EtOAc & $\begin{array}{l}\text { Hot plate test, } \\
\text { tail flick test, } \\
\text { AA-induced } \\
\text { writhing test }\end{array}$ & Adult Wistar rats & $\begin{array}{c}\text { Hot plate test after } 30 \mathrm{~min} \\
\text { significantly increased analgesic } \\
\text { activity by extract at } \\
100 \mathrm{mg} / \mathrm{kg}=8.03, \\
200 \mathrm{mg} / \mathrm{kg}=8.51 ; \\
400 \mathrm{mg} / \mathrm{kg}=8.93 ; \text { standard } \\
\text { diclofenac sod. }=9.66 \text {. } \\
\text { Tail flick test after } 30 \text { mins } \\
\text { significantly increased analgesic } \\
\text { activity at } 100 \mathrm{mg} / \mathrm{kg} \\
\text { extract }=6.78, \\
200 \mathrm{mg} / \mathrm{kg}=8.16 ; \\
400 \mathrm{mg} / \mathrm{kg}=7.98 ; \text { standard } \\
\text { diclofenac sod. }=8.11 \text {. } \\
\text { Significant reduced writhing } \\
\text { shown by extract at } 100,200, \text { and } \\
400 \mathrm{mg} / \mathrm{kg}=20.18,33.42, \text { and } \\
43.46 \%, \text { respectively; standard } \\
\text { diclofenac sodium }=52.01 \%\end{array}$ & {$[167]$} \\
\hline & M. Pigra & Stems & $\mathrm{MeOH}$ & $\begin{array}{l}\text { AA-induced } \\
\text { writhing test }\end{array}$ & Swiss albino mice male & $\begin{array}{c}\text { Significant reduction in writhing; } \\
\text { extract } \\
(400 \mathrm{mg} / \mathrm{kg} / \mathrm{bw})=85.01 \% \\
\begin{array}{c}\text { aspirin } \\
(400 \mathrm{mg} / \mathrm{kg} / \mathrm{bw})\end{array}=59.97 \%\end{array}$ & [97] \\
\hline & M. albida & Roots & Aq. & $\begin{array}{l}\text { AA-induced } \\
\text { writhing test, } \\
\text { hot plate test }\end{array}$ & Male ICR mice & $\begin{array}{l}\text { Extract }(50 \mathrm{mg} / \mathrm{kg}) \text { and dypirone } \\
(500 \mathrm{mg} / \mathrm{kg}) \text { reduced writhing. } \\
\text { Fentanyl }(0.1 \mathrm{mg} / \mathrm{kg}) \text { and extract } \\
\text { at variable concentrations } \\
\text { showed pain latency }\end{array}$ & [106] \\
\hline \multirow[t]{2}{*}{$\begin{array}{l}\text { Antiepile- } \\
\text { ptic } \\
\text { activity }\end{array}$} & \multirow[t]{2}{*}{ M. pudica } & Leaves & EtOAc & $\begin{array}{l}\text { Electric } \\
\text { shocks, } \\
\text { PTZ-induced } \\
\text { convulsions, } \\
\text { INH-induced } \\
\text { convulsions }\end{array}$ & Swiss albino mice & $\begin{array}{c}\text { In electric shock test, extract at } \\
100,200, \text { and } 400 \mathrm{mg} / \mathrm{kg} \text { and } \\
\text { diazepam } 04 \mathrm{mg} / \mathrm{kg} \text { exhibited } \\
\text { delayed onset time of } \\
\text { convulsion }=1.87,2.69,3.21, \text { and } \\
3.53 \mathrm{~s}, \text { as well as decreased } \\
\text { duration of convulsion of } 68.09, \\
53.54,42.21, \text { and } 38.89 \mathrm{~s}, \\
\text { respectively. } \\
\text { In PTZ-induced convulsion test, } \\
\text { extract at } 100,200, \text { and } \\
400 \mathrm{mg} / \mathrm{kg} \text { and diazepam } \\
04 \mathrm{mg} / \mathrm{kg} \text { showed delayed onset } \\
\text { time of convulsion }=5.38,6.08, \\
6.98, \text { and } 7.81 \mathrm{~min} \text { and decreased } \\
\text { duration of convulsion of } 14.76, \\
12.65,11.13, \text { and } 9.39 \text { min, } \\
\text { respectively. } \\
\text { In INH-induced convulsion test, } \\
\text { extract at } 100 \mathrm{mg} / \mathrm{kg}=37.21, \\
200 \mathrm{mg} / \mathrm{kg}=45.49, \\
400 \mathrm{mg} / \mathrm{kg}=58.62 \text { min, } \\
\text { diazepam } 04 \mathrm{mg} / \mathrm{kg}=69.14 \mathrm{~min} \\
\text { delayed convulsion latency }\end{array}$ & {$[167]$} \\
\hline & & Roots & $\mathrm{EtOH}$ & $\begin{array}{l}\text { Maximal- } \\
\text { electroshock- } \\
\text { induced } \\
\text { seizures } \\
\text { (MES) and } \\
\text { pentylenete- } \\
\text { trazole } \\
\text { (PTZ)- } \\
\text { induced } \\
\text { seizures }\end{array}$ & Adult Swiss albino mice & $\begin{array}{l}\text { In MES, the } \% \text { inhibition of } \\
\text { convulsions in mice at different } \\
\text { doses }(1000 \mathrm{mg} / \mathrm{kg}=42.41 \% \text {; } \\
2000 \mathrm{mg} / \mathrm{kg}=52.35 \%) \text { were } \\
\text { noted and standard valproate } \\
\text { showed } 73.86 \% \text { inhibition at } \\
200 \mathrm{mg} / \mathrm{kg} \text {. In PTZ-induced } \\
\text { seizure, the clonic convulsion } \\
\text { onset time, duration of clonic } \\
\text { convulsions, and postictal } \\
\text { depression were observed for a } \\
\text { period of } 30 \text { min. Extract }(1000 \\
\text { and } 2000 \mathrm{mg} / \mathrm{kg}) \text { showed } \\
\text { significant decreases in numbers } \\
\text { and durations of myoclonic jerks, } \\
\text { clonic seizures, and postictal } \\
\text { depression. }\end{array}$ & {$[35]$} \\
\hline
\end{tabular}


Table 2. Cont.

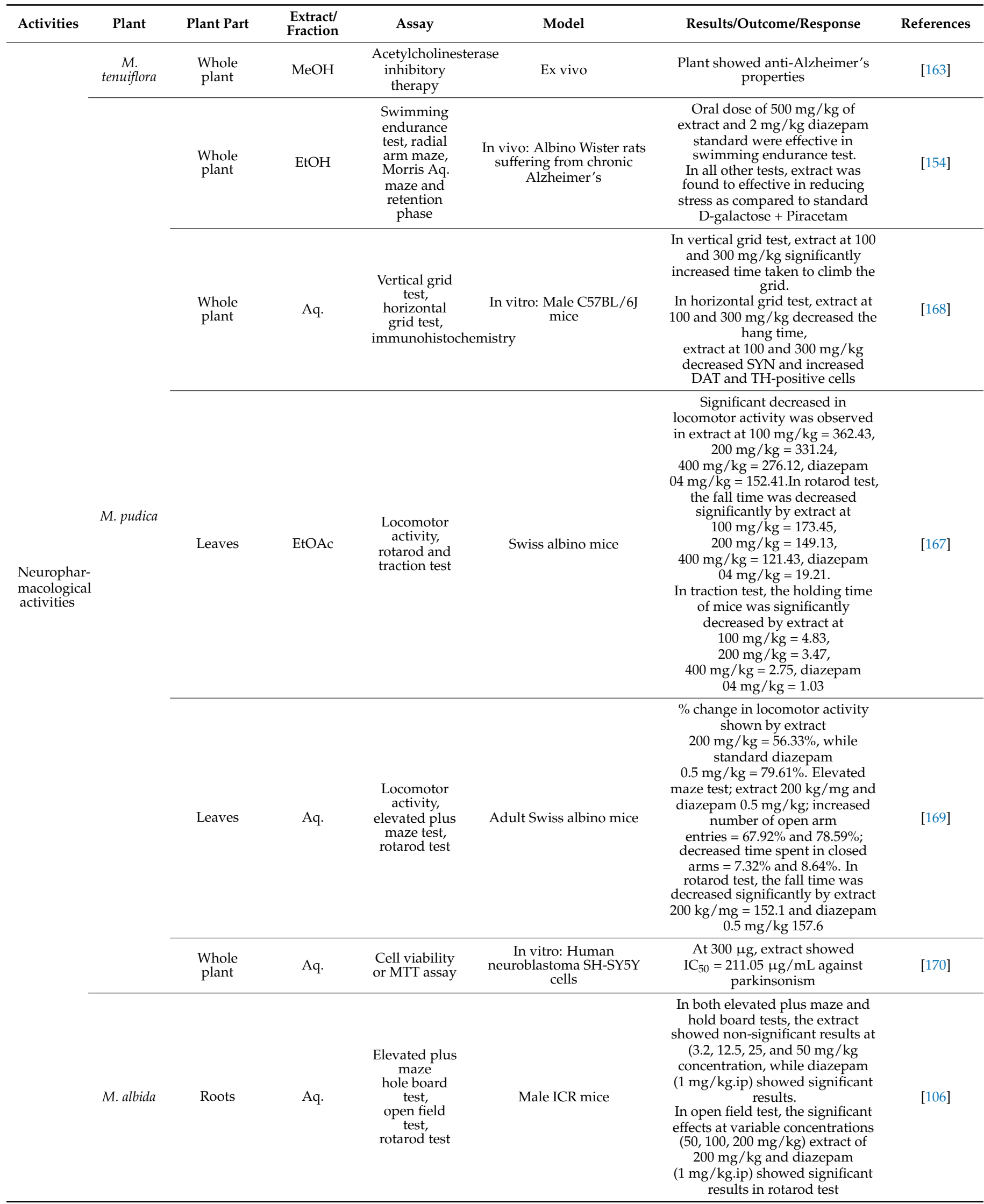


Table 2. Cont

\begin{tabular}{|c|c|c|c|c|c|c|c|}
\hline Activities & Plant & Plant Part & $\begin{array}{l}\text { Extract/ } \\
\text { Fraction }\end{array}$ & Assay & Model & Results/Outcome/Response & References \\
\hline \multirow{3}{*}{$\begin{array}{l}\text { Antiallergic } \\
\text { and } \\
\text { antihyper- } \\
\text { uricemic } \\
\text { activities }\end{array}$} & $\begin{array}{l}\text { M. } \\
\text { tenuiflora }\end{array}$ & Bark & $\begin{array}{l}\text { Glyceric } \\
\text { extract }\end{array}$ & Patch test & $\begin{array}{l}\text { Women suffering from } \\
\text { acute eczema }\end{array}$ & Positive result was observed & {$[113]$} \\
\hline & \multirow[t]{2}{*}{ M. pudica } & \multirow{2}{*}{ Leaves } & \multirow{2}{*}{ EtOH 70\% } & \multirow{2}{*}{$\begin{array}{l}\text { Inhibitory } \\
\text { activity assay }\end{array}$} & $\begin{array}{c}\text { In vitro: Male rats (Rattus } \\
\text { norvegicus) }\end{array}$ & $\begin{array}{c}\text { Inhibition \% of uric acid } \\
\text { formation in } M \text {. pudica tablet } \\
\mathrm{IC}_{50}=68.04 \mathrm{ppm} \text {, extract } \mathrm{IC}_{50} \\
=32.75 \mathrm{ppm} \text {, allopurinol } \\
\text { (standard) } \mathrm{IC}_{50}=18.73 \mathrm{ppm}\end{array}$ & \multirow[t]{2}{*}[171]{} \\
\hline & & & & & $\begin{array}{l}\text { Ex vivo: Swiss-Webster } \\
\text { mice (Mus musculus) }\end{array}$ & $\begin{array}{c}\text { Inhibitory activity on uric acid } \\
\text { formation shown by } \mathrm{M} \text {. pudica } \\
\text { tablet } 125 \mathrm{mg} / \mathrm{kg}=36 \% \\
\text { extract }=43 \%\end{array}$ & \\
\hline \multirow{6}{*}{$\begin{array}{l}\text { Laravicidal, } \\
\text { antipara- } \\
\text { sitic, and } \\
\text { molluscici- } \\
\quad \text { dal } \\
\text { activities }\end{array}$} & \multirow{4}{*}{$\begin{array}{l}\text { M. } \\
\text { tenuiflora }\end{array}$} & $\begin{array}{l}\text { Leaves and } \\
\text { stem }\end{array}$ & & $\begin{array}{l}\text { Parasitological } \\
\text { and } \\
\text { histological } \\
\text { analysis }\end{array}$ & Female lambs & No significant effect observed & {$[172]$} \\
\hline & & Leaves & $\begin{array}{l}\mathrm{Hex}, \mathrm{ACE}, \\
\mathrm{MeOH}\end{array}$ & $\begin{array}{l}\text { Antiprotozoal } \\
\text { assay }\end{array}$ & $\begin{array}{l}\text { In vitro: E. histolytica, } \\
\text { G. lamblia }\end{array}$ & $\begin{array}{c}\text { At concentration of } \\
\text { 2.5-200 } \mu \mathrm{g} / \mathrm{mL} ; \text { E. histolytica and } \\
\text { G. lamblia showed activities in } \\
\text { Hex }\left(\mathrm{IC}_{50}\right)=65.9 \text { and } \\
80.2 \mu \mathrm{g} / \mathrm{mL}, \mathrm{ACE}=80.7 \text { and } \\
116.8 \mu \mathrm{g} / \mathrm{mL}, \mathrm{MeOH}=73.5 \text { and } \\
95.5 \mu \mathrm{g} / \mathrm{mL}, \text { respectively }\end{array}$ & {$[173]$} \\
\hline & & \multirow[b]{2}{*}{ Stems } & \multirow[b]{2}{*}{$\mathrm{EtOH}$} & & $\begin{array}{l}\text { In vitro: Biomphalaria } \\
\text { glabrata }\end{array}$ & $\begin{array}{c}\text { At } 100 \mu \mathrm{g} / \mathrm{mL} \mathrm{LC}_{10}=6.59 \\
\mathrm{mg} / \mathrm{L} ; \mathrm{LC}_{50}=20.22 \mathrm{mg} / \mathrm{L} ; \\
\mathrm{LC}_{90}=62.05 \mathrm{mg} / \mathrm{L}\end{array}$ & [174] \\
\hline & & & & $\begin{array}{l}\text { MTT assay } \\
\text { and counting } \\
\text { parasites }\end{array}$ & $\begin{array}{l}\text { In vitro: Human } \\
\text { leishmaniases }\end{array}$ & $\begin{array}{l}\text { Extract of Mimosa at } \\
\text { concentrations of } 500 \text { and } 1000 \\
\text { mg/L rapidly reduced parasite } \\
\text { proliferation }\end{array}$ & {$[175]$} \\
\hline & M. pudica & Leaves & Aq. & $\begin{array}{l}\text { Larvicidal } \\
\text { assay }\end{array}$ & Larvae (Aedes aegypti) & $\begin{array}{l}\text { Poor larvicidal action at dose of } \\
2000 \mathrm{mg} / \mathrm{kg}\end{array}$ & [176] \\
\hline & $\begin{array}{l}\text { M. } \\
\text { caesalpini- } \\
\text { ifolia }\end{array}$ & Leaves & $\begin{array}{l}\text { Dry plant } \\
\text { leaves and } \\
\text { condensed } \\
\text { tannin }\end{array}$ & Worm burden & In vivo: Goats & $\begin{array}{l}\text { Significantly controlled the } \\
\text { gastrointestinal nematodes } \\
\text { (Haemonchus, Tricho strongylus, } \\
\text { Oesophagostomum) in goats }\end{array}$ & {$[177]$} \\
\hline \multirow{3}{*}{$\begin{array}{l}\text { Antispasmo- } \\
\text { lytic, } \\
\text { an- } \\
\text { tivenom, } \\
\text { and } \\
\text { antiviral } \\
\text { activities - }\end{array}$} & \multirow[b]{2}{*}{$\begin{array}{l}\text { M. } \\
\text { tenuiflora }\end{array}$} & \multirow[b]{2}{*}{ Bark } & $\begin{array}{l}\mathrm{BuOH} \\
\mathrm{EtOAc} \\
\mathrm{MeOH}\end{array}$ & In vitro & Guinea pigs and rats & $\begin{array}{l}\text { Buthanol, EtOAc, and } \mathrm{MeOH} \text { at } \\
30.0 \mu \mathrm{g} / \mathrm{mL} \text { showed significant } \\
\text { results. }\end{array}$ & [135] \\
\hline & & & $\begin{array}{l}\text { Aq. extract } \\
\text { and } \\
\text { fractions } \\
\text { (DCM, } \\
\text { BuOH and } \\
\text { EtOAc) }\end{array}$ & Envenomation & $\begin{array}{l}\text { Male BALB/c mice } \\
\text { (in vitro) }\end{array}$ & $\begin{array}{c}\text { Inhibition }(\%) \text { at } 30 \mathrm{mg} / \mathrm{kg} \\
\text { Aq. extract }=76 \% ; \text { at } 40 \mathrm{mg} / \mathrm{kg} \text {; } \\
\text { DCM fraction }=73 \% \text { butyl } \\
\text { alcohol, fraction }=81 \% ; \text { EtOAc } \\
\text { fraction }=86 \%\end{array}$ & [40] \\
\hline & M. hamta & $\begin{array}{l}\text { Whole } \\
\text { plant and } \\
\text { callus } \\
\text { tissue }\end{array}$ & $\begin{array}{l}\text { EtOH } \\
\text { extract, } \\
\text { Fractions, } \\
\text { Aq., CF, PE, } \\
\text { BZ }\end{array}$ & $\begin{array}{l}\text { Plaque } \\
\text { inhibition } \\
\text { method }\end{array}$ & $\begin{array}{l}\text { In vivo: } H \text {. simplex, } \\
\text { Poliomyelitis type } 1, V \text {. } \\
\text { stomatitis }\end{array}$ & $\begin{array}{c}\text { EtOH extract showed significant } \\
\text { activities against all three viruses, } \\
\text { while PE and CF fractions were } \\
\text { found to be active against } V \text {. } \\
\text { stomatitis }\end{array}$ & {$[60]$} \\
\hline
\end{tabular}

\subsection{Antimicrobial Activity}

Valencia-Gómez et al. [129] determined the antibacterial activity of biofilms made from chitosan and M. tenuiflora bark. Composite biofilms in different concentrations (100:0, 90:10, 80:20, and 70:30) successfully inhibited the growth of E. coli and M. lysodeikticus. SouzaAraújo et al. [130] measured the antimicrobial activity of pyroligneous acid (PA) obtained from slow pyrolysis of wood of M. tenuiflora against E. coli, P. aeruginosa, S. aureus, C. albicans, and $C$. neoformans using the agar diffusion method. The growth of all microorganisms was inhibited by pyroligneous acid at different tested concentrations (20,50, and 100\%), whereas gentamicin was used as a standard drug. The antimicrobial potential of $\mathrm{EtOH}$ $(95 \%)$ extract of $M$. tenuiflora bark against different bacterial and fungal strains has been reported. Active doses of the extract inhibited the growth of E. coli, B. subtilis, M. luteus, and P. oxalicum. Gonçalves et al. [131] reported the antimicrobial potential of the hydroalcoholic extract of $M$. tenuiflora bark against various bacterial strains using the agar well diffusion method. The results revealed that the extract successfully inhibited the growth of $S$. 
pyogenes, P. Mirabilis, S. sonnei, S. pyogenes, and Staphylococcus spp. Padilha et al. [132] described the antibacterial activity of the EtOH extract of $M$. tenuiflora stem bark against $S$. aureus by using the minimum inhibitory concentration (MIC) with the agar dilution method and time-kill assay. At concentrations up to 4x MIC, only a bacteriostatic effect was observed, while at 8.x MIC a fast bactericidal effect was observed [133]. The minimum inhibitory concentration shown by active doses of $95 \%$ M. tenuiflora EtOH extract against $S$. epidermidis and A. calcoaceticus were $>10.0 \mu \mathrm{g} / \mathrm{mL}, S$. aureus and M. luteus $=10.0 \mu \mathrm{g} / \mathrm{mL}, E$. coli and K. pneumonia $=20.0 \mu \mathrm{g} / \mathrm{mL}$, and C. albicans $=70.0 \mu \mathrm{g} / \mathrm{mL}$ [134]. The antimicrobial potential of $\mathrm{BuOH}, \mathrm{MeOH}$, and EtOAc extracts of $M$. tenuiflora bark against S. aureus, E. coli, and C. albicans has been reported [135]. De Morais-Leite et al. [136] determined the antibacterial potential of the $\mathrm{EtOH}$ extract of $M$. tenuiflora bark via the minimum inhibitory concentration (MIC) and the minimum bactericidal concentration (MBC) values against S. aureus (ATCC 25.925 and ATCC 25.213), E. coli (ATCC 8859 and ATCC 2536), and $P$. aeruginosa (ATCC 25.619). S. aureus (ATCC 25.925) and P. aeruginosa (ATCC 25.619) showed MIC and MBC values of 128 and $256 \mu \mathrm{g} / \mathrm{mL}$, respectively, while S. aureus (ATCC 25.213) showed $\mathrm{MIC}=512$ and $\mathrm{MBC}=1024 \mu \mathrm{g} / \mathrm{mL}$. For E. coli (ATCC 8859) and E. coli (ATCC 2536), the observed values were $\mathrm{MIC}=1024$ and $\mathrm{MBC}>1024 \mu \mathrm{g} / \mathrm{mL}$. Silva and his colleagues reported on the antimicrobial potential of the EtOH extract of $M$. tenuiflora bark using the minimum inhibitory concentration (MIC) values against S. aureus, E. coli, C. albicans, and $T$. interdigitale. Lower MIC values were observed against S. aureus [137].

Racadio [116] and Molina [117] reported on the antimicrobial activity of the EtOH extract of $M$. pudica leaves against S. aureus, B. subtilis, and C. albicans using the Kirby-Bauer disc diffusion method. Inhibition zones were observed against $S$. aureus $=21.8 \mathrm{~mm}(4.61 \%)$, B. subtilis $=23.7 \mathrm{~mm}(9.56 \%)$, and C. albicans $=6.1 \mathrm{~mm}(1.96 \%)$. Nagarajan et al. [139] determined the antibacterial activity of Aq. extracts of $M$. pudica leaves and stems against E. coli, staphylococcus sp., Bacillus sp., Pseudomonas sp., and Streptococci sp. by disc diffusion method. Zones of inhibition were observed against order E. coli $(18 \mathrm{~mm})>$ Bacillus sp. $(12.5 \mathrm{~mm})>$ Pseudomonas $\mathrm{sp} .(12 \mathrm{~mm})>$ Staphylococcus $\mathrm{sp} .(11 \mathrm{~mm})>$ Streptococcai $\mathrm{sp}$. (9 mm). Abirami et al. [139] reported on the antimicrobial potential of extracts (ACE, EtOAc, petroleum ether, and Aq.) of M. pudica leaves using the well diffusion method. The antimicrobial efficacy levels of all of the extracts were determined against E. coli, $P$. aeurogiosa, L., Bacillus, S. typhi, S. aureus, P. foedians, F. oxysporum, and P. variotii at different concentrations of $30,60,90$, and $120 \mu \mathrm{L} / \mathrm{mL}$. ACE extract showed a maximum zone of inhibition against $S$. aureus, while Aq. extract showed a maximum activity against $E$. coli. Petroleum ether showed a higher zone of inhibition against $S$. typhi. Durgadevi and Karthika [62] determined the antimicrobial potential of Aq. extract of M. pudica leaves by using the agar well diffusion method against B. cereus, E. coli, P. valgaris, $P$. auroginosa, S. aureus, A. flavus, A. niger, A. terreus, Fusarium sp., and Penicillium sp. at different concentrations $(25,50,75$ and $100 \mathrm{mg})$. The extract showed significant zones of inhibition at $100 \mathrm{mg}$ concentration. Sheeba et al. [140] determined the antibacterial activity of the $\mathrm{MeOH}$ extract of $M$. pudica leaves using the disc diffusion method against $P$. aeruginosa, $S$. aureus, and $V$. harveyi. The plant extract showed zones of inhibition against S. aureus $(10.66 \mathrm{~mm})$, P. aeruginosa $(8.66 \mathrm{~mm})$, and $V$. harveyi $(8.00 \mathrm{~mm})$, while ampicillin was used as the standard antibiotic. Sheeba et al. [140] determined the antimycobacterial activity of $\mathrm{MeOH}$ extracts of $M$. pudica leaves against $M$. tuberculosis using disc diffusion and agar well diffusion methods. Extract exhibited a zone of inhibition against $M$. tuberculosis (disc diffusion $=7.00 \mathrm{~mm}$; agar well diffusion method $=4.33 \mathrm{~mm}$ ). Kakad et al. [141] determined the antibacterial activity of $\mathrm{MeOH}$ extract of $M$. pudica leaves against two Gram-positive (B. subtilis, S. aureus) and three Gram-negative (P. aeroginosa, P. vulgaris, and $S$. typhi) bacterium using the agar well diffusion method. Significant results were obtained and data were compared with the standard antibiotics penicillium (100 $\mu \mathrm{g} / \mathrm{disc})$ and gentamicin (10 $\mu \mathrm{g} /$ disc). Muhammad et al. [82] measured the antifungal activity of extracts (EtOH and Aq.) of M. pudica leaves against T. verrucosum, M. ferrugineum, T. shoenleinii, T. rubrum, M. canis, T. concentricum, T. soudanense, and M. gyseum at four different 
concentrations (150, 200, 250, and $300 \mathrm{mg})$. T. verrucosum, M. ferrugineum, T. shoenleinii, $M$. canis, T. soudanense, and M. gyseum were sensitive to EtOH extract.

Thakur et al. [142] determined the antimicrobial activity of hydroalcoholic extract of M. pudica leaves against E. coli, S. aureus, P. aeruginosa, and B. cereus using the disc diffusion method. The extract showed significant results at 25,50 , and $100 \mathrm{~mL} /$ disk concentrations. Le Thoa et al. [143] measured the antibacterial activity of Aq. and EtOH extracts of $M$. pudica leaves and stems using the agar well diffusion method. The $\mathrm{EtOH}$ extract showed significant zones of inhibition against different strains $(E$. coli $=11 \mathrm{~mm}$, S. aureus $=19 \mathrm{~mm}, B$. cereus $=17 \mathrm{~mm}, S$. typhi $=16 \mathrm{~mm}$ ), while the Aq. extract significantly inhibited S. aureus $=14 \mathrm{~mm}$ and $B$. subtilis $=15 \mathrm{~mm}$. The results were compared with standard chloramphenicol. Dhanya and Thangavel [144] measured the antimicrobial potential of $\mathrm{MeOH}$ extracts of $M$. pudica leaves, flowers, and roots against $S$. aureus, E. coli, and Pseudomonas sp. using the disc diffusion method. Zones of inhibition shown by the extract of the leaves in decreasing order were: S. aureus $(23.5 \mathrm{~mm})>$ E. coli $(20 \mathrm{~mm})$ $>$ Pseudomonas sps $(14 \mathrm{~mm})$. The flower extract showed activity against Pseudomonas sp. $22.5>$ E. coli $14>$ S. aureus $12 \mathrm{~mm}$. The root extract also showed significant activity against $R$. solani $(29 \mathrm{~mm})>A$. niger $(21 \mathrm{~mm})>$ M. phaseolina $(17.7 \mathrm{~mm})$. Ahuchaogu et al. [145] screened the antimicrobial potential of the $\mathrm{EtOH}$ extract of $M$. pudica whole plant against $S$. aureus, P. aeroginosa, E. coli, M. smegmatis, and E. faecalis at various concentrations $(25,50$, and $100 \mathrm{mg} /$ disc). At $100 \mathrm{mg} /$ disc, maximum antimicrobial activity was observed and a comparison was made with standard chloramphenicol. Chukwu et al. [146] determined the antimicrobial activity of absolute EtOH extract of $M$. pudica whole plant against the tested microorganisms (A. flavus and T. rubrum) at three different concentrations $(25,50$, and $100 \mathrm{mg} / \mathrm{mL}$ ). At $100 \mathrm{mg} / \mathrm{mL}$, the extract was very found to be highly active against $A$. flavus and T. rubrum (100 mg/mL $=22$ and $17 \mathrm{~mm}$, respectively). Rosado-Vallado et al. [23] screened the antimicrobial potential of $\mathrm{MeOH}$ and Aq. extracts of $M$. Pigra leaves against various microorganisms (S. aureus, E. coli, P. aeruginosa, B. subtilis, A. niger, and C. albicans) using the agar-well diffusion method. Itraconazole $(0.025 \mathrm{mg} / \mu \mathrm{L})$, nystatin $(50 \mathrm{IU} / \mathrm{mL})$, and amikacin $(0.03 \mathrm{mg} / \mathrm{mL})$ were used as positive controls for bacteria, yeast, and fungi. Both plant extracts were found to be active against $P$. aeruginosa, C. albicans, S. aureus, and B. subtilis and inactive against E. coli and A. niger. De Morais et al. [147] determined the antifungal activity of $60 \% \mathrm{MeOH}, \mathrm{DCM}$, and EtOAc fractions of $M$. pigra leaves by measuring the minimum inhibitory concentration (MIC) values against dermatophyte strains (T. mentagrophytes, E. floccosum, M. gypseum, and T. rubrum). The $\mathrm{MeOH}$ extract showed the lowest MIC values against all dermatophytes (1.9 to $1000 \mathrm{mg} / \mathrm{mL}$ ). DCM, EtOAc, and Hex fractions showed significant results. Jain et al. [60] determined the in vitro antimicrobial activity of EtOH extracts and fractions (Aq., CF, PE, and BZ) of M. hamata whole plant against E. coli, K. pneumonia, P. aeruginosa, S. aureus, P. vulgaris, A. flavus, $F$. moniliforme, and R. bataticola by disc diffusion method. At $500 \mathrm{mg} /$ disc, the EtOH extract and Aq. fraction inhibited the growth of all bacteria and fungi, although the activity of the Aq. fraction was less than that of the EtOH extracts. PE was found to be active against fungi. Ali et al. [148] measured the antimicrobial activity of crude $\mathrm{Hex}$ and $\mathrm{MeOH}$ extracts of $M$. hamata whole plant. The Hex extract showed potent \% growth inhibition against B. cereus $(29.75 \%)$, C. diphteriae $(1.40 \%)$, P. aeroginosa $(74.11 \%)$, A. niger $(30.50 \%), M$. canis $(36.21 \%)$, and M. phaseolina $(89.95 \%)$, while the $\mathrm{MeOH}$ extract also showed potent activity against B. cereus (59.49\%), C, diphteriae (30.16\%), E. coli (6.31\%), S. sonii $(73.13 \%)$, . aeroginosa $(32.74 \%)$, S. typhi (16.84\%), S. pyogenes (57.18\%), T. longifuses $(67.26 \%)$, P. boydii $(95.10 \%)$, M. canis (45.31\%), T. simii $(75.00 \%)$, F. solani (54.75\%), and T. schoenleinii (84.18\%). Standard ampicillin and rifampicin showed $99-100 \%$ growth inhibition. Mahmood et al. [5] investigated the antimicrobial potential of crude $\mathrm{MeOH}$ extract of $M$. pigra leaves against E. coli, B. subtilis, P. aeruginosa, K. pneumonia, A. niger, and A. flavus by agar tube diffusion and agar tube dilution methods for bacteria and fungi, respectively. The plant showed significant inhibition of E. coli, P. aeruginosa, and K. pneumonia bacteria and minor activity against $B$. subtilis, while no activity was observed against fungi. Silva and his colleagues 
reported the antimicrobial potential of the EtOH extracts of $M$. verrucosa and M. pteridifolia bark via the minimum inhibitory concentration (MIC) values against $S$. aureus, E. coli, $C$. albicans, T. interdigitale. M. verrucose, and M. pteridifolia, showing lower MIC values of $250 \mu \mathrm{g} / \mathrm{mL}$ and $500 \mu \mathrm{g} / \mathrm{mL}$, respectively, against S. aureus [137] (Table 2).

\subsection{Antioxidant Activity}

Magalhães et al. [149] determined the antioxidant potential of the EtOH extract and various fractions ( $n$-hex, DCM, EtOAc, and $\mathrm{HyOH}$ ) of $M$. tenuiflora leaves, twigs, barks, and roots using DPPH and ABTS radical scavenging activities. The EtOH extract showed the lowest $\mathrm{EC}_{50}$ values against $\mathrm{DPPH}\left(\mathrm{EC}_{50}=132.99 \mu \mathrm{g} / \mathrm{mL}\right)$ and $\mathrm{ABTS}\left(\mathrm{EC}_{50}=189.14 \mu \mathrm{g} / \mathrm{mL}\right)$ radicals. The EtOAc fraction proved to have potent antioxidant activity against $\mathrm{DPPH}$ $\left(\mathrm{EC}_{50}=141.20 \mu \mathrm{g} / \mathrm{mL}\right)$ and ABTS $\left(\mathrm{EC}_{50}=273.00\right)$ radicals. Silva and colleagues determined the antioxidant potential of the EtOH extract of $M$. tenuiflora bark using DPPH and ABTS scavenging assays. The plant showed potent scavenging effects against DPPH and ABTS radicals, with $\mathrm{IC}_{50}$ values of 17.21 and $3.57 \mu \mathrm{g} / \mathrm{mL}$, respectively. The results were compared with Trolox [137]. Almalki [30] reported the antioxidant potential of $M$. pudica leaves (Hex extract) by using the DPPH, hydroxyl, nitric oxide, and superoxide radical scavenging assays. The extracts showed significant scavenging effects at concentrations between 5 and $25 \mathrm{mM}$ against DPPH $\left(\mathrm{IC}_{50}=20.83 \mathrm{mM}\right)$, hydroxyl $\left(\mathrm{IC}_{50}=19.37 \mathrm{mM}\right)$, nitric oxide $\left(\mathrm{IC}_{50}=21.62 \mathrm{mM}\right)$, and superoxide $\left(\mathrm{IC}_{50}=22.19 \mathrm{mM}\right)$ radicals, while the standards butylated hydroxytoluene and vitamin $C$ showed excellent antioxidant potential as compared to the plant extract. Lee et al. [150] determined the antioxidant potential of hydrophilic extracts (ACE-Aq.-AA (8.0 mL, 70:29.5:0.5) of M. pudica leaves using oxygen radical absorbance capacity (ORAC) and DPPH free radical scavenging assays. The extract showed significant results in the ORAC (1187.9 $=\mu \mathrm{mol} \mathrm{TE}{ }^{-1}$ FW $)$ and DPPH $\left(E_{50}=243.2 \mathrm{mg} \mathrm{kg}^{-1}\right)$ assays, while the total vitamin $\mathrm{C}$ content was found to be $259 \mu \mathrm{g} / \mathrm{g}$ FW. Durgadevi and Karthika [62] measured the antioxidant activity of the Aq. extract of $M$. pudica leaves using the $\mathrm{H}_{2} \mathrm{O}_{2}$ scavenging assay. Different concentrations $(0.2,0.4,0.6,0.8$, and $1.0 \%$ ) of the extract showed $(34.6,39.4,49.6,54.6$, and 58.3\%) significant antioxidant activity. The results were compared with standard thiobarbituric acid. Das et al. [151] determined the antioxidant potential of the $\mathrm{MeOH}$ extract of $M$. pudica leaves via DPPH free radical scavenging assay. The $\mathrm{IC}_{50}$ values of extracts and ascorbic acid were found to be 126.71 and $20.13 \mu \mathrm{g} / \mathrm{mL}$, respectively, while the total antioxidant capacity of the extract was $\mathrm{IC}_{50}=5.038 \mathrm{mg} / \mathrm{g}$ AAE. Chimsook [152] screened the antioxidant activity levels of PE, EtOAc, absolute EtOH, and Aq. extract of $M$. pudica leaves using ABTS assay. The extracts showed significant results $\left(\mathrm{EC}_{50} ; \mathrm{PE}=40.6, \mathrm{EtOAc}=27.2\right.$, absolute $\mathrm{EtOH}=73.8, \mathrm{Aq} .=13.2 \mu \mathrm{g} / \mathrm{mL}$ ), while standard ascorbic acid showed $\mathrm{EC}_{50}=11.5 \mu \mathrm{g} / \mathrm{mL}$. Parmar et al. [31] screened the antioxidant activity of the HyEtOH extract and L-mimosine compound of M. pudica whole plant (stems, leaves, roots, and flower buds) using the DPPH free radical scavenging assay. L-mimosine treatment exhibited lower antioxidant activity than the extract.

Jose et al. [153] screened the in vitro antioxidant activity of isolated flavonoids from EtOAc-soluble fractions of M. pudica whole plant by using DPPH and hydroxyl radical scavenging assays. Significant DPPH radical scavenging was observed $\left(\mathrm{IC}_{50}=56.32 \mu \mathrm{g} / \mathrm{mL}\right)$ as compared to the reference standard (ascorbic acid $\mathrm{IC}_{50}=21.11 \mu \mathrm{g} / \mathrm{mL}$ ). The isolated flavonoid also showed significant \% inhibition at concentrations of $20-140 \mu \mathrm{g} / \mathrm{mL}$, while ascorbic acid showed significant \% inhibition. Ittiyavirah and Pullochal [154] measured the antioxidant activity of the $\mathrm{EtOH}$ extract of $\mathrm{M}$. pudica whole plant by using $\mathrm{H}_{2} \mathrm{O}_{2}$ and superoxide scavenging assays. The plant showed significant $\mathrm{H}_{2} \mathrm{O}_{2}$ scavenging $\left(\mathrm{IC}_{50}=19 \mathrm{mg} / \mathrm{mL}\right)$, while standard ascorbic acid showed $\mathrm{IC}_{50}=5.2 \mathrm{mg} / \mathrm{mL}$. Significant superoxide scavenging was also observed $\left(\mathrm{IC}_{50}=80.4 \mathrm{mg} / \mathrm{mL}\right)$ and gallic acid was used as the standard $\left(\mathrm{IC}_{50}=50.10 \mathrm{mg} / \mathrm{mL}\right)$. Tunna et al. [46] determined the antioxidant potential of the $\mathrm{MeOH}$ extract and fractions ( $n$-hex, EtOAc, ACE, and MeOH) of M. pudica aerial parts using the DPPH free radical scavenging assay. The plant showed significant 
DPPH radical scavenging and the results were compared with standard ascorbic acid $\left(\mathrm{IC}_{50}=20.13 \mu \mathrm{g} / \mathrm{mL}\right)$. Silva et al. [32] measured the total phenol and antioxidant potential of the EtOH extract and EtOAc fraction of $M$. caesalpiniifolia leaves using the DPPH free radical scavenging assay. The results for the total phenol and antioxidant activity showed a concentration of $46.8 \mathrm{~g}$ gallic acid eq. $/ \mathrm{kg}$ with an antioxidant activity of $35.3 \mathrm{~g}$ vitamin C eq. $/ \mathrm{kg}$ in the $\mathrm{EtOH}$ extract and $71.50 \mathrm{~g}$ gallic acid eq. $/ \mathrm{kg}$ with an antioxidant activity of $65.3 \mathrm{~g}$ vitamin C eq. $/ \mathrm{kg}$ in the EtOAc fraction. Rakotomalala et al. [155] determined the antioxidant capacity of the $\mathrm{HyMeOH}$ extract of $M$. pigra leaves using DPPH free radical scavenging activity and oxygen radical absorbance capacity (ORAC) assays. The extract showed significant antioxidant potential $(\mathrm{DPPH}=1268$ and $\mathrm{ORAC}=2287 \mu \mathrm{mol} \mathrm{TE} / \mathrm{g})$ as compared to the standard drugs chlorogenic acid $(\mathrm{DPPH}=2927$ and ORAC $=11.939$ $\mu \mathrm{mol} \mathrm{TE} / \mu \mathrm{mol})$ and quercetin $(\mathrm{DPPH}=6724 \mu \mathrm{mol} \mathrm{TE} / \mu \mathrm{mol}$ and $\mathrm{ORAC}=22,218 \mu \mathrm{mol}$ $\mathrm{TE} / \mu \mathrm{mol})$.

Saxena et al. [29] determined the in vitro antioxidant properties of the EtOH extract and sub-fractions (EtOAc and diethyl-ether) of $M$. hamata whole plant using DPPH free radical and $\mathrm{H}_{2} \mathrm{O}_{2}$ scavenging assays. The EtOH extract (76.01\%) and EtOAc and diethylether sub-fractions (96.63\%) showed \% inhibition of DPPH scavenging at $100 \mu \mathrm{g} / \mathrm{mL}$ concentration, while the standard drug ascorbic acid showed $93.52 \%$ inhibition. The $\mathrm{EtOH}$ extract (67.81\%) and EtOAc and diethyl-ether sub-fractions (88.43\%) showed significant $\mathrm{H}_{2} \mathrm{O}_{2}$ scavenging activity at $100 \mu \mathrm{g} / \mathrm{mL}$. The results were compared to the standard drug ascorbic acid (86.87\%). Chandarana et al. [33] determined the antioxidant potential of cycloHex, EtOAc, and $\mathrm{MeOH}$ extracts of $M$. hamata stem using DPPH free radical and ABTS scavenging assays. The $\mathrm{MeOH}\left(\mathrm{IC}_{50}=0.70 \mu \mathrm{g} / \mathrm{mL}\right)$, EtOAc $\left(\mathrm{IC}_{50}=0.85 \mu \mathrm{g} / \mathrm{mL}\right)$, cycloHex $\left(\mathrm{IC}_{50}=0.95 \mu \mathrm{g} / \mathrm{mL}\right)$ extracts showed significant DPPH free radical scavenging as compared to standard ascorbic acid $\left(\mathrm{IC}_{50}=0.60 \mu \mathrm{g} / \mathrm{mL}\right.$ ). In the ABTS scavenging assay, the $\mathrm{MeOH}$ extract showed the highest scavenging activity $\left(\mathrm{IC}_{50}=0.35 \mu \mathrm{g} / \mathrm{mL}\right)$, followed by EtOAc $\left(\mathrm{IC}_{50}=0.37 \mu \mathrm{g} / \mathrm{mL}\right)$ and cycloHex extracts $\left(\mathrm{IC}_{50}=0.40 \mu \mathrm{g} / \mathrm{mL}\right)$, while the standard drug ascorbic acid showed the highest activity $\left(\mathrm{IC}_{50}=0.32 \mu \mathrm{g} / \mathrm{mL}\right)$. Singh et al. [156] screened the antioxidant activity levels of $\mathrm{PE}, \mathrm{CF}, \mathrm{BuOH}$, and Aq. extracts of $M$. hamata (stem, leaves, roots, and seeds) using a DPPH free radical scavenging assay. Different extracts of $M$. hamata showed significant DPPH scavenging levels, as represented by $\mathrm{IC}_{50}$ values (leaves, $51.30-56.50 \mu \mathrm{g} / \mathrm{mL}$; stem, $51.80-61.80 \mu \mathrm{g} / \mathrm{mL}$; roots, $26.33-73.16 \mu \mathrm{g} / \mathrm{mL}$; seeds, $16.60-51.16 \mu \mathrm{g} / \mathrm{mL}$ ). Jiménez et al. [157] determined the antioxidant activity of $M$. albida whole plant with the help of various assays (DPPH radical scavenging, ferric reducing antioxidant power (FRAP), Trolox equivalent antioxidant capacity (TEAC), oxygen radical absorption capacity (ORAC), LDL-C oxidation inhibition). The plant showed significant antioxidant potential in various assays $(\mathrm{DPPH}=1540 \mu \mathrm{mol} \mathrm{TE} / \mathrm{g}$, FRAP $=1070 \mu \mathrm{mol} \mathrm{TE} / \mathrm{g}$, TEAC $=1770 \mu \mathrm{mol} \mathrm{TE} / \mathrm{g}, \mathrm{ORAC}=1870 \mu \mathrm{mol} \mathrm{TE} / \mathrm{g})$. The LDL-C oxidation inhibition assay showed greater than $50 \%$ inhibition at $100 \mu \mathrm{g} / \mathrm{mL}$ concentration of the extract. Manosroi et al. [127] investigated the antioxidant efficacy of the Aq. extract of M. Invisia leaves using a DPPH free radical scavenging assay. M. invisa showed significant free radical scavenging activity $\left(\mathrm{IC}_{50}=0.119 \mathrm{mg} / \mathrm{mL}\right.$ ), which was 0.49 -fold that of the positive control (ascorbic acid). Silva and colleagues determined the antioxidant potential of the $\mathrm{EtOH}$ extract of M. verrucosa and M. pteridifolia bark using DPPH and ABTS scavenging assays. The plant showed potent scavenging effects against DPPH and ABTS radicals, while Trolox was used as the standard antioxidant [137]. (Table 2).

\subsection{Anticancer Activity}

Valencia-Gómez et al. [129] screened the cytotoxicity of biocomposite films made from $M$. tenuiflora cortex and chitosan against (3T3) fibroblasts using MTT assays. Chitosan- $M$. tenuiflora films at different concentrations (100:0, 90:10, 80:20, and 70:30) were used. The cells decreased significantly in the 90:10 and 80:20 chitosan- $M$. Tenuiflora films. Cytotoxicity increased for high-concentration M. tenuiflora (70:30) and chitosan films (100:0). Silva and colleagues reported on the cytotoxicity of $M$. tenuiflora bark EtOH extract against four 
human cancer cell lines (HL-60, HCT-116, PC-3, and SF-295). No activity was observed against any tested cancer lines up to $50 \mu \mathrm{g} / \mathrm{mL}$ concentration [137]. Chimsook [152] reported on the in vitro anticancer activity levels of different extracts (PE, EtOAc, absolute $\mathrm{EtOH}$, and Aq.) of $M$. pudica leaves against three human cancer cell lines derived from lung (CHAGO), liver $\left(\mathrm{HepG}_{2}\right.$ ), and colon (SW620) samples using an MTT assay. The EtOAc extract was found to be potent $\left(\mathrm{IC}_{50}=29.74 \mu \mathrm{M}\right)$ against CHAGO cells, while the EtOAc and absolute EtOH extracts inhibited the SW620 cells, with $\mathrm{IC}_{50}$ values of 11.12 and $5.85 \mu \mathrm{M}$, respectively. $\mathrm{HepG}_{2}$ cell growth was inhibited by EtOAc $\left(\mathrm{IC}_{50}=29.81 \mu \mathrm{M}\right)$ and absolute EtOH $\left(\mathrm{IC}_{50}=10.11 \mu \mathrm{M}\right)$ extracts. The results were compared with standard amonafide, which showed significant cytotoxicity in CHAGO $\left(\mathrm{IC}_{50}=1.05 \mu \mathrm{M}\right)$, SW620 $\left(\mathrm{IC}_{50}=0.32 \mu \mathrm{M}\right)$, and $\mathrm{HepG}_{2}\left(\mathrm{IC}_{50}=1.71 \mu \mathrm{M}\right)$ cell lines. Parmar et al. [31] screened the anticancer activity of the Hy-EtOH extracts of M. pudica whole-plant samples (stems, leaves, roots, and flower buds) and L-mimosine using MTT assay against the Daudi cell line. At concentrations of $12.5-400 \mu \mathrm{g} / \mathrm{mL}$, the $\mathrm{IC}_{50}$ values were found to be $201.65 \mu \mathrm{g} / \mathrm{mL}$ and $86.61 \mu \mathrm{M}$ at $72 \mathrm{~h}$ for M. pudica extract and L-mimosine, respectively. Rakotomalala et al. [155] screened the cell viability and proliferation of smooth muscle in male Wistar rats from $\mathrm{HyMeOH}$ extract of $M$. pigra leaves using an MTT assay. No significant effects were observed by the extract (at a concentration of 0.01 to $1 \mathrm{mg} / \mathrm{mL}$ ) on smooth muscle cell proliferation or cell viability. Saeed et al. [98] measured the antitumor activity of M. pigra fruit extract via oral administration. This plant has been used by Sudanese healers against tumors.

Silva et al. [158] screened the anticancer activity of an EtOH extract of $M$. caesalpiniifolia leaves against the human breast cancer cell line MCF-7 by using the SRB assay. The extract at $5.0 \mu \mathrm{g} / \mathrm{mL}$ for $24 \mathrm{~h}$ the reduced protein $(50 \%)$ and cyclophosphamide $(30 \%)$ contents, while treatment for $48 \mathrm{~h}$ reduced protein to $80 \%$ and cyclophosphamide to $55 \%$, with the extract showing maximum effect at $320.0 \mu \mathrm{g} / \mathrm{mL}$, which demonstrates that the extract exhibited cytotoxic effect against MCF-7 cells. Monção et al. [49] reported on the anticancer activity of an EtOH extract and fractions ( $n$-Hex, DCM, EtOAc, and Aq.) of M. caesalpiniifolia stem bark using an MTT assay against HCT-116, OVCAR-8, and SF-295 cancer cells. The percentage inhibition of cell proliferation for the EtOH extract and $n$-Hex fraction varied from $69.5 \%$ to $84.8 \%$ and $65.5 \%$ to $86.4 \%$, respectively, while the DCM fraction and betulinic acid showed inhibition levels above $86.5 \%$ and doxorubicin (at $0.3 \mu \mathrm{g} / \mathrm{mL}$ ) $>83.0 \%$. EtOAc and Aq. fractions showed minimal inhibition of cell proliferation. Nandipati et al. [122] determined the cytotoxicity of the $\mathrm{MeOH}$ extract of M. rubicaulis stem against an Ehrlich ascites carcinoma (EAC) tumor model in Swiss albino mice against cancer cell lines (such as EAC, MCF-7, and MDA-MB 435S) using an XTT assay. The extract at a concentration of $200 \mu \mathrm{g} / \mathrm{mL}$ reduced the cytotoxicity of the cell lines (EAC 78.3\%, MCF-7 $=79 \%$, MDA-MB $435 \mathrm{~S}=83 \%$ ), while standard amoxifen exhibited maximal cytotoxic effects on EAC $(99.3 \%)$, MCF-7 (95.5\%), and MDA-MB 435S (99.4\%) cell lines. They also measured the antitumor activity of the M. rubicaulis (MeOH extract) against an Ehrlich ascites carcinoma (EAC) tumor model in Swiss albino mice who received 100, 200, and $400 \mathrm{mg} / \mathrm{kg}$ bw by measuring hematological parameters IRBC, WBC, hemoglobin, and PCV). At a dose of $400 \mathrm{mg} / \mathrm{kg}$, the level of WBC increased while decreases in RBC and PCV were observed as compared to the standard drug 5-FU $20 \mathrm{mg} / \mathrm{kg}$ ip. Silva and colleagues reported on the cytotoxicity of $M$. verrucosa and M. pteridifolia bark EtOH extracts against four human cancer cell lines (HL-60, HCT-116, PC-3, and SF-295). No activity was observed against any of the tested cancer lines up to $50 \mu \mathrm{g} / \mathrm{mL}$ concentration [137] (Table 2).

\subsection{Antidiabetic Activity}

Tunna et al. [46] investigated the antidiabetic potential of $\mathrm{MeOH}$ extract and fractions (Hex, EtOAc, ACE, and $\mathrm{MeOH}$ ) of M. pudica aerial parts using $\alpha$-amylase and $\alpha$-glucosidase inhibitory assays. The percentages of inhibition in $\alpha$-amylase and $\alpha$-glucosidase inhibitory assays shown by the $\mathrm{MeOH}$ extract were found to be $33.86 \%$ and $95.65 \%$, while the fractions also showed potent inhibitory effects ( $\mathrm{Hex}=10.583 \%$ and $0.884 \%, \mathrm{EtOAc}=18.65 \%$ and $51.87 \%, \mathrm{ACE}=15.64 \%$ and $16.04 \%, \mathrm{MeOH}=27.21 \%$ and $4.83 \%)$. Standard acarbose 
showed 28.24 and $36.93 \%$ inhibition effects, respectively. This study has proven the strong antidiabetic activity of tested extracts, which could lead to future studies with respect to obtaining new antidiabetic agents from M. pudica. Piyapong and Ampa [159] screened the hypoglycemic activity of $80 \% \mathrm{EtOH}$ extract of M. pudica whole plant in diabetic male albino Wistar rats using an oral glucose tolerance test (OGTT) and fasting blood glucose test (FBG). In the OGTT, after $30 \mathrm{~min}$ of extract administration, the extract $(500 \mathrm{mg} / \mathrm{kg} \mathrm{bw}$ ) did not decrease blood glucose $(572.83 \mathrm{mg} / \mathrm{dL})$ in diabetic rats as compared to standard glybenclamide $(0.5 \mathrm{mg} / \mathrm{kg}$ bw $=473.50 \mathrm{mg} / \mathrm{dL})$. In the FBG test, after 1 week of administration, the extract ( $500 \mathrm{mg} / \mathrm{kg} \mathrm{bw}$ ) decreased the blood glucose level to $421.00 \mathrm{mg} / \mathrm{dL}$, while standard glybenclamide $(0.5 \mathrm{mg} / \mathrm{kg} \mathrm{bw})$ also significantly decreased blood glucose level (572.67 mg/dL). Konsue et al. [160] determined the antidiabetic activity of Aq. and $\mathrm{HyEtOH}$ extracts of M. pudica whole plant in diabetic male albino Wistar rats using fasting blood glucose levels (FBG) and hematological values, including red blood cell (RBC), white blood cell (WBC), hemoglobin ( $\mathrm{Hb})$, platelet, hematocrit (Hct), mean corpuscular volume $(\mathrm{MCV})$, mean corpuscular hemoglobin $(\mathrm{MCH})$, and mean corpuscular hemoglobin concentration (MCHC) counts, as well as differential white blood cell, lymphocyte, monocyte, neutrophil, and eosinophil counts, at three different concentration $(125,250$, and $500 \mathrm{mg} / \mathrm{kg}$ bw). At $250 \mathrm{mg} / \mathrm{kg}$ bw concentration, Aq. ( $517.00 \mathrm{mg} / \mathrm{dL})$ and $\mathrm{HyEtOH}(484.00 \mathrm{mg} / \mathrm{dL})$ extracts significantly decreased fasting blood glucose levels. The results were compared with standard glibenclamide. No effect was observed on RBC, Hb, Hct, platelet, $\mathrm{MCH}$, $\mathrm{MCHC}$, lymphocytes, monocytes neutrophils, or eosinophils, while in diabetic rats the WBC and MCV were decreased by the extract. From this study, it was concluded that use of M. pudica Aq. extract could be a potential method of diabetes prevention. Lee et al. [150] determined the enzymatic activity of hydrophilic extracts (ACE-Aq.-AA (8.0 $\mathrm{mL}, 70: 29.5: 0.5)$ ) of $M$. pudica leaves using $\alpha$-amylase and $\alpha$-glucosidase inhibitory assays. M. pudica showed significant inhibition of $\alpha$-amylase $(189.3 \mu \mathrm{mol} \mathrm{AE} / \mathrm{g})$ and $\alpha$-glucosidase $(6.6 \mu \mathrm{mol} \mathrm{AE} / \mathrm{g})$. Acarbose was used as the positive control and statistically significant results were obtained.

Manosroi et al. [127] determined the hypoglycemic activity of $M$. invisa leaves (Aq. extract) in normoglycemic and diabetic male ICR mice. Alloxan monohydrate at $75 \mathrm{mg} / \mathrm{kg}$ $b w$ was injected into the mouse tail vein. After the 3rd day, diabetes was confirmed and various doses $(100,200$, and $400 \mathrm{mg} / \mathrm{kg} \mathrm{bw})$ of the plant extract were orally given to the 18-h-fasted normal and diabetic mice. Insulin and glibenclamide were used as standards and hypoglycemic effect was measured by decreased fasting blood glucose (FBG). M. invisa significantly reduced the fasting blood glucose (FBG) by $14.84 \%$ in normoglycemic mice at $1 \mathrm{~h}$ with the $200 \mathrm{mg} / \mathrm{kg}$ bw dose, which was 0.24- and 0.47-fold the values for insulin and glibenclamide, respectively. M. invisa also showed significant FBG reductions of $16.60 \%$ and $9.28 \%$ at doses of 100 and $400 \mathrm{mg} / \mathrm{kg}$ bw at $240 \mathrm{~min}$, which were 0.27 - and 0.52 -fold the values for insulin and 0.15 - and 0.29 -fold the values for glibenclamide, respectively. In diabetic mice, $M$. invisa only showed a significant reduction in fasting blood glucose (FBG) of $25.01 \%$, at $180 \mathrm{~min}$ with the lower dose of $100 \mathrm{mg} / \mathrm{kg}$ bw, which was 0.35 -fold that of insulin and 0.55-fold that of glibenclamide, respectively. Ahmed et al. [97] determined the glucose tolerance properties of the $\mathrm{MeOH}$ extract of $M$. pigra stem in Swiss albino male mice using the glucose oxidase method. Mice orally received different concentrations of extract (50, 100, 200 and $400 \mathrm{mg} / \mathrm{kg} / \mathrm{bw})$ and standard drug glibenclamide $(10 \mathrm{mg} / \mathrm{kg} / \mathrm{bw})$. After $1 \mathrm{~h}$, all mice orally received $2 \mathrm{~g}$ glucose $/ \mathrm{kg}$ bw. All doses of the extract decreased the concentration of glucose almost $37.84,39.83,42.39$, and $50.50 \%$, respectively, while glibenclamide reduced the concentration of glucose almost $56.33 \%$. Ao et al. [161] screened the antihyperglycemic activity of the EtOH extract of $M$. pigra roots in albino rats by checking fasting blood glucose (FBG) levels. Diabetes was induced through intraperitoneal injection $(160 \mathrm{mg} / \mathrm{kg})$ of alloxan monohydrate. Diabetic albino rats orally received EtOH extract (250 and $500 \mathrm{mg} / \mathrm{kg}$ ) and glibenclamide $(10 \mathrm{mg} / \mathrm{kg}$ ). In an acute study, administration of the extract at $250 \mathrm{mg} / \mathrm{kg}$ concentration showed a significant blood glucose reduction $(360.00 \mathrm{mg} / \mathrm{dL})$, while at the $500 \mathrm{mg} / \mathrm{kg}$ dose no significant results $(391.80 \mathrm{mg} / \mathrm{dL})$ were 
obtained as compared to diabetic untreated mice; however, the extract showed a significant hypoglycemic effect, while the glibenclamide showed no significant reduction in blood glucose. During prolonged treatment, a fluctuation was observed in the blood glucose levels of the diabetic treated albino rats. The extract $(250$ and $500 \mathrm{mg} / \mathrm{kg}$ ) showed a reduction in blood glucose levels (Table 2).

\subsection{Wound Healing}

Choi et al. [162] measured the wound-healing effects of a herbal mixture of M. tenuiflora leaves (20\%) and A. vulgaris (20\%) on human keratinocyte (HaCaT), umbilical vein endothelial cells (HUVECs), and mouse fibroblast (3T3-L1) using a scratch test. Fusidic acid was used as the standard. According to the histological study, synthesis of collagen, reepithelialization, and re-generation of appendages of skin and hair follicles were promoted by the herbal mixture. Immunohistochemical studies showed that blood vessel stabilization, improvement of angiogenesis, and accelerated granulation tissue formation were also achieved through use of the herbal mixture. The herbal mixture can also promote the migration of keratinocytes, endothelial cells, and fibroblasts and the proliferation of macrophages and lymphatic vessels; therefore, the herbal mixture can be used therapeutically for the treatment of cutaneous wounds. Zippel et al. [108] screened the wound-healing efficiency of Aq. extracts and EtOH-precipitated compounds from M. tenuiflora bark by measuring the mitochondrial (MTT, WST-1), proliferation (BrdU incorporation), and necrosis (LDH) activities on human primary dermal fibroblasts and $\mathrm{HaCaT}$ keratinocytes. The Aq. extract (10 and $100 \mu \mathrm{g} / \mathrm{mL}$ ) caused loss of cell viability and proliferation in dermal fibroblasts, while the EtOH-precipitated compound EPC $(10 \mu \mathrm{g} / \mathrm{mL})$ significantly stimulated mitochondrial activity and proliferation of dermal fibroblasts and showed minor stimulation on human kerationocytes at $100 \mu \mathrm{g} / \mathrm{mL}$. Molina et al. [50] measured the wound-healing activity of $10 \%$ powder of $M$. tenuiflora bark in adult humans for external use. The results were found to be significant for inflammation and venous leg ulceration diseases. Arunakumar et al. [163] reported on the wound-healing activity of the $\mathrm{MeOH}$ extract of M. tenuiflora whole plant by using a chorioallantoic membrane (CAM) model in 9-day-old fertilized chick eggs. The extract increased the numbers of capillaries on the treated CAM surfaces, which might be beneficial for wound healing. Rivera-Arce et al. [24] determined the therapeutic effectiveness of the $M$. tenuiflora cortex extract in the treatment of venous leg ulceration disease. Patients received a hydrogel containing 5\% crude extract standardized in a tannin concentration (1.8\%). A randomized, double-blind, placebo-controlled clinical trial was conducted. Therapeutic effectiveness was achieved in all patients in the extract group after the 8 th treatment week, with ulcer size being reduced by $92 \%$ as compared to the control group (Table 2).

\subsection{Hypolipidemic Activity}

Piyapong and Ampa [159] screened the hypolipidemic effects of $80 \%$ EtOH extract of M. pudica whole plant in diabetic male albino Wistar rats using biochemical data, including total cholesterol (TC), triglyceride (TG), high-density lipoprotein (HDL), and low-density lipoprotein (LDL) levels. In diabetic rats, the levels of TC, TG, and LDL were significantly reduced by plant extract doses and glibenclamide, while plant extract at the dose of $500 \mathrm{mg} / \mathrm{kg}$ bw significantly increased HDL. These results indicate that $M$. pudica possesses a hypolipidemic effect in diabetic rats and may lead to decreased risk of cardiovascular disease and related complications. Purkayastha et al. [58] reported on the hypolipidemic effect of an $\mathrm{EtOH}$ extract of M. pudica leaves in Wistar albino rats with hepatic injury induced by $\mathrm{CCl}_{4}$ by measuring biochemical parameters such as triglyceride (TG), total cholesterol (TC), very low density lipoprotein (VLDL), low density lipoprotein (LDL), and high density lipoprotein (HDL) levels. The extract at the dose of $400 \mathrm{mg} / \mathrm{kg}$ showed significant decreases in biochemical parameters $(\mathrm{TG}=96.8 \mathrm{mg} / \mathrm{dL}, \mathrm{TC}=98.7 \mathrm{mg} / \mathrm{dL}$, $\mathrm{VLDL}=26.9 \mathrm{mg} / \mathrm{dL}, \mathrm{LDL}=37.4 \mathrm{mg} / \mathrm{dL}, \mathrm{HDL}=34.3 \mathrm{mg} / \mathrm{dL})($ Table 2$)$. 


\subsection{Anti-Inflammatory and Hepatoprotective Activity}

Da Silva-Leite et al. [164] determined the healing efficacy of an alcoholic extract prepared from polysaccharides extracted from $M$. tenuiflora barks (EP-Mt) using $\mathrm{MeOH} / \mathrm{NaOH}$ and $\mathrm{EtOH}$ precipitation. The activity was determined in Wistar rat models of acute inflammation (paw edema and peritonitis). The activity was measured with three different doses $\left(0.01,0.1\right.$, and $\left.1.0 \mathrm{mg} \mathrm{kg}^{-1}\right)$ of plant extract, with the maximum effect with the $1 \mathrm{mg} \mathrm{kg}^{-1}$ concentration as compared to saline. Durgadevi and Karthika [62] reported on the anti-inflammatory activity of an Aq. extract of $M$. pudica leaves by using bovine serum albumin and egg methods. Extracts at different concentrations $(0.2,0.6,0.6,0.8$, and $1.0 \%)$ showed significant anti-inflammatory activity (serum albumin: 51.5, 59.7, 55.7, 71.5, and $83.7 \%$, respectively; egg: $42.5,39.6,48.2,56.7,65.3$, and $76.7 \%$, respectively) when compared with diclofenac sodium. Onyije et al. [165] measured the anti-inflammatory activity of Aq. extract of M. pudica leaves on adult male Sprague-Dawley rats with cadmium $\left(\mathrm{CdCl}_{2}\right)$ induced inflammation of the testes. A sperm analysis was carried out, measuring motility, morphology, and sperm count. Significant activation of sperm motility was observed at different doses of the extract $(250 \mathrm{mg} / \mathrm{kg}=13.00 \% ; 500 \mathrm{mg} / \mathrm{kg}=9.00 \%)$ compared with the control group (Aq. $=15.00 \%)$. Both doses of the extract showed significant effects on sperm morphology. The sperm counts at different extracts doses $\left(250 \mathrm{mg} / \mathrm{kg}=4.18 \times 10^{6} / \mathrm{cc}\right.$; $\left.500 \mathrm{mg} / \mathrm{kg}=2.54 \times 10^{6} / \mathrm{cc}\right)$ were enhanced as compared to control group $\left(12.78 \times 10^{6} / \mathrm{cc}\right)$. This study confirmed that $M$. pudica has ethnomedical uses as a therapeutic intervention for infertility; however, when this plant is used as an aphrodisiac, there is also an added benefit of antioligospermia effects. Kumaresan et al. [57] reported on the hepatoprotective activity of a crude powder of M. pudica whole plant on male albino rats. Injection in parallel with $\mathrm{CCl}_{4}$ and paraffin were given to rats to induce jaundice. Various hepatic parameters such as acid phosphatase (ACP), total bilirubin, gamma glutamyl transferase $(\gamma-\mathrm{GT})$, alkaline phosphatase (ALP), and lipid peroxide (LPO) levels in tissue, serum, aspartate transaminase (AST), and alanine transaminase (ALT) samples were checked. All of these parameters played roles in liver impairment. A dose of $100 \mathrm{mg} / \mathrm{kg}$ of extract powder significantly reduced the levels of all parameters and protected the hepatic cells.

Silva et al. [166] reported on the protective action of $\mathrm{HyOH}$ extract and EtOAc fraction of $M$. caesalpiniifolia leaves in adult male Wistar rats suffering from colitis. The $\mathrm{HyOH}$ extract $(125$ and $250 \mathrm{mg} / \mathrm{kg}$ ) and EtOAc fraction $(25 \mathrm{mg} / \mathrm{kg})$ were able to decrease TNF- $\alpha$ immune expression in rats and were found to be effective at lower doses after inducing colitis. The extract showed lower tissue damage at both doses, while the EtOAc fraction was effective at the highest dose $(50 \mathrm{mg} / \mathrm{kg})$ only in terms of decreasing COX-2 immune expression. COX-2 and TNF- $\alpha$ played pivotal roles in chronic colitis caused by TNBS. Rakotomalala et al. [155] measured the in vitro anti-inflammatory ability of $\mathrm{HyMeOH}$ extract of $M$. pigra leaves in male Wistar rats to reduce TNF $\alpha$-induced bound vascular cell adhesion molecule 1 (VCAM-1) expression in endothelial cells. The extract at different concentrations $(0.01-1 \mathrm{mg} / \mathrm{mL})$ inhibited the induction of VCAM- 1 in response to TNF $\alpha$, with a maximal inhibitory effect of $90 \%$ at $1 \mathrm{mg} / \mathrm{mL}$, while the standard drug pyrrolidine dithiocarbamate $(200 \mathrm{mM})$ showed $98 \%$ inhibitory effect. In vivo chronic hypoxic PAH cardiac remodeling was also determined in male Wistar rats. Rats were orally treated with extract ( $400 \mathrm{mg} / \mathrm{kg} /$ day) in a hypobaric chamber for 21 days. The extract reduced hypoxic PAH in rats by decreasing pulmonary arterial pressure by $22.3 \%$ and pulmonary artery and cardiac remodeling by $20.0 \%$ and $23.9 \%$, respectively (Table 2 ).

\subsection{Antinociceptive Activity}

Patro et al. [167] determined the antinociceptive effects of M. pudica leaves (EtOAc extract) on adult Wistar albino rats using AA-induced writhing, hot plate, and tail flick models at three concentration $(100,200$ and $400 \mathrm{mg} / \mathrm{kg})$. In the hot plate and tail flick tests, after $30 \mathrm{~min}$ the extract and the standard diclofenac sodium significantly increased the analgesic activity. The extract doses of 100,200 , and $400 \mathrm{mg} / \mathrm{kg}$ decreased the writhing by $20.18,33.42$, and $43.46 \%$ respectively, while the standard diclofenac sodium showed 
$52.01 \%$ writhing inhibition against AA. Ahmed et al. [97] determined the antinociceptive activity of the $\mathrm{MeOH}$ extract of M. pigra stem in Swiss albino male mice via AA-induced writhing test. Mice orally received various extract doses of 50,100, 200, and $400 \mathrm{mg} / \mathrm{kg} / \mathrm{bw}$, decreasing writhing by $70.01,74.96,77.51$, and $85.01 \%$, respectively. Aspirin was used as the standard drug.

Rejón-Orantes et al. [106] screened the antinociceptive effects of an Aq. extract of M. albida roots in male ICR mice via AA-induced writhing and hot plate tests. In the AA-induced writhing test, the Aq. plant extract at different concentrations (12.5, 25, and $50 \mathrm{mg} / \mathrm{kg}$ ) and the reference analgesic drug (dypirone, 100 and $500 \mathrm{mg} / \mathrm{kg}$ ) were administered $60 \mathrm{~min}$ before the AA $(0.6 \%)$ administration. Counts of the writhing responses (abdominal wall contractions and rotation of pelvis followed by extension of hind limb) were carried out during the test $(20 \mathrm{~min})$. M. albida extract $(50 \mathrm{mg} / \mathrm{kg})$ and dypirone $(500 \mathrm{mg} / \mathrm{kg}$ ) prevented the abdominal writhing. This study model was also helpful in an investigation of the opioid system involvement in the antinociceptive effects of the $M$. albida extract. The extract and fentanyl decreased the writhing, although naloxone was only able to antagonize the effects of fentanyl, leaving the antinociceptive potential of the M. albida extract intact. Fentanyl seemed to be more potent than the extract. In the hot plate test, pain reaction (hind paw licking and jumping) was determined as the response latency. Before the test, the response latency was determined, after administration of either M. albida extract, fentanyl $(0.1 \mathrm{mg} / \mathrm{kg})$, or the vehicle $(\mathrm{NaCl})$. Fentanyl (30 and $60 \mathrm{~min})$ after treatment and extract $(12.5,25$, and $50 \mathrm{mg} / \mathrm{kg}$ ) at $60 \mathrm{~min}$ from its injection produced significant increases in pain latency (Table 2).

\subsection{Antiepileptic Activity}

Patro et al. [167] measured the antiepileptic effects of EtOAc extract of M. pudica leaves on Swiss albino mice using a maximal electroshock (MES)-induced seizure model, PTZ-induced seizure model, and INH-induced seizure model at different extract doses $(100,200$ and $400 \mathrm{mg} / \mathrm{kg} /$ day). In the maximum electric shock test, the extract at 100, 200 , and $400 \mathrm{mg} / \mathrm{kg}$ concentrations and the standard drug diazepam $(0.4 \mathrm{mg} / \mathrm{kg})$ caused delayed onset of convulsion by $1.87,2.69,3.21$, and $3.53 \mathrm{~s}$, respectively; as well as decreased duration of convulsion by $68.09,53.54,42.21$, and 38.89 s, respectively. In the PTZ-induced convulsion test, the extract at different concentrations of 100,200 , and $400 \mathrm{mg} / \mathrm{kg}$ and diazepam $(04 \mathrm{mg} / \mathrm{kg}$ ) caused delayed onset of convulsion $(5.38,6.08,6.98$, and $7.81 \mathrm{~min}$, respectively) and decreased duration of convulsion (14.76, 12.65, 11.13, and $9.39 \mathrm{~min}$, respectively). Regarding the INH-induced convulsions, the extract at different concentrations $(100,200$, and $400 \mathrm{mg} / \mathrm{kg}$ ) showed delayed convulsion latency times of 37.21, 45.49, and $58.62 \mathrm{~min}$, respectively; the results were compared with diazepam $(04 \mathrm{mg} / \mathrm{kg}=69.14 \mathrm{~min}$ delayed convulsion latency). Prathima et al. [35] measured the antiepileptic activity of the EtOH extract of M. pudica roots in adult Swiss albino mice. Maximal electroshock (MES) and pentylenetetrazole (PTZ)-induced seizures were performed. In the maximal electroshock-induced seizures (MES), the durations of tonic hind limb flexion (THLF), tonic hind limb extension (THLE), clonus, and stupor were noted. In the MES tests, the percentages of inhibition of convulsions in mice at different doses $(1000 \mathrm{mg} / \mathrm{kg}=42.41 \%$; $2000 \mathrm{mg} / \mathrm{kg}=52.35 \%$ ) were noted, while standard valproate showed $73.86 \%$ inhibition at $200 \mathrm{mg} / \mathrm{kg}$. In the pentylenetetrazole (PTZ)-induced seizures, the clonic convulsion onset times, durations of clonic convulsions, and postictal depression were observed for a period of $30 \mathrm{~min}$. The extract (1000 and $2000 \mathrm{mg} / \mathrm{kg}$ ) significantly decreased the number and duration of myoclonic jerks and clonic seizures and the duration of postictal depression (Table 2).

\subsection{Neuropharmacological Activities}

Arunakumar et al. [163] determined the anti-Alzheimer's potential of the $\mathrm{MeOH}$ extract of $M$. tenuiflora whole plant by using acetylcholinesterase inhibitory therapy (AChEIs). The results showed that $M$. tenuiflora is a rich source of compounds with potential anti- 
Alzheimer's activity. Ttiyavirah and Pullochal [154] measured the antistress activity of EtOH extract of $M$. pudica plant in albino Wistar rats by performing swimming endurance, radial arm maze, Morris Aq. maze, and retention phase tests. Adaptogenic activity was assessed by using oral doses of $500 \mathrm{mg} / \mathrm{kg}$ of extract and $2 \mathrm{mg} / \mathrm{kg}$ diazepam as the standard compound in the swimming endurance test. In the other three tests, the extract was found to effectively reduced stress as compared to standard D-galactose + piracetam. Significant improvements in memory were observed from the test paradigms for the Morris Aq. Maze and radial arm maze tests. The results from the study indicated that the EtOH extract of Mimosa pudica possessed significant antistress activity, along with a potential protective effect against a chronic Alzheimer's model. Mv et al. [168] measured the neuroprotective effects of M. pudica plant in a Parkinson's male C57BL/6J model at 100 and $300 \mathrm{mg} / \mathrm{kg}$ concentrations of extracts using a vertical grid test, horizontal grid test, and immunohistochemistry measurements. In the vertical grid test, the extract at different concentrations (100 and $300 \mathrm{mg} / \mathrm{kg}$ ) significantly increased the time taken to climb the grid. In the horizontal grid test, the extract decreased the hang time. The extract at 100 and $300 \mathrm{mg} / \mathrm{kg}$ doses decreased SYN- and increased DAT- and TH-positive cells. Patro et al. [167] measured the motor coordination activity of the EtOAc extract of M. pudica leaves in Swiss albino mice by performing locomotor activity, rotarod, and traction tests with three different extract concentrations $(100,200$, and $400 \mathrm{mg} / \mathrm{kg})$, while diazepam at $0.4 \mathrm{mg} / \mathrm{kg}$ concentration was used as the standard drug. Significant decreases in locomotor activity were observed. In the rotarod test, the fall time was significantly decreased, while in the traction test, the holding time was also significantly decreased. Kishore et al. [169] screened the CNS activities of Aq. extract of $M$. Pudica leaves in adult albino mice using locomotor activity, elevated plus maze, and rotarod tests at a dose of $200 \mathrm{mg} / \mathrm{kg}$. Percentage changes in locomotor activity were caused by the extract $(200 \mathrm{mg} / \mathrm{kg}=56.33 \%)$ and standard diazepam $(0.5 \mathrm{mg} / \mathrm{kg}=79.61 \%)$. In the elevated plus maze test, the extract $(200 \mathrm{~kg} / \mathrm{mg})$ and diazepam $(0.5 \mathrm{mg} / \mathrm{kg})$ increased the numbers of open arm entries by $67.92 \%$ and $78.59 \%$ while decreasing the times spent in closed arm positions by $7.32 \%$ and $8.64 \%$, respectively. In the rotarod test, the fall times were decreased significantly by the extract $(200 \mathrm{~kg} / \mathrm{mg}=152.1)$ and diazepam $(0.5 \mathrm{mg} / \mathrm{kg}=157.6)$. Mahadevan et al. [170] measured the in vitro neuroprotective effects of the Aq. extract of $M$. pudica whole plant against Parkinson's disease in SH-SY5Y human neuroblastoma cell lines using cell viability assay or MTT assay. The extract significantly upregulated TH and DAT and downregulated $\alpha$-synuclein expression in intoxicated cell lines. This disease occurs due to decreases in the dopaminergic neurons and tyrosine hydroxylase (TH) and increases in $\alpha$-synuclein protein levels.

Rejón-Orantes et al. [106] determined the exploratory and motor coordination activities of the Aq. extract of M. albida roots in male ICR mice. Various concentrations of the extract $(50,100$, and $200 \mathrm{mg} / \mathrm{kg}$ ) and the vehicle $\mathrm{NaCl}$ were given to mice before tests. For exploratory activity, an open field test was performed to evaluate the locomotor activity of mice. Locomotory activity (number of lines crossed by the animal) was recorded for $5 \mathrm{~min}$. The extract produced a significant decrease in the number of lines crossed by the animal as compared to the vehicle. For motor coordination activity, the rotarod test was performed. The number of falls from the rolling rod were recorded during the test $(3 \mathrm{~min})$. The number of falls from the rotarod were significantly increased after supplementation of Aq. extract from the roots of M. albida (100 and $200 \mathrm{mg} / \mathrm{kg}$ ) as compared to the vehicle. Rejón-Orantes et al. [106] reported on the anxiolytic activity of Aq. root extract of M. albida in male ICR mice by using elevated plus maze and hole board tests. In the elevated plus maze test, the extract at various concentrations $(3.2,12.5,25$, and $50 \mathrm{mg} / \mathrm{kg})$, dypirone $(1 \mathrm{mg} / \mathrm{kg})$, and the vehicle $(\mathrm{NaCl})$ were administrated to mice before testing. In the beginning, the mice were placed on the central plate facing the open arms. Then, the time spent (\%) on the open arms was calculated. Significant increases in exploration of open arms in the elevated plus maze test were caused by diazepam. Regarding the hole board apparatus, animals were placed in position and head dippings were counted. Head dippings were significantly enhanced 
by the diazepam. At all extract doses, M. albida showed no significant effect in either test (Table 2).

\subsection{Antiallergic and Antihyperurisemic Activity}

Lauriola and Corazza [113] determined the antiallergic activity of the glyceric acid extract of $M$. tenuiflora bark in a non-atopic 30-year-old woman who had developed acute eczema of the neck in the retroauricular and laterocervical areas. The plant extract was applied on her skin and patch tests were performed. $M$. tenuiflora potentially soothed the skin with its good antimicrobial properties. Sumiwi et al. [171] measured the antihyperurisemic activity of the EtOH (70\%) extract of $M$. pudica leaves in vitro and ex vivo in Swiss Webster mice (Mus musculus). The $\mathrm{IC}_{50}$ values for the inhibition of uric acid formation with M. pudica tablet, M. pudica extract, and allopurinol were $68.04 \mathrm{ppm}, 32.75 \mathrm{ppm}$, and $18.73 \mathrm{ppm}$, respectively. The ex vivo results showed that $M$. pudica tablet at $125 \mathrm{mg} / \mathrm{kg}$ of body weight and the extract reduced uric acid levels in hyperurisemic mice by $36 \%$ and $43 \%$, respectively. Mimosa pudica tablets at $125 \mathrm{mg} / \mathrm{kg}$ of bodyweight inhibited uric acid formation in hyperuricemic mice; therefore, this pharmaceutical dosage form could be proposed as an antihyperurisemic drug (Table 2).

\subsection{Larvicidal, Antiparasitic, and Molluscicidal Activity}

Oliveira et al. [172] measured the effects of $M$. tenuiflora leaves and stem on the larval establishment of $H$. contortus in sheep. The rate of larval establishment was not reduced by the leaves, but stem intake caused a $27.9 \%$ reduction; however, no significant reduction was observed. Bautista et al. [173] determined the antiparasitic activity of $\mathrm{Hex}, \mathrm{MeOH}$, and ACE extracts of $M$. tenuiflora leaves against $E$. histolytica and G. lamblia. The extracts showed significant inhibition (Hex: $\mathrm{IC}_{50}=65.9$ and $80.2 \mu \mathrm{g} / \mathrm{mL} ; \mathrm{ACE}: \mathrm{IC}_{50}=80.7$ and $116.8 \mu \mathrm{g} / \mathrm{mL}$; MeOH: 73.5 and $95.5 \mu \mathrm{g} / \mathrm{mL}$ ) against both E. histolytica and G. lamblia, but against G. lamblia. Santos et al. [174] determined the molluscicidal activity of the EtOH extract of $M$. tenuiflora stems against the snail species Biomphalaria glabrata. The extract showed excellent activity at the $100 \mu \mathrm{g} / \mathrm{mL}$ concentration $\left(\mathrm{LC}_{90}=62.05 \mathrm{mg} / \mathrm{L}\right.$; $\left.\mathrm{LC}_{50}=20.22 \mathrm{mg} / \mathrm{L} ; \mathrm{LC}_{10}=6.59 \mathrm{mg} / \mathrm{L}\right)$. Shamsuddini et al. [175] determined the effects of M. tenuiflora stem extracts against human leishmaniases by using an MTT assay and by counting parasites with various concentrations $(10,100,500$, and $1000 \mathrm{micg} / \mathrm{mL})$ of $M$. tenuiflora extracts. Different concentrations of $M$. tenuiflora extract have different effects on the multiplication of Leishmania protozoa in culture medium. The multiplication of promastigotes was found to be suppressed at 1000 and $500 \mathrm{micg} / \mathrm{mL}$ concentrations. This finding suggested that $M$. tenuiflora extract contains both inhibitory and acceleratory effects on Leishmania growth in vitro. Surendra et al. [176] determined the larvicidal action of Aq. extract of M. pudica leaves against Aedes aegypti larvae at different doses (250, 500, 750, 1000 , and $2000 \mu \mathrm{g} / \mathrm{m}$ ). The potential was determined at $0,1,2,3,4,6,12$, and $24 \mathrm{~h}$ and the percentage mortality rates were calculated. Percentage mortality was approximately zero at all concentrations over $24 \mathrm{~h}$. The Aq. extract was found to possess poor larvicidal actions; thus, it can be concluded that Mimosa pudica was not suitable for larvicidal actions. Brito et al. [177] reported in vivo anthelmintic (AH) activity of $M$. caesalpiniifolia leaf powder supplementation against nematodes (Haemonchus, Trichostrongylus, and Oesophagostomum) in male goats. Goats were given a M. caesalpiniifolia leaf powder that was rich in condensed tannins (days 1-7 and 14-21). After 28 days, the worm burden was estimated. Postmortem worm counts indicated a decreased in Haemonchus adult worm burden (57.7\%) in goats. For the CT group, no anthelmintic effect against Oesophagostomum was observed; thus, to control gastrointestinal nematode (GIN) infections in goats, feeding with dry $M$. caesalpiniifolia leaves proved encouraging (Table 2).

\subsection{Antispasmolytic, Antivenom, and Antiviral Activity}

Lozoya et al. [135] screened the antispasmolytic activity of $\mathrm{BuOH}, \mathrm{EtOAc}$, and $\mathrm{MeOH}$ extracts of $\mathrm{M}$. Tenuiflora in guinea pig and mouse models. $\mathrm{BuOH}, \mathrm{EtOAc}$, and $\mathrm{MeOH}$ at 
$30.0 \mu \mathrm{g} / \mathrm{mL}$ showed significant results by increasing the muscular tonus and frequency of contraction of the uterus. Increases in muscular tonus in the stomach in rats and relaxation of the ileum in guinea pigs were observed. Bitencourt et al. [40] measured the neutralizing capacity of the extract of $M$. tenuiflora bark on the inflammation induced by Tityus serrulatus scorpion venom in male BALB/c mice. Animals were inoculated intravenously with saline, Aq. extracts $(20,30$, or $40 \mathrm{mg} / \mathrm{kg}$ ) and fractions, DCM, butyl alcohol, and EtOAc $(40 \mathrm{mg} / \mathrm{kg})$. The EtOAc fraction showed potent inhibition against inflammatory cells. The EtOAc fraction showed 83,67 , and $86 \%$ inhibition at doses of 20 , 30 , and $40 \mathrm{mg} / \mathrm{kg}$, respectively. The Aq. extract showed $76 \%$ cell inhibition at a dose of $30 \mathrm{mg} / \mathrm{kg}$. Jain et al. [60] determined the in vivo antiviral activity of EtOH extract and fractions (Aq., CF, PE, and BZ) of M. hamata whole plant against $H$. Simplex, poliomyelitis, and $V$. stomatitis using the plaque inhibition method. The EtOH extract was found to be active against all three viruses. $\mathrm{CF}$ and $\mathrm{PE}$ were found to be active against V. stomatitis. None of the fractions were active against poliomyelitis (Table 2).

\section{Toxicological Studies of the Genus Mimosa Concerning Hemolysis, Antimutagenic, Genotoxic, and Teratogenic Effects}

Magalhães et al. [149] determined the toxicity of the EtOH extract and fractions (Hex, DCM, EtOAc, and $\mathrm{HyOH}$ ) of $M$. tenuiflora leaves, roots, twigs, and barks using non-specific toxicity to A. salina L. and cytotoxicity to African green monkey kidney (Vero) cells via MTT assay. Only the $\mathrm{HyOH}$ fraction killed $50 \%$ of the nauplii $\left(\mathrm{LC}_{50}=793.70 \mu \mathrm{g} / \mathrm{mL}\right)$. The fraction of $M$. tenuiflora with the highest antioxidant potential (FATEM) was not toxic to A. salina L. $\left(\mathrm{LC}_{50}>1000.00 \mu \mathrm{g} / \mathrm{mL}\right)$ or Vero cells $\left(\mathrm{CC}_{50}=512.6 \mu \mathrm{g} / \mathrm{mL}\right)$. Meckes-Lozoya et al. [135] investigated the hemolytic effects of $\mathrm{BuOH}, \mathrm{EtOAc}$, and $\mathrm{MeOH}$ extracts of $M$. tenuiflora stem bark against enterocytes. $\mathrm{BuOH}$ and EtOAc extracts at $250.0 \mathrm{~g} / \mathrm{mL}$ and $\mathrm{MeOH}$ at $500.0 \mu \mathrm{g} / \mathrm{mL}$ increased hemolysis by $74 \%, 48 \%$, and $68 \%$, respectively. Furthermore, de Morais-Leite et al. [136] measured the hemolytic effects of EtOH extract of $M$. tenuiflora bark on human erythrocytes (types A, B, and O). At the concentration of $1000 \mu \mathrm{g}$ only, hemolysis was observed in erythrocytes type A at 3.0\%, but at the concentration of $2000 \mu \mathrm{g}$ all three human erythrocytes (A, B, and $\mathrm{O}$ ) presented hemolysis (23.1, 5.17, and $1.08 \%$ respectively). Overall, the extract showed low toxicity for the human erythrocyte cells. Silva and colleagues reported the hemolytic potential of EtOH bark extract of $M$. tenuiflora against human RBCs at various concentrations (250, 500, and $1000 \mu \mathrm{g} / \mathrm{mL})$. At the $1000 \mu \mathrm{g} / \mathrm{mL}$ concentration, highest hemolysis was observed (90\%). While at low concentrations (125, $62.5,31.25,15.8 \mu \mathrm{g} / \mathrm{mL}$ ), no activity was observed [137] (Table 3).

Prathima et al. [35] measured the acute toxicity of the EtOH extract of M. pudica roots in adult Swiss albino mice at different doses $(0.5,1,2,4$, and $5 \mathrm{~g} / \mathrm{kg}$ p.o.). There was no mortality amongst the mice treated with the graded dose of extract up to a dose of $5000 \mathrm{mg} / \mathrm{kg}$ at a duration of $72 \mathrm{~h}$. Cadmium (Cd) is a well-recognized pollutant with great neuroendocrine-disrupting efficacy. It damages the hypothalamic-pituitary-testicular axis in mature male Wistar rats. The aqueous (Aq.) extract of $M$. pudica leaves was administered orally to rats at a dose of $200 \mathrm{mg} / \mathrm{kg}$ for 40 consecutive days. At the end of the analysis period, the extract was used as a therapeutic intervention for infertility [178]. The acute toxicity of EtOAc [167] and EtOH [58] extracts of M. pudica leaves on adult Wistar albino rats was determined. No mortality or signs of toxicity were observed at the dose of $2000 \mathrm{mg} / \mathrm{kg}$. Nghonjuyi et al. [22] measured the in vivo toxicity of $\mathrm{HyOH}$ extracts of $\mathrm{M}$. pudica leaves in Kabir chicks. Single doses of $\mathrm{HyOH}$ extracts were administered orally at doses ranging from 40 to $5120 \mathrm{mg} / \mathrm{kg}$ for the acute toxicity test. No death was recorded at doses lower than $2560 \mathrm{mg} / \mathrm{kg}$. Very low hypoactivity was observed at the extract dose of $5120 \mathrm{mg} / \mathrm{kg}$. In the sub-chronic study, these extracts were given orally as a single administration to chicks at doses of $80,160,320$, and $640 \mathrm{mg} / \mathrm{kg} /$ day for 42 days. No toxicity was observed with oral sub-chronic low dose administration. Das et al. [151] measured the cytotoxicity of the $\mathrm{MeOH}$ extract of $M$. pudica leaves using a brine shrimp lethality bioassay. The $\mathrm{LC}_{50}$ of the extract was found to be $282.4 \mu \mathrm{g} / \mathrm{mL}$, whereas the reference standard vincristine sulphate exhibited an $\mathrm{LC}_{50}$ of $0.45 \mu \mathrm{g} / \mathrm{mL}$. The results of the above findings clearly demonstrated 
that the leaves of M. pudica showed mild cytotoxic properties. Olusayo et al. [179] screened the acute toxicity of the EtOH extract of M. pigra roots in adult Wistar rats. No mortality was observed at $5000 \mathrm{mg} / \mathrm{kg}$, which showed that the plant is relatively safe. In sub-acute toxicity tests, three groups of adult Wistar rats were given different concentration of the extract of 250,500 , and $1000 \mathrm{mg} / \mathrm{kg} / \mathrm{bw}$, which corresponded to $1 / 20 \mathrm{th}, 1 / 10 \mathrm{th}$, and $1 / 5$ th of the $5000 \mathrm{mg} / \mathrm{kg}$ dose, respectively. To determine the biochemical (ast, alt, alp, total protein, cholesterol, urea, creatinine, and total bilirubin) and hematological (pcv, $\mathrm{rbc}$, and $\mathrm{hb}$ ) parameters, rat blood samples were collected on the 29th day. The results of the study showed that there were significant increases in packed hemoglobin, cell volume, and red blood cell count at different extract doses (500 and $1000 \mathrm{mg} / \mathrm{kg}$ ). The extract produced no significant changes in the levels of total bilirubin, total cholesterol, total protein, aspartate aminotransferase, or alkaline phosphatase in any of the groups that were treated, although a significant increase in the level of alanine transaminase was observed. Serum levels of urea and creatinine were not affected. The findings of this study showed that the roots of $M$. pigra may be safe at doses below $500 \mathrm{mg} / \mathrm{kg}$ but may pose toxicological risks at doses greater than $500 \mathrm{mg} / \mathrm{kg}$, with the liver being most affected with prolonged usage. Monção et al. [180] reported on an in vivo toxicological and androgenic evaluation of the $\mathrm{EtOH}$ extract of $M$. caesalpiniifolia leaves in adult male Wistar rats using body weight loss and serum biochemical parameters (ALP, AST, urea, and creatinine). In the toxicological evaluation, the extract induced a body weight loss at the highest tested dose $(750 \mathrm{mg} / \mathrm{kg})$. No androgenic activity was observed at any dose level $(250,500$, or $750 \mathrm{mg} / \mathrm{kg}$ ). Monção et al. [180] reported on the in vitro cytotoxicity of the EtOH extract of M. caesalpiniifolia leaves using an MTT assay in murine macrophages and a brine shrimp lethality assay in Artemia salina. The extract showed $\mathrm{LC}_{50}$ values of $1765 \mu \mathrm{g} / \mathrm{mL}$ against Artemia salina and $706.5 \mu \mathrm{g} / \mathrm{mL}$ against murine macrophages. Rejón-Orantes et al. [106] reported acute toxicity of Aq. extract of M. albida roots in male ICR mice. Different doses $(3.2,12.5,25.50,100,200,300$, and $400 \mathrm{mg} / \mathrm{kg})$ of $M$. albida extract were given to various mice groups and their mortality rates were recorded until $48 \mathrm{~h}$; no mortality was observed. Nandipati et al. [122] reported acute toxicity of $\mathrm{MeOH}$ extract $(500-4000 \mathrm{mg} / \mathrm{kg}$ ) of $M$. rubicaulis stem against Swiss albino mice, administered by oral gavage. No mortality was witnessed at the dose of $4000 \mathrm{mg} / \mathrm{kg}$. Silva and colleagues reported the hemolytic potential of the EtOH bark extracts of $M$. verrucosa and M. pteridifolia against human RBCs at various concentrations $(250,500$, and $1000 \mu \mathrm{g} / \mathrm{mL})$. For the M. verrucosa extract at the $1000 \mu \mathrm{g} / \mathrm{mL}$ concentration, the highest hemolysis rate was observed (100\%). At low concentrations (125, $62.5,31.25$, and $15.8 \mu \mathrm{g} / \mathrm{mL}$ ), no activity was observed [138], while M. pteridifolia showed no hemolysis with any tested concentrations (Table 3).

Silva et al. [181] measured the mutagenic and antimutagenic effects of crude EtOH extract of M. tenuiflora stem bark against $S$. typhimurium strains (TA97, TA98, TA100, TA102) using the Ames test. No mutation was induced in any of the strains at concentrations of 50 and $100 \mu \mathrm{g} / \mathrm{mL}$ of extract. The extract showed antimutagenic effects in all strains, although no antimutagenic effect was observed in TA98. The genotoxicity of crude EtOH extract of $M$. tenuiflora stem bark using a micronucleus test in the peripheral blood of albino Swiss mice has been reported [181]. The extract (100 to $200 \mathrm{mg} / \mathrm{kg}$ ) and cyclophosphamide (reference drug, $50 \mathrm{mg} / \mathrm{kg}$ ) were given to mice, whereby the extract at 100 and $200 \mathrm{mg} / \mathrm{kg}$ increased the numbers of micronucleus by 8.75 and 9.91 , respectively, as compared to cyclophosphamide $(50 \mathrm{mg} / \mathrm{kg}=43.5)$. Medeiros et al. [182] determined the teratogenic effects of $M$. tenuiflora seeds in pregnant Wistar rats, whereby a $10 \%$ dose of $M$. tenuiflora seeds was given to rats in a Brazilian semiarid climate. The extract was given from the 6th to the 21st day of pregnancy. No differences were observed in weight gain in the lungs, heart, liver, or kidneys of rats or in food or Aq. consumption between treated and controlled rats. Ninety bone malformations were observed in 40 of the 101 fetuses, including skeletal malformations such as scoliosis, bifid sternum, cleft palate, and hypoplasia of the nasal bone. Scientists measured $[183,184]$ the teratogenic effects of M. tenuiflora in pregnant goats and lambs in the semiarid rangelands of Northeastern Brazil. The four goats fed on 
fresh green M. tenuiflora during pregnancy delivered 4 kids, 3 of which had abnormalities, including cleft lip, ocular bilateral dermoids, unilateral corneal opacity, buphthalmos (with a cloudy brownish appearance of the anterior chamber due to an iridal cyst), and segmental stenosis of the colon. Dantas et al. [185] measured the teratogenic effects of green fresh $M$. tenuiflora in pregnant goats in the semiarid rangelands of Northeastern Brazil. A high frequency of embryonic deaths was observed in pregnant goats if $M$. tenuiflora was ingested in the first 60 days of gestation. Gardner et al. [186] determined the teratogenicity of $M$. tenuiflora leaves and seeds on pregnant rats in Northeastern Brazil. Compounds extracted from $M$. tenuiflora showed higher incidence rates of soft tissue cleft palate and skeletal malformations. Silva et al. [32] measured the antigenotoxic activities of the EtOH extract and EtOAc fraction of M. caesalpiniifolia leaves using a comet challenge assay and micronucleus test. The extract at a concentration of $125 \mathrm{mg} / \mathrm{kg}$ bw inhibited oxidative DNA damage in liver cells, which was induced by hydrogen peroxide $\left(\mathrm{H}_{2} \mathrm{O}_{2}\right)$ in animals intoxicated with cadmium $(\mathrm{Cd})$. Furthermore, the EtOAc fraction decreased the genomic damage and mutagenesis induced by cadmium exposure. The genus Mimosa is able to modulate the toxic effects caused by cadmium exposure as a result of antigenotoxic and antioxidant activities in blood and liver cells of rats (Table 3).

Table 3. Toxicological studies of the genus Mimosa regarding hemolysis, antimutagenic, genotoxic, and teratogenic effects.

\begin{tabular}{|c|c|c|c|c|c|c|c|}
\hline Activities & Plant & Plant Part & Extract/Fraction & Assay & Model & Results/Outcome/Response & References \\
\hline \multirow{10}{*}{$\begin{array}{l}\text { Toxicological } \\
\text { studies }\end{array}$} & \multirow{4}{*}{$\begin{array}{l}\text { M. } \\
\text { tenuiflora }\end{array}$} & $\begin{array}{l}\text { Leaves, } \\
\text { twigs, barks, } \\
\text { roots }\end{array}$ & $\begin{array}{c}\text { EtOH extract } \\
\text { and fractions } \\
\text { (Hex, DCM, } \\
\text { EtOAc and } \\
\text { HyOH }\end{array}$ & $\begin{array}{l}\text { Non-specific } \\
\text { toxicity } \\
\text { (2) Cytotoxicity } \\
\text { to Vero cells by } \\
\text { MTT assay }\end{array}$ & $\begin{array}{l}\text { (1) Artemia } \\
\text { salina L. } \\
\text { (2) Vero cells of } \\
\text { African green } \\
\text { monkey } \\
\text { kidney }\end{array}$ & $\begin{array}{l}\text { Only the HyOH fraction } \\
\text { killed } 50 \% \text { of the nauplii } \\
\text { (LC50 }=793.70 \mu \mathrm{g} / \mathrm{mL} \text { ). } \\
\text { Fractions of EtOH extract } \\
\text { were not toxic to } A \text {. salina L. } \\
\text { (LC50 > } 1000.00 \mu \mathrm{g} / \mathrm{mL} \text { ). } \\
\text { Fractions of EtOH extract } \\
\text { were not toxic to Vero cells } \\
\text { (CC50 }=512.6 \mu \mathrm{g} / \mathrm{mL})\end{array}$ & [149] \\
\hline & & \multirow[b]{2}{*}{ Stem bark } & $\begin{array}{l}\mathrm{BuOH} \\
\text { EtOAc } \\
\mathrm{MeOH}\end{array}$ & In vitro & Erythrocytes & $\begin{array}{c}\text { Buthanol } \\
250 \mu \mathrm{g} / \mathrm{mL}=74 \% ; \text { EtOAc } \\
250 \mathrm{~g} / \mathrm{mL}=48 \% ; \mathrm{MeOH} \\
500 \mu \mathrm{g} / \mathrm{mL}=68 \%\end{array}$ & [135] \\
\hline & & & $\mathrm{EtOH}$ & $\begin{array}{l}\text { Hemolytic } \\
\text { assay }\end{array}$ & $\begin{array}{c}\text { Human } \\
\text { erythrocytes } \\
\text { type A, B, and } \\
\text { O }\end{array}$ & $\begin{array}{c}\text { At } 1000 \mu \mathrm{g} \text { concentration, } \\
\text { only hemolysis of } \\
\text { erythrocyte A ( } 3 \% \text { ) was } \\
\text { observed, while at } 2000 \mu \mathrm{g} \\
\text { concentration, extract } \\
\text { showed hemolysis on type } \\
\mathrm{A}=23.1 \% \text {; type } \mathrm{B}=5.17 \% \\
\text { type } \mathrm{O}=1.08 \%\end{array}$ & [136] \\
\hline & & Bark & $\mathrm{EtOH}$ & $\begin{array}{l}\text { Hemolytic } \\
\text { assay }\end{array}$ & Human RBCs & $\begin{array}{c}\% \text { hemolysis at } \\
1000 \mu \mathrm{g} / \mathrm{mL}=90 \% \\
500 \mu \mathrm{g} / \mathrm{mL}=35 \% \\
250 \mu \mathrm{g} / \mathrm{mL}=17 \%\end{array}$ & [137] \\
\hline & \multirow{6}{*}{ M. pudica } & Roots & $\mathrm{EtOH}$ & Acute toxicity & $\begin{array}{l}\text { Swiss albino } \\
\text { mice }\end{array}$ & $\begin{array}{l}\text { No mortality was observed } \\
\text { at extract dose up to } \\
5000 \mathrm{mg} / \mathrm{kg}\end{array}$ & [35] \\
\hline & & \multirow{5}{*}{ Leaves } & Aq. & $\begin{array}{l}\text { Histoarchitecture } \\
\text { parameters }\end{array}$ & $\begin{array}{l}\text { Mature male } \\
\text { Wistar } \\
\text { rats/cadmium- } \\
\text { induced } \\
\text { toxicity }\end{array}$ & $\begin{array}{l}\text { Extract doses of } 200 \mathrm{mg} / \mathrm{kg} \\
\text { were found effective }\end{array}$ & [178] \\
\hline & & & EtOAc & Acute toxicity & $\begin{array}{l}\text { Adult Wistar } \\
\text { rats }\end{array}$ & $\begin{array}{l}\text { No mortality or signs of } \\
\text { toxicity were observed at } \\
\text { the dose of } 2000 \mathrm{mg} / \mathrm{kg}\end{array}$ & [167] \\
\hline & & & $\mathrm{EtOH}$ & Acute toxicity & $\begin{array}{l}\text { Wistar albino } \\
\text { rats }\end{array}$ & $\begin{array}{l}\text { No mortality as observed } \\
\text { up to the dose level of } \\
2000 \mathrm{mg} / \mathrm{kg} \mathrm{bw}\end{array}$ & [58] \\
\hline & & & \multirow[b]{2}{*}{$\mathrm{HyOH}$} & & \multirow{2}{*}{$\begin{array}{l}\text { In vivo } \\
\text { toxicity/Kabir } \\
\text { chicks }\end{array}$} & $\begin{array}{l}\text { Very low toxicity observed } \\
\text { at high dose of } 5120 \mathrm{mg} / \mathrm{kg}\end{array}$ & \multirow[b]{2}{*}{ [22] } \\
\hline & & & & & & $\begin{array}{l}\text { Sub-chronic toxicity } \\
\text { observed at doses of } 80,160 \text {, } \\
\text { 320, and } 640 \mathrm{mg} / \mathrm{kg}\end{array}$ & \\
\hline
\end{tabular}


Table 3. Cont.

\begin{tabular}{|c|c|c|c|c|c|c|c|}
\hline Activities & Plant & Plant Part & Extract/Fraction & Assay & Model & Results/Outcome/Response & References \\
\hline \multirow{9}{*}{$\begin{array}{l}\text { Toxicological } \\
\text { studies }\end{array}$} & M. pudica & Leaves & $\mathrm{MeOH}$ & $\begin{array}{l}\text { Brine shrimp } \\
\text { lethality } \\
\text { bioassay }\end{array}$ & & $\begin{array}{c}\text { Extract } 1-500 \mu \mathrm{g} / \mathrm{mL} ; \\
\mathrm{LC} 50=282.3495 \mu \mathrm{g} / \mathrm{mL}) \\
\text { standard vincristine } \\
\text { sulphate; } \\
\mathrm{LC} 50=0.45 \mu \mathrm{g} / \mathrm{mL}\end{array}$ & [151] \\
\hline & & & & Acute toxicity & $\begin{array}{l}\text { Adult Wistar } \\
\text { rats }\end{array}$ & No mortality observed & \\
\hline & M. pigra & Roots & $\mathrm{EtOH}$ & $\begin{array}{l}\text { Hematological } \\
\text { and } \\
\text { biochemical } \\
\text { parameters }\end{array}$ & $\begin{array}{l}\text { Adult Wistar } \\
\text { rats }\end{array}$ & $\begin{array}{l}\text { Doses greater than } \\
500 \mathrm{mg} / \mathrm{kg} \text { posed } \\
\text { toxicological risks }\end{array}$ & {$[179]$} \\
\hline & \multirow[t]{2}{*}{$\begin{array}{l}\text { M. caesalpi- } \\
\text { niifolia }\end{array}$} & \multirow[t]{2}{*}{ Leaves } & \multirow[t]{2}{*}{$\mathrm{EtOH}$} & $\begin{array}{l}\text { Body weight } \\
\text { and serum } \\
\text { biochemical } \\
\text { parameters } \\
\text { (ALP), AST, } \\
\text { urea, and } \\
\text { creatinine }\end{array}$ & $\begin{array}{l}\text { In vivo: Male } \\
\text { adult Wistar } \\
\text { rats }\end{array}$ & $\begin{array}{l}\text { Toxicological evaluation } \\
\text { induced a body weight loss, } \\
\text { which was observed at the } \\
\text { highest tested dose of } \\
750 \mathrm{mg} / \mathrm{kg} \\
\text { Extract did not show } \\
\text { androgenic activity at any } \\
\text { doses }(250,500,750 \mathrm{mg} / \mathrm{kg})\end{array}$ & [180] \\
\hline & & & & $\begin{array}{l}\text { Brine shrimp } \\
\text { and MTT assay }\end{array}$ & $\begin{array}{c}\text { In vitro: } \\
\text { Artemia } \\
\text { salina and } \\
\text { murine } \\
\text { macrophages }\end{array}$ & $\begin{array}{c}\text { LC50 = } 1765 \text { mg.L }{ }^{-1} \\
\text { (Artemia salina) } \\
\text { LC50 = 706.5 mg. }{ }^{-1} \\
\text { (murine macrophages) }\end{array}$ & [180] \\
\hline & M. albida & Roots & Aq. & Acute toxicity & Male ICR mice & $\begin{array}{l}\text { No mortality observed at } \\
\text { different extract doses }(3.2, \\
12.5,25.50,100,200,300, \\
\text { and } 400 \mathrm{mg} / \mathrm{kg})\end{array}$ & {$[106]$} \\
\hline & $\begin{array}{l}\text { M. rubicau- } \\
\quad \text { lis }\end{array}$ & Stems & $\mathrm{MeOH}$ & Acute toxicity & $\begin{array}{l}\text { Swiss albino } \\
\text { mice }\end{array}$ & $\begin{array}{c}\text { Doses (range of } \\
500-4000 \mathrm{mg} / \mathrm{kg} \text { ) did not } \\
\text { lead to acute toxicity }\end{array}$ & [122] \\
\hline & $\begin{array}{l}\text { M. verruco- } \\
\text { sa }\end{array}$ & Bark & $\mathrm{EtOH}$ & $\begin{array}{l}\text { Hemolytic } \\
\text { assay }\end{array}$ & Human RBCs & $\begin{array}{c}\% \text { hemolysis at } \\
1000 \mu \mathrm{g} / \mathrm{mL}=100 \% \\
500 \mu \mathrm{g} / \mathrm{mL}=72 \% \\
250 \mu \mathrm{g} / \mathrm{mL}=43 \%\end{array}$ & {$[137]$} \\
\hline & $\begin{array}{l}\text { M. pteridi- } \\
\text { folia }\end{array}$ & Bark & $\mathrm{EtOH}$ & $\begin{array}{l}\text { Hemolytic } \\
\text { assay }\end{array}$ & Human RBCs & No activity observed & {$[137]$} \\
\hline \multirow{6}{*}{$\begin{array}{l}\text { Antimutag- } \\
\text { enic, } \\
\text { genotoxic, } \\
\text { and terato- } \\
\text { genicef- } \\
\text { fects }\end{array}$} & \multirow{6}{*}{$\begin{array}{l}M . \\
\text { tenuiflora }\end{array}$} & \multirow[t]{2}{*}{ Stems, bark } & \multirow[t]{2}{*}{$\begin{array}{l}\text { crude } \mathrm{EtOH} \\
\text { extract }\end{array}$} & $\begin{array}{c}\text { Ames } \\
\text { mutagenic/ } \\
\text { antimutagenic } \\
\text { test }\end{array}$ & $\begin{array}{c}\text { S. typhimurium } \\
\text { TA 97, TA 98, } \\
\text { TA 100, TA } 102 \\
\text { strains }\end{array}$ & $\begin{array}{l}\text { Extracts at } 50 \text { and } 100 \\
\mu \mathrm{g} \cdot \mathrm{mL}^{-1} \text { did not induce } \\
\text { mutations in any strain } \\
\text { Extracts at } 50 \text { and } \\
100 \mu \mathrm{g} / \mathrm{mL} \text { showed } \\
\text { antimutagenic effects in all } \\
\text { strains (TA97, TA100, and } \\
\text { TA102) }\end{array}$ & \multirow[t]{2}{*}[181]{} \\
\hline & & & & $\begin{array}{l}\text { Micronucleus } \\
\text { test }\end{array}$ & $\begin{array}{l}\text { In vivo: } \\
\text { Erythrocytes of } \\
\text { albino Swiss } \\
\text { mice }\end{array}$ & $\begin{array}{l}\text { Extracts at } 100 \text { and } \\
200 \mu \mathrm{g} / \mathrm{mL} \text { did not show } \\
\text { significant results }\end{array}$ & \\
\hline & & Seeds & $10 \%$ of seeds & In vivo & $\begin{array}{l}\text { Pregnant } \\
\text { Wistar rats } \\
\text { (Rattus } \\
\text { novergicus) }\end{array}$ & $\begin{array}{l}90 \text { bone malformations } \\
\text { were observed in } 40 \text { of the } \\
101 \text { rats, including scoliosis, } \\
\text { lordosis, and a shorter head }\end{array}$ & {$[182]$} \\
\hline & & Green forage & In vivo & $\begin{array}{l}\text { Fed green } \\
\text { forage of } M \text {. } \\
\text { tenuiflora } \\
\text { throughout } \\
\text { gestation } \\
\text { period }\end{array}$ & $\begin{array}{l}\text { Pregnant goats } \\
\text { and lambs }\end{array}$ & $\begin{array}{c}3 \text { of } 4 \text { kids had } \\
\text { abnormalities including } \\
\text { cleft lip, unilateral corneal } \\
\text { opacity, ocular bilateral } \\
\text { dermoids, buphthalmos } \\
\text { with a cloudy brownish } \\
\text { appearance in the anterior } \\
\text { chamber due to an iridal } \\
\text { cyst, and segmental stenosis } \\
\text { of the colon }\end{array}$ & {$[184]$} \\
\hline & & Green forage & & In vitro & Pregnant goats & $\begin{array}{l}\text { Embryonic deaths were } \\
\text { observed }\end{array}$ & {$[185]$} \\
\hline & & $\begin{array}{l}\text { Leaves and } \\
\text { seeds }\end{array}$ & $\begin{array}{l}\text { Compounds } \\
\text { extracted } \\
\text { from } M \text {. } \\
\text { tenuiflora }\end{array}$ & & $\begin{array}{l}\text { In vitro: } \\
\text { Pregnant rats }\end{array}$ & $\begin{array}{l}\text { Soft tissue cleft palate and } \\
\text { skeletal malformations } \\
\text { were observed in pups }\end{array}$ & [186] \\
\hline
\end{tabular}


Table 3. Cont.

\begin{tabular}{|c|c|c|c|c|c|c|c|}
\hline Activities & Plant & Plant Part & Extract/Fraction & Assay & Model & Results/Outcome/Response & References \\
\hline & $\begin{array}{c}\text { M. cae- } \\
\text { salpiniifolia }\end{array}$ & Leaves & $\begin{array}{l}\text { EtOH and } \\
\text { EtOAc } \\
\text { fraction }\end{array}$ & $\begin{array}{c}\text { Comet, } \\
\text { challenge assay, } \\
\text { and } \\
\text { micronucleus } \\
\text { Test }\end{array}$ & $\begin{array}{l}\text { In vivo: Wister } \\
\text { rats }\end{array}$ & $\begin{array}{c}\text { Plant extract significantly } \\
\text { prevented genotoxicity in } \\
\text { liver and peripheral blood } \\
\text { cells }\end{array}$ & [32] \\
\hline
\end{tabular}

\section{Conclusions}

Herbal medicines are used to cure different ailments worldwide. Drugs are becoming resistant to treatment, so there is a dire need to find novel natural sources of traditional compounds. In this review, we presented ethnogeographical distribution and the traditional, nutritional and pharmacological values of Mimosa species. All species showed versatile potential pharmacological activities, such as antimicrobial, antioxidant, anticancer, antidiabetic, wound-healing, hypolipidemic, anti-inflammatory, hepatoprotective, antinociceptive, antiepileptic, neuropharmacological, toxicological, antiallergic, antihyperurisemic, larvicidal, antiparasitic, molluscicidal, antimutagenic, genotoxic, teratogenic, antispasmolytic, antiviral, and antivenom effects. In the future, the plants from this genus should be promising in the development of new drugs. This genus consists of 400 species but only $20-25$ are well known, while the rest have not yet been explored; therefore, the species of the genus Mimosa may hold potential for drug discovery. The best possible efforts have been made to review and summarize the available information. This review could be a useful tool in assisting researchers in discovering new medicinal benefits of the genus Mimosa.

Author Contributions: Conceptualization, I.M. and K.R.; methodology, R.A.; A.A. and H.K.; software, L.G.M. and M.Z.-U.-H.; validation, T.R.; investigation, I.M. and T.R.; resources, K.R.; data curation, I.M. and K.R.; writing-original draft preparation, I.M. and K.R.; writing-review and editing, I.M. and K.R.; visualization, K.R.; supervision, K.R. All authors have read and agreed to the published version of the manuscript.

Funding: This research received no external funding.

Institutional Review Board Statement: Not applicable.

Informed Consent Statement: Not applicable.

Data Availability Statement: All the data produced here are available and can be produced when required.

Conflicts of Interest: The authors declare no conflict of interest.

$\begin{array}{ll}\text { Abbreviations } & \\ \mathrm{BuOH} & \text { Butanol } \\ \mathrm{Hex} & \text { Hexane } \\ \mathrm{ACE} & \text { Acetone } \\ \mathrm{MeOH} & \text { Methanol } \\ \mathrm{EtOAc} & \text { Ethyl acetate } \\ \mathrm{EtOH} & \text { Ethanol } \\ \mathrm{DEE} & \text { Diethyl ether } \\ \mathrm{AA} & \text { Acetic acid } \\ \mathrm{DM} & \text { Dry matter } \\ \text { M. lysodeikticus } & \text { Micrococcus lysodeikticus } \\ \text { E. aerogenes } & \text { Enterobacter aerogenes } \\ \text { P. aeruginosa } & \text { Pseudomonas aeruginosa } \\ \text { P. Mirabilis } & \text { Proteus mirabilis } \\ \text { C. albicans } & \text { Candida albicans } \\ \text { S. epidermidis } & \text { Staphylococcus epidermidis } \\ & \end{array}$




\begin{tabular}{|c|c|}
\hline M. luteus & Micrococcus luteus \\
\hline S. typhi & Salmonella typhi \\
\hline P. variotii & Paecilomyces variotii \\
\hline P. valgaris & Proteus vulgaris \\
\hline A. niger & Aspergillus niger \\
\hline T. mentagrophytes & Trichophyton mentagrophytes \\
\hline M. gypseum & Microsporum gypseum \\
\hline B. subtilis & Bacillus subtilis \\
\hline F. moniliforme & Fusarium verticillioide \\
\hline C. diphtheria & Corynebacterium diphtheria \\
\hline M. phaseolina & Macrophomina phaseolina \\
\hline F. solani & Fusarium solani \\
\hline S. boydii & Shigella boydii \\
\hline $\mathrm{ZOI}$ & zone of inhibition \\
\hline ABTS & 2,2-azinobis-(3-ethylbenzothiazoline-6-sulfonate) \\
\hline $\mathrm{IC}_{50}$ & inhibitory concentration \\
\hline $\mathrm{NO}$ & Nitric oxide \\
\hline RBC & Red blood cell count \\
\hline WBC & White blood cell count \\
\hline PCV & Packed-cell volume \\
\hline ICR mice & Institute of Cancer Research \\
\hline EPC & EtOH-precipitated compounds \\
\hline VLU & venous leg ulceration \\
\hline $\mathrm{TNF} \alpha$ & Tumor Necrosis factor alpha \\
\hline VCAM-1 & vascular cell adhesion molecule 1 \\
\hline TNBS & Trinitrobenzenesulfonic acid \\
\hline $\mathrm{HyOH}$ & Hydroalcohol \\
\hline Aq. & Aqueous \\
\hline $\mathrm{PE}$ & Pet. Ether \\
\hline CF & Chloroform \\
\hline $\mathrm{Bz}$ & Benzene \\
\hline DCM & Dichloromethane \\
\hline HyMeO & Hydromethanol \\
\hline $\mathrm{HyEtOH}$ & Hydroethanol \\
\hline E. coli & Escherichia coli \\
\hline S. aureus & Staphylococcus aureus \\
\hline K. pneumonia & Klebsiella pneumonia \\
\hline S. sonnei & Shigella sonnei \\
\hline S. pyogenes & Streptococcus pyogenes \\
\hline C. neoformans & Cryptococcus neoformans \\
\hline A. calcoaceticus & Acinetobacter calcoaceticus \\
\hline L. bacillus & Lacto bacillus \\
\hline F. oxysporum & Fusarium oxysporum \\
\hline B. cereus & Bacillus cereus \\
\hline A. flavus & Aspergillus flavus \\
\hline A. terreus & Aspergillus terreus \\
\hline E. floccosum & Epidermophyton floccosum \\
\hline T. rubrum & Trichophyton rubrum \\
\hline P. vulgaris & Proteus vulgaris \\
\hline R. bataticola & Rhizoctonia bataticola \\
\hline M. canis & Microsporum canis \\
\hline P. boydii & Pseudallescheria boydii \\
\hline T. schoenleinii & Trichophyton schoenleinii \\
\hline R. solani & Rhizoctonia solani \\
\hline DPPH & 2,2-diphenyl-1-picrylhydrazyl \\
\hline $\mathrm{EC}_{50}$ & effective concentration \\
\hline $\mathrm{OH}$ & Hydroxide \\
\hline $\mathrm{TE}$ & Trolox equivalent \\
\hline
\end{tabular}




$\begin{array}{ll}\text { SRB assay } & \text { sulforhodamine B } \\ \text { XTT assay } & \text { Cell Proliferation Kit II } \\ \mathrm{CCl}_{4} & \text { Carbon tetrachloride } \\ \text { CAM } & \text { Chorioallantoic membrane } \\ \text { L-NAME } & \text { N-Nitro-L-arginine methyl ester hydrochloride } \\ \mathrm{COX}-2 & \text { cyclooxygenase- } \\ \text { PAH } & \text { Hypoxic pulmonary hypertension }\end{array}$

\section{References}

1. Ahuchaogu, A.A.; Chukwu, O.J.; Echeme, J.O. Secondary metabolites from Mimosa Pudica: Isolation, purification and nmr characterization. J. Appl. Chem. 2017, 10, 15-20. [CrossRef]

2. Joyamma, V.; Rao, S.; Hrishikeshavan, H.; Aroor, A.; Kulkarni, D. Biochemical mechanisms and effects of Mimosa pudica (Linn) on experimental urolithiasis in rats. Indian J. Exp. Biol. 1990, 28, 237-240.

3. Gupta, R.; Vairale, M.; Deshmukh, R.; Chaudhary, P.; Wate, S. Ethnomedicinal uses of some plants used by Gond tribe of Bhandara district, Maharashtra. Ind. J. Tradit. Know. 2010, 9, 713-717.

4. Hussain, N.; Modan, M.H.; Shabbir, S.G.; Zaidi, S. Antimicrobial principles in Mimosa hamata. J. Nat. Prod. 1979, 42, 525-527. [CrossRef] [PubMed]

5. Mahmood, A.; Mahmood, A.; Qureshi, R.A. Antimicrobial activities of three species of family mimosaceae. Pak. J. Pharm. Sci. 2012, 25, 203-206. [PubMed]

6. Muddiman, S.; Hodkinson, I.; Hollis, D. Legume-feeding psyllids of the genus Heteropsylla (Homoptera: Psylloidea). Bull. Entomol. Res 1992, 82, 73-117. [CrossRef]

7. Amalraj, T.; Ignacimuthu, S. Hyperglycemic effect of leaves of Mimosa pudica Linn. Fitoterapia 2002, 73, 351-352. [CrossRef]

8. Silva, A.S.; Araújo, S.B.; Souza, D.C.; Silva, F.A. Study of the $\mathrm{Cu}, \mathrm{Mn}, \mathrm{Pb}$ and $\mathrm{Zn}$ dynamics in soil, plants and bee pollen from the region of Teresina (PI), Brazil. An. Acad. Bras. Ciencs 2012, 84, 881-889. [CrossRef]

9. Camargo-Ricalde, S.L. Descripción, distribución, anatomía, composición química y usos de Mimosa tenuiflora (FabaceaeMimosoideae) en México. Rev. Biol. Trop. 2000, 48, 939-954.

10. Galinato, M.I.; Moody, K.; Piggin, C.M. Upland rice weeds of South and Southeast Asia. IRRI Los Baños 1999, $155,161$.

11. Lemes, P.G.; Castro, A.; Zanuncio, J. Oncideres ocularis (Coleoptera: Cerambycidae) Girdling Mimosa bimucronata (Fabaceae) in Brazil. Fla. Entomol. 2014, 97, 1240-1243. [CrossRef]

12. Jiang, Y.; Massiot, G.; Lavaud, C.; Teulon, J.-M.; Guéchot, C.; Haag-Berrurier, M.; Anton, R. Triterpenoid glycosides from the bark of Mimosa tenuiflora. Phytochemistry 1991, 30, 2357-2360. [CrossRef]

13. Ueda, M.; Takada, N.; Yamamura, S. Molecular approach to the nyctinastic movement of the plant controlled by a biological clock. Int. J. Mol. Sci. 2001, 2, 156-164. [CrossRef]

14. Lorenzi, H. Árvores brasileiras: Manual de identificação e cultivo de plantas arbóreas nativas do Brasil. In Nova Odessa, 2nd ed.; Editora Plantarum: Sao Paulo, Brazil, 1998; p. 10.

15. Fernandes, G.; Ferrari, R. Fruits of Mimosa foliolosa (Fabales: Fabaceae) as Sleeping Shelter for Megachile (Pseudocentron) botucatuna (Hymenoptera: Megachilidae). Neotrop. Entomol. 2012, 41, 518-520. [CrossRef]

16. Baggio, A.J.; Carpanezzi, A.A. Exploração seletiva do sub-bosque: Uma alternativa para aumentar a rentabilidade dos bracatingais. In Embrapa Florestas-Circular Técnica (Infoteca-e); Embrapa-Portuguese: Empresa Brasileira de Pesquisa Agropecuária, Brasília, Brazil, 1998.

17. Nworgu, F.; Egbunike, G. Nutritional potential of Centrosema pubescens, Mimosa invisa and Pueraria phaseoloides Leaf Meals on growth performance responses of broiler chickens. Am. J. Experim. Agric. 2013, 3, 506. [CrossRef]

18. Erkan, G.; Şengül, K.; Kaya, S. Dyeing of white and indigo dyed cotton fabrics with Mimosa tenuiflora extract. J. Saudi Chem.Soc. 2014, 18, 139-148. [CrossRef]

19. Silva, T.M.S.; dos Santos, F.P.; Evangelista-Rodrigues, A.; da Silva, E.M.S.; da Silva, G.S.; de Novais, J.S.; dos Santos, F.d.A.R.; Camara, C.A. Phenolic compounds, melissopalynological, physicochemical analysis and antioxidant activity of jandaíra (Melipona subnitida) honey. J. Food Compost. Anal. 2013, 29, 10-18. [CrossRef]

20. Apolinário, V.; Dubeux, J., Jr.; Lira, M.; Luiz, R.; Mello, A.; Santos, M.V.F.; Sampaio, E.V.S.B.; Muir, J. Tree legumes provide marketable wood and add nitrogen in warm-climate silvopasture systems. Crop. Econ. Prod. Mang. 2015, 107, 1915-1920. [CrossRef]

21. Chiocchio, I.; Mandrone, M.; Sanna, C.; Maxia, A.; Tacchini, M.; Poli, F. Screening of a hundred plant extracts as tyrosinase and elastase inhibitors, two enzymatic targets of cosmetic interest. Ind. Crop. Prod. 2018, 122, 498-505. [CrossRef]

22. Nghonjuyi, N.W.; Tiambo, C.K.; Taïwe, G.S.; Toukala, J.P.; Lisita, F.; Juliano, R.S.; Kimbi, H.K. Acute and sub-chronic toxicity studies of three plants used in Cameroonian ethnoveterinary medicine: Aloe vera (L.) Burm. f. (Xanthorrhoeaceae) leaves, Carica papaya L. (Caricaceae) seeds or leaves, and Mimosa pudica L. (Fabaceae) leaves in Kabir chicks. J. Ethnopharmcol. 2016, 178, 40-49. [CrossRef]

23. Rosado-Vallado, M.; Brito-Loeza, W.; Mena-Rejon, G.; Quintero-Marmol, E.; Flores-Guido, J. Antimicrobial activity of Fabaceae species used in Yucatan traditional medicine. Fitoterapia 2000, 71, 570-573. [CrossRef] 
24. Rivera-Arce, E.; Chávez-Soto, M.A.; Herrera-Arellano, A.; Arzate, S.; Agüero, J.; Feria-Romero, I.A.; Cruz-Guzmán, A.; Lozoya, X. Therapeutic effectiveness of a Mimosa tenuiflora cortex extract in venous leg ulceration treatment. J. Ethnopharmacol. 2007, 109, 523-528. [CrossRef] [PubMed]

25. Rahman, A.H.M.; Debnath, A. Ethno-botanical study at the village Pondit Para under Palash Upazila of Narsingdi District, Bangladesh. Int. J. Adv. Res. 2015, 3, 1037-1052.

26. Grieve, M. A Modem Herbal; Jonathan Cope: London, UK, 1931.

27. Oliveira, F.F.M.; Barbosa, K.M.K.M.; de Oliveira, G.F.; Dantas, I.M.; Camacho, R.G.V. Micropropagação de Mimosa caesalpiniaefolia Benth. a partir de segmentos nodais e ápices caulinares. Rev. Caatinga 2007, 20, 152-159.

28. Nana, F.; Sandjo, L.P.; Keumedjio, F.; Kuete, V.; Ngadjui, B.T. A new fatty aldol ester from the aerial part of Mimosa invisa (Mimosaceae). Nat. Prod. Res. 2012, 26, 1831-1836. [CrossRef]

29. Saxena, R.; Sharma, R.; Chandra Nandy, B.; Hardainiyan, S. The study of phenolic compound and antioxidant potential of crude extract and fractions of Mimosa Himata. International Res. J. Pharm. 2017, 8, 83-86. [CrossRef]

30. Almalki, M. In-Vitro Antioxidant properties of the leaf extract of Mimosa pudica Linn. Indian J. Sci. Tech. 2016, 9, 1-6. [CrossRef]

31. Parmar, F.; Kushawaha, N.; Highland, H.; George, L.-B. In vitro antioxidant and anticancer activity of Mimosa pudica linn extract and L-mimosine on lymphoma daudi cellsl. Int. J. Pharm. Pharm. Sci. 2015, 7, 100-104.

32. Silva, M.J.D.; Vilegas, W.; Silva, M.A.d.; de Moura, C.F.G.; Ribeiro, F.A.P.; da Silva, V.H.P.; Ribeiro, D.A. Mimosa (Mimosa caesalpiniifolia) prevents oxidative DNA damage induced by cadmium exposure in Wistar rats. Toxicol. Mech. Methods 2014, 24, 567-574. [CrossRef]

33. Chandarana, M.; Singh, R.; Jasrai, Y. Determination of the phenolic and flavonoid contents in Mimosa hamata Willd., as well as their radical scavenging activity. Int. J. Pharmacog. Phytochem. 2013, 28, 1121-1126.

34. Borneo, R.; León, A.; Aguirre, A.; Ribotta, P.; Cantero, J. Antioxidant capacity of medicinal plants from the Province of Cordoba (Argentina) and their in vitro testing in model food system. Food Chem. 2009, 112, 664-670. [CrossRef]

35. Prathima, C.; Shashikumara; Thippeswamy, T.; Jayanthi, M.K. Evaluation of anticonvulsant activity of Mimosa pudica root linn in swiss albino mice. Int. J. Pharm. Pharm. Sci. 2016, 8, 49-52. [CrossRef]

36. Ganguly, M.; Devi, N.; Mahanta, R.; Borthakur, K.M. Effect of Mimosa pudica root extract on vaginal estrous and serum hormones for screening of antifetility activity in albino mice. Contracept 2008, 76, 482-485. [CrossRef] [PubMed]

37. Jiang, Y.; You, X.-Y.; Fu, K.-L.; Yin, W.-L. Effects of extract from Mangifera indica Leaf on monosodium urate crystal-induced gouty arthritis in rats. Evid. Based Complement. Alternat. Med. 2012, 967573. [CrossRef]

38. Patel, N.K.; Bairwa, K.; Gangwal, R.; Jaiswal, G.; Jachak, S.M.; Sangamwar, A.T.; Bhutani, K.K. 2'-Hydroxy flavanone derivatives as an inhibitors of pro-inflammatory mediators: Experimental and molecular docking studies. Bioorg. Med. Chem. Lett. 2015, 25, 1952-1955. [CrossRef] [PubMed]

39. Borsato, D.M.; Prudente, A.S.; Döll-Boscardin, P.M.; Borsato, A.V.; Luz, C.F.; Maia, B.H.; Cabrini, D.A.; Otuki, M.F.; Miguel, M.D.; Farago, P.V. Topical anti-inflammatory activity of a monofloral honey of Mimosa scabrella provided by Melipona marginata during winter in Southern Brazil. J. Med. Food 2014, 17, 817-825. [CrossRef] [PubMed]

40. Bitencourt, O.M.A.; Lima, S.M.C.J.D.; Torres-Rêgo, M.; Fernandes, M.J.; Silva-Júnior, D.A.A.; Tambourgi, V.D.; Fernandes-Pedrosa, F.M.D. Neutralizing Effects of Mimosa tenuiflora Extracts against Inflammation Caused by Tityus serrulatus Scorpion Venom. Biomed. Res. Int. 2014, 2014, 378235. [CrossRef] [PubMed]

41. Cruz, M.P.; Andrade, C.M.F.; Silva, K.O.; de Souza, E.P.; Yatsuda, R.; Marques, L.M.; David, J.P.; David, J.M.; Napimoga, M.H.; Clemente-Napimoga, J.T. Antinoceptive and anti-inflammatory activities of the ethanolic extract, fractions and flavones isolated from Mimosa tenuiflora (Willd.) Poir (Leguminosae). PLoS ONE 2016, 11, e0150839. [CrossRef]

42. Vikram, P.K.; Malvi, R.; Jain, D. Evaluation of analgesic and anti-inflammatory potential of Mimosa pudica Linn. Int. J. Curr. Pharm. Res. 2015, 4, 47-50.

43. Elango, V.; Oliver, C.; Raghu, P.S. Antiulcer activity of the leaf ethanolic extract of Mimosa pudica in rats. Hygeia J. Drugs Med. 2012, 4, 34-40.

44. Le Tran, Q.; Tezuka, Y.; Ueda, J.-y.; Nhan, N.; Maruyama, Y.; Begum, K.; Kim, H.; Wataya, Y.; Kim Tran, Q.; Kadota, S. In Vitro Antiplasmodial Activity of Antimalarial Medicinal Plants Used in Vietnamese Traditional Medicine. J. Ethnopharmacol. 2003, 86, 249-252. [CrossRef]

45. Marimuthu, S.; Rahuman, A.; Rajakumar, G.; Thirunavukkarasu, S.; Kirthi, V.; Chidambaram, J.; Bagavan, A.; Abduz Zahir, A.; Elango, G.; Kamaraj, D.C. Evaluation of green synthesized silver nanoparticles against parasites. Parasitol. Res. 2010, 108, 1541-1549. [CrossRef]

46. Tunna, T.; Zaidul, I.; Ahmed, Q.; Ghafoor, K.; Al-Juhaimi, F.; Uddin, M.; Hasan, M.; Ferdous, S. Analyses and profiling of extract and fractions of neglected weed Mimosa pudica Linn. traditionally used in Southeast Asia to treat diabetes. S. Afr. J. Bot. 2015, 99, 144-152. [CrossRef]

47. Sutar, N.; Sutar, U.N.; Behera, B.C. Antidiabetic activity of the leaves of Mimosa pudica Linn. in albino rats. J. Herb. Med. Toxicol. 2009, 3, 123-126.

48. Jose, J.; Dhanya, A.; Haridas, K.R.; Kumar, T.S.; Jayaraman, S.; Variyar, E.J.; Sudhakaran, S. Structural characterization of a novel derivative of myricetin from Mimosa pudica as an anti-proliferative agent for the treatment of cancer. Biomed. Pharm. 2016, 84, 1067-1077. [CrossRef] 
49. Monção, B.N.; Araújo, Q.B.; Silva, D.J.; Lima, J.D.; Ferreira, M.P.; Airoldi, P.F.; Pessoa, C.; Citó, M.A. Assessing Chemical Constituents of Mimosa caesalpiniifolia Stem Bark: Possible Bioactive Components Accountable for the Cytotoxic Effect of $M$. caesalpiniifolia on Human Tumour Cell Lines. Molecules 2015, 20, 4204-4224. [CrossRef]

50. Molina, M.; Contreras, C.; Tellez-Alcantara, P. Mimosa pudica may possess antidepressant actions in the rat. Phytomedicine 1999, 6, 319-323. [CrossRef]

51. Saifuddin Khalid, M.; Shah, J.; Suresh, D.K.; Singh, R.; Narasimha Reddy, I.V.; Kumar, S. Evaluation of anti-diarrhoeal potential of ethanolic extract of Mimosa pudica leaves. Int. J. Green Pharm. 2011, 5, 75. [CrossRef]

52. Balakrishnan, N.; Bhaskar, V.; Jayakar, B.; Sangameswaran, B. Antibacterial activity of Mimosa pudica, Aegle marmelos and Sida cordifolia. Pharm. Mag. 2006, 2, 198-199.

53. Saraswat, R.; Pokharkar, R. GC-MS studies of Mimosa pudica. Int. J. Pharm. Tech. Res. 2012, 4, 93-98.

54. Paul, J.; Khan, S.; Mohammed, S.; Asdaq, S. Wound healing evaluation of chloroform and methanolic extracts of mimosa pudica roots in rats. Indian J. Phys. Anthropol. Hum. Gen. 2010, 1, 223-227.

55. De Souza, R.O.S.; de Albuquerque, U.P.; Monteiro, J.M.; de Amorim, E.L.C. Jurema-Preta (Mimosa tenuiflora [Willd.] Poir.): A Review of its Traditional Use, Phytochemistry and Pharmacology. Braz. Arch. Biol. Technol. 2008, 51, 937-947. [CrossRef]

56. Gohar, U.F.; Iqbal, I.; Shah, Z.; Mukhtar, H.; Zia-Ul-Haq, M. COVID-19: Recent Developments in Therapeutic Approaches. In Alternative Medicine Interventions for COVID-19; Zia-Ul-Haq, M., Bin-Jumah, M.N., Alothamn, S.I., Henidi, H.A., Eds.; Springer: Cham, Switzerland, 2021; pp. 249-274.

57. Kumaresan, R.; Veerakumar, S.; Elango, V. A study on hepatoprotective activity of Mimosa pudica in albino rats. Int. J. Pharmacog. Phytochem. Res. 2015, 7, 337-339.

58. Purkayastha, A.; Chakravarty, P.; Dewan, B. Hypolipidemic effect of ethanolic extract of Mimosa Pudica leaves on dyslipidemia following hepatic injury induced by Carbon tetrachloride in albino rats. Int. J. Pharm. Sci. Res. 2016, 7, 3284-3290. [CrossRef]

59. Lin, L.-C.; Chiou, C.-T.; Cheng, J.-J. 5-Deoxyflavones with cytotoxic activity from Mimosa diplotricha. J. Nat. Prod. 2011, 74, 2001-2004. [CrossRef]

60. Jain, S.; Jain, R.; Vlietinck, A. In vivo and in vitro antimicrobial efficacy of Mimosa hamata. Indian J. Biotech. 2004, 3, $271-273$.

61. Mehta, B.K.; Savita Sharma, K.; Dubey, A. 4-Ethylgallic acid from two Mimosa species. Phytochemistry 1988, $27,3004-3005$. [CrossRef]

62. Durgadevi, G.; Karthika, N. Screening of phytochemicals and pharmacological studies on Mimosa pudica L. Asian J. Innov. Res. 2018, 3, 19-28.

63. Zia-Ul-Haq, M. Past, present and future of Carotenoids Research. In Carotenoids: Structure and Function in the Human Body; Zia-Ul-Haq, M., Dewanjee, S., Riaz, M., Eds.; Springer: Cham, Switzerland, 2021; pp. 827-854.

64. Mathew, J.J.; Vazhacharickal, P.J.; Sajeshkumar, N.K.; Joy, J.K. Phytochemical analysis and in-vitro hemostatic activity of Mimosa Pudica, Hemigraphis colorata and chromolaena Odorata leaf extracts. CIBTech J. Pharma. Scie. 2016, 5, 16-34.

65. Kharissova, O.V.; Dias, H.V.R.; Kharisov, B.I.; Pérez, B.O.; Pérez, V.M.J. The greener synthesis of nanoparticles. Trends Biotechnol. 2013, 31, 240-248. [CrossRef] [PubMed]

66. Mapala, K.; Pattabi, M. Mimosa pudica flower extract mediated green synthesis of gold nanoparticles. Nano. World. J. 2017, 3, 44-50. [CrossRef]

67. Muhammad, G.; Hussain, M.A.; Amin, M.; Hussain, S.Z.; Hussain, I.; Bukhari, S.N.A.; Hassan, M.N. Glucuronoxylan-mediated silver nanoparticles: Green synthesis, antimicrobial and wound healing applications. R. Soc. Chem. 2017, 7, 42900-42908. [CrossRef]

68. Prabhakar, R.; Samadder, S. Jyotsana, Aquatic and terrestrial weed mediated synthesis of iron nanoparticles for possible application in wastewater remediation. J. Clean. Prod. 2017, 168, 1201-1210. [CrossRef]

69. Raziya, S.; Durga, B.; Ganesh, R.S.; Govind, B.; Annapurna, N. Synthesis and characterization of CDS nanoparticles from Mimosa Pudica plant extract. Res. J. Pharm. Biol. Chem. Sci. 2017, 8, 2196-2203.

70. Henam, P.S.; Heikham, F.D.; Henam, S.D. sustainable synthesis of ultrasmall biogenic platinum nanoparticles for selective aqueous phase conversion of glucose and effective hydrogen peroxide decomposition. Ind. Eng. Chem. Res. 2018, 57, 5190-5194. [CrossRef]

71. Fatimah, I.; Pradita, R.Y.; Nurfalinda, A. Plant extract mediated of ZnO Nanoparticles by using ethanol extract of Mimosa Pudica leaves and coffee powder. Proedia Eng. 2016, 148, 43-48. [CrossRef]

72. Rajan, J.P.; Singh, K.B.; Kumar, S.; Mishra, R.K. Trace elements content in the selected medicinal plants traditionally used for curing skin diseases by the natives of Mizoram, India. Asian Pac. J. Trop. Med. 2014, 7, S410-S414. [CrossRef]

73. Yongpisanphop, J.; Babel, S.; Kruatrachue, M.; Pokethitiyook, P. Phytoremediation potential of plants growing on the Pbcontaminated soil at Song Tho Pb mine, Thailand. Soil Sed. Contamin. Int. J. 2017, 26, 426-437. [CrossRef]

74. De Albuquerque, U.P. The use of medicinal plants by the cultural descendants of African people in Brazil. Acta Farm. Bonaer. 2001, 20, 139-144.

75. Lewis, G.P. Legumes of Bahia; Royal Botanic Gardens: London, UK, 1987.

76. Gaujac, A.; Martinez, S.T.; Gomes, A.A.; de Andrade, S.J.; Pinto, A.d.C.; David, J.M.; Navickiene, S.; de Andrade, J.B. Application of analytical methods for the structural characterization and purity assessment of N,N-dimethyltryptamine, a potent psychedelic agent isolated from Mimosa tenuiflora inner barks. Microchem J. 2013, 109, 78-83. [CrossRef] 
77. Albuquerque, U.; Medeiros, P.; Luiz S de Almeida, A.; Monteiro, J.; Lins Neto, E.; Gomes de Melo, J.; Patrícia dos Santos, J. Medicinal plants of the caatinga (semi-arid) vegetation of NE Brazil: A quantitative approach. J. Ethnopharmacol. 2008, 114, 325-354. [CrossRef]

78. Dourado, D.A.O.; Conceição, A.d.S.; Santos-Silva, J. O gênero Mimosa L. (Leguminosae: Mimosoideae) na APA Serra Branca/Raso da Catarina, Bahia, Brasil. Biota. Neotropica. 2013, 13, 225-240. [CrossRef]

79. Freitas, A.D.; Borges, W.; Mirella de Morais Andrade, M.; Valadares de Sá Barretto Sampaio, E.; de Rosália, C.; Passos, S.; Xavier G.; Mello Mulato, B.; Lyra, M.d.C. Characteristics of nodule bacteria from Mimosa spp grown in soils of the Brazilian semiarid region. Afr. J. Microbiol. Res. 2014, 8, 788-796. [CrossRef]

80. Silva, C.G.; Marinho, M.G.V.; Lucena, M.F.A.; Costa, J.G.M. Levantamento etnobotânico de plantas medicinais em área de Caatinga na comunidade do Sítio Nazaré, município de Milagres, Ceará, Brasil. Rev. Bras. Plantas Med. 2015, 17, 133-142. [CrossRef]

81. Agra, M.d.F.; Silva, K.N.; Basílio, I.J.L.D.; Freitas, P.F.d.; Barbosa-Filho, J.M. Survey of medicinal plants used in the region Northeast of Brazil. Rev. Bras. De Farmacogn. 2008, 18, 472-508. [CrossRef]

82. Muhammad, M.; Abdullahi, K.; Shehu, K.; Shinkafi, S. Antifungal activity of Mimosa pudica leaves extracts against fungal isolates from razor bumps in Sokoto Metropolis, Nigeria. Ann. Biol. Sci. 2015, 3, 16-19.

83. Ayissi Mbomo, R.-E.; Gartside, S.; Ngo Bum, E.; Njikam, N.; Okello, E.; McQuade, R. Effect of Mimosa pudica (Linn.) extract on anxiety behaviour and GABAergic regulation of 5-HT neuronal activity in the mouse. J. Psychopharmacol. 2011, 26, 575-583. [CrossRef] [PubMed]

84. Mendieta, R.M.; Rodríguez, A. Plantas medicinales del estado de Yucatán. Bol. Soc. Bot. Mex. 1981, 43, 94-95. [CrossRef]

85. Ramesh, S.; Karthikeyan, K.; Chandran, C. Photochemical screening and pharmacognostic studies on Mimosa pudica L (Sensitive plant). Int. J. Fauna Biol. Stud. 2017, 4, 170-175.

86. Paranjpe, P. Indian Medicinal Plants: Forgotten Healers: A Guide to Ayurvedic Herbal Medicine with Identity, Habitat, Botany, Photochemistry, Ayurvedic Properties, Formulations E Clinical Usage; Chaukhamba Sanskrit Pratishthan: New Delhi, India, 2001; p. 26.

87. Rajendran, R.; Hemalatha, S.; Akasakalai, K.H.; Madhukrishna, C.; Sohil, B.; Meenakshi Sundaram, R. Hepatoprotective activity of Mimosa pudica leaves against Carbontetrachloride induced toxicity. J. Nat. Prod. 2009, 2, 116-122.

88. Vinothapooshan, G.; Sundar, K. Anti-ulcer activity of Mimosa pudica leaves against gastric ulcer in rats. Res. J. Pharm. Biol. Chem. Sci. 2010, 1, 606.

89. Sharma, P.; Yelne, M.; Dennis, T. Database on Medicinal Plants Govt. of India; Janakpuri: Delhi, India, 2001; pp. 369-379.

90. Ghani, A. Medicinal Plants of Bangladesh with Chemical Constituents and Uses, Asiatic Society of Bangladesh; Nimtali: Dhaka, Bangladesh, 2003; pp. 302-303.

91. Subramani, M.; Priyagrace, S.; Vijayaraghavan, R.; Velmurugan, A.; Govindarajan, P.; Michael, A. Antitoxin activity of Mimosa pudica root extracts against Naja naja and Bangarus caerulus venoms. Bangladesh J. Pharmacol. 2009, 4, 105-109. [CrossRef]

92. Zhou, J.; Qu, F. Treating gynaecological disorders with traditional Chinese medicine: A review. Afr. J. Trad. Compl. Alternat. Med. 2009, 6, 494-517. [CrossRef]

93. Zeng, Y.; Li, Y.; Wei, H.; Xiong, C.; Liao, L.; Miao, T.-W.; Ma, B.; Fu, J.-J. Chinese oral herbal paste for the treatment of stable chronic obstructive pulmonary disease: Protocol for a systematic review and meta-analysis. Medicine 2019, 98, e16444. [CrossRef] [PubMed]

94. Mbatchou, V.; Ayebila, A.J.; Apea, D.O. Antibacterial activity of phytochemicals from Acacia nilotica, Entada africana and Mimosa pigra L. on Salmonella typhi. J. Anim. Plant. Sci. 2011, 10, 1248-1258.

95. Irvine, F.R. Woody Plants of Ghana: With Special Reference to Their Uses; Oxford University Press: London, UK, 1961; Volume 1, p. 868.

96. Mohammed, M.S.; Khalid, H.S.; Muddathir, A.E.; El-Tahir, K.; Khan, A.A.; Algadir, H.A.; Osman, W.; Siddiqui, N.A. Effect of some plants' extracts used in Sudanese folkloric medicines on carrageenan-induced inflammation. Pak. J. Pharm. Sci. 2015, 28, 159-165.

97. Ahmed, T.; Khandaker, I.; Rahman, S.; Mou, S.M.; Choudhury, M.S.; Mahal, M.J.; Jahan, S.; Hossain, M.; Rahmatullah, M. Antihyperglycemic and antinociceptive activity of Fabaceae family plants-An evaluation of Mimosa pigra L. stems. Adv. Nat. Appl. Sci. 2012, 6, 1490-1495.

98. Saeed, M.E.M.; Abdelgadir, H.; Sugimoto, Y.; Khalid, H.E.; Efferth, T. Cytotoxicity of 35 medicinal plants from Sudan towards sensitive and multidrug-resistant cancer cells. J. Ethnopharmacol. 2015, 174, 644-658. [CrossRef]

99. Grosvenor, P.W.; Gothard, P.K.; McWilliam, N.C.; Supriono, A.; Gray, D.O. Medicinal plants from Riau Province, Sumatra, Indonesia. Part 1: Uses. J. Ethnopharmacol. 1995, 45, 75-95. [CrossRef]

100. Carvalho, P. Sabiá-Mimosa caesalpiniifolia. Embrapa Florestas-Circular Técnica (Infoteca-E). Embrapa Florestas. Circ. Técnica. 2007, 135, 10.

101. Saxena, R.; Sharma, R.; Nandy, B.; Jasuja, D.N. Qualitative and quantitative estimation of bioactive compounds in Mimosa hamata. Int. J. Pharm. Pharm. Sci. 2014, 6, 72-75.

102. Nadkarni, A. Nadkarni's Indian Materia Medica; Popular Prakashan Private Ltd.: Bombay, India, 1954. 
103. Chopra, R.N.; Nayar, S.L.; Chopra, I.C.; Asolkar, L.V.; Kakkar, K.K.; Chakre, O.J.; Varma, B.S.; Council of Scientific \& Industrial, Research. Glossary of Indian Medicinal Plants; [with] Supplement; Council of Scientific \& Industrial Research: New Delhi, India, 1956; Volume 3, pp. 1956-1992.

104. Gupta, M.; Arias, T.; Etheart, J.; Hatfield, G. The occurrence of tryptamine and N-methyltryptamine in Mimosa somnians. J. Nat. Prod. 1979, 42, 234-236. [CrossRef]

105. Aguiar, L.C.G.G.; Barros, R.F.M. Plantas medicinais cultivadas em quintais de comunidades rurais no domínio do cerrado piauiense (Municipio de Demerval Lobao, Piauí, Brasil). Rev. Bras. De Plantas Med. 2012, 14, 419-434. [CrossRef]

106. Rejón-Orantes, J.P.; Perdomo Suaréz, D.; Rejón-Rodríguez, A.; Hernández Hernández, S.; García Liévano, O.E.; López Rodríguez, D.; Perez de la Mora, M. Aqueous root extracts from Mimosa albida Humb. \& Bonpl. ex Willd display antinociceptive activity in mice. J. Ethnopharmacol. 2013, 149, 522-526. [CrossRef] [PubMed]

107. Ticktin, T.; Dalle, S.P. Medicinal plant use in the practice of midwifery in rural Honduras. J. Ethnopharmacol. 2005, 96, 233-248. [CrossRef] [PubMed]

108. Zippel, J.; Deters, A.; Hensel, A. Arabinogalactans from Mimosa tenuiflora (Willd.) Poiret bark as active principles for woundhealing properties: Specific enhancement of dermal fibroblast activity and minor influence on HaCaT keratinocytes. J. Ethnopharmacol. 2009, 124, 391-396. [CrossRef]

109. Sanchez-León, V; Yashté, L. Plantas de Xhiapas, Sus Usos, Valores e Importancia: El tepescohuite Tuxtla Gutierrez; Chippas. Editorial Instituto de Historia Natural, Depto: De Botanica, Mexico, 1991; p. 4.

110. Camargo-Ricalde, S.; Grether, R.; Martínez-Bernal, A. Uso medicinal del “tepescohuite", Mimosa tenuiflora (Leguminoseae) en Mexico. Contacto 1994, 5, 29-34.

111. Grether, R. Nota sobre la identidad del tepexcohuite en México. Bol. Soc. Bot. Mexico 2017, 48, 151-152. [CrossRef]

112. Vepsäläinen, J.J.; Auriola, S.; Tukiainen, M.; Ropponen, N.; Callaway, J. Isolation and characterization of yuremamine, a new phytoindole. Planta Medica 2005, 71, 1053-1057. [CrossRef]

113. Lauriola, M.; Corazza, M. Allergic contact dermatitis caused by argan oil, neem oil, and Mimosa tenuiflora: Allergic contact dermatitis caused by herbal therapies. Contact Dermatitis. 2016, 75, 388-390. [CrossRef]

114. Evans, S.; Hofmann, A. Plantas de los dioses. In Orígenes Del Uso De Los Alucinógenos; Fondo de Cultura: México City, México, 2008

115. Genest, S.; Kerr, C.; Shah, A.; Rahman, M.M. Comparative bioactivity studies on two Mimosa species. Bol. Latinoam. Caribe Plantas Med. Aromat. 2008, 7, 38-43.

116. Racadio, S.P. The medicinal prospects of Makahiya (Mimosa Pudica Linn) plant. Adv. Life Sci. 2016, 6, 7-12. [CrossRef]

117. Molina, G.G.V. Inhibitory activity of Makahiya (Mimosa pudica Linn) leaf extract of three test organisms. Int. J. Sci. Eng. Res. 2015, 6, 150-158. [CrossRef]

118. Vaidyaratanm, P.S. Indian Medicinal Plants Database Kottakkal; Arya Vidyashala: Kerala, India; Orient Longman: Hyderabad, Telangana, 2001; Volume 2, pp. 36-37.

119. Podadera, D.S.; Engel, V.L.; Parrotta, J.A.; Machado, D.L.; Sato, L.M.; Durigan, G. Influence of removal of a non-native tree species Mimosa caesalpiniifolia Benth. on the regenerating plant communities in a tropical semideciduous forest under restoration in Brazil. Environ. Manag. 2015, 56, 1148-1158. [CrossRef]

120. Sousa, S.; Campos Reis, A.; Facio Viccini, L. Polyploidy, B chromosomes, and heterochromatin characterization of Mimosa caesalpiniifolia Benth. (Fabaceae-Mimosoideae). Tree Genet. Gen. 2012, 9, 613-619. [CrossRef]

121. Ribaski, J.; Lima, P.C.F.; de Oliveira, V.R.; Drumond, M.A. Sabiá (Mimosa caesalpiniaefolia) árvore de múltiplo uso no Brasil. In Embrapa Florestas-Comunicado Técnico (INFOTECA-E); Embrapa-Portuguese; Empresa Brasileira de Pesquisa Agropecuária: Brasília, Brazil, 2003; p. 4.

122. Nandipati, M.C.; Sumalatha, G.; Baburao, C.; Babu, J.R.; Sridevi, C. Antitumor activity of Mimosa Rubicaulis Lam against Ehrlich Ascites carcinoma in swiss albino mice. Int. J. Pharm. Sci. Res. 2014, 5, 1514. [CrossRef]

123. Umadevi, S.; Gopi, V.; Elangovan, V. Regulatory mechanism of gallic acid against advanced glycation end products induced cardiac remodeling in experimental rats. Chem. Biol Int. 2014, 208, 28-36. [CrossRef] [PubMed]

124. Schlickmann, F.; Boeing, T.; Mariano, L.N.B.; da Silva, L.M.; de Andrade, S.F.; de Souza, P.; Cechinel-Filho, V. Gallic acid, a phenolic compound isolated from Mimosa bimucronata (DC.) Kuntze leaves, induces diuresis and saluresis in rats. Naunyn Schmiedebergs Arch. Pharmacol. 2018, 391, 649-655. [CrossRef]

125. Berhaut, J. Flore illustrée du Sénégal, tome IV. Preface de M. Leopold Sendar Senghor. J. Agric. Trop. Bot. Appl. 1975, 21, 269-270.

126. Bouquet, A. Féticheurs et Médecines Traditionnelles du Congo (Brazzaville); Orstom: Paris, France, 1969; Volume 36, p. 282.

127. Manosroi, J.; Zaruwa, M.; Manosroi, A. Potent hypoglycemic effect of Nigerian anti-diabetic medicinal plants. J. Complement. Integr. Med. 2011, 8, 1-14. [CrossRef]

128. Jayanegara, A.; Kreuzer, M.; Wina, E.; Leiber, F. Significance of phenolic compounds in tropical forages for the ruminal bypass of polyunsaturated fatty acids and the appearance of biohydrogenation intermediates as examined in vitro. Anim. Prod. Sci. 2011, 51, 1127-1136. [CrossRef]

129. Valencia-Gómez, L.E.; Martel-Estrada, S.A.; Vargas-Requena, C.; Rivera-Armenta, J.L.; Alba-Baena, N.; Rodríguez-González, C.; Olivas-Armendáriz, I. Chitosan/Mimosa tenuiflora films as potential cellular patch for skin regeneration. Inter. J. Biol. Macromol. 2016, 93, 1217-1225. [CrossRef] [PubMed] 
130. De Souza Araújo, E.; Pimenta, A.; Feijó, F.; Castro, R.; Fasciotti, M.; Monteiro, T.; de Lima, K. Antibacterial and antifungal activities of pyroligneous acid from wood of Eucalyptus urograndis and Mimosa tenuiflora. J. App. Micro. 2018, 124, 85-96. [CrossRef] [PubMed]

131. Gonçalves, A.; Alves Filho, A.; Menezes, H. Estudo comparativo da atividade antimicrobiana de extratos de algumas árvores nativas. Arq. Inst. Biol. 2005, 72, 353-358.

132. Padilha, I.Q.; Pereira, A.V.; Rodrigues, O.G.; Siqueira-Júnior, J.P.; Pereira, M.d.S.V. Antimicrobial activity of Mimosa tenuiflora (Willd.) Poir. from Northeast Brazil against clinical isolates of Staphylococcus aureus. Rev. Bras. Farmacogn. 2010, 20 , 45-47. [CrossRef]

133. Heinrich, M.; Kuhnt, M.; Wright, C.W.; Rimpler, H.; Phillipson, J.D.; Schandelmaier, A.; Warhurst, D.C. Parasitological and microbiological evaluation of Mixe Indian medicinal plants (Mexico). J. Ethnopharmcol. 1992, 36, 81-85. [CrossRef]

134. Lozoya, X.; Navarro, V.; Arnason, J.; Kourany, E. Experimental evaluation of mimosa tenuiflora (willd.) poir.(Tepescohuite) I. Screening of the antimicrobial properties of bark extracts. Arch. Investig. Med. 1989, 20, 87-93.

135. Meckes Lozoya, M.; Lozoya, X.; González, J.L. Propiedades farmacológicas in vitro de algunos extractos de Mimosa tenuiflora (tepescohuite). Arch. Investig. Med. (Mex) 1990, 21, 163-169.

136. De Morais Leite, S.C.; Medeiros, C.; Soares, A.I.; Maia, P.C.G.G.S.; Magalhães, M.I.S.; Freitas, F.O.R.; Pessôa, H.D.L.F.; Nogueira, T.B.D.S.; Sousa, A.; de Morais, A.M.B.; et al. Antibacterial and hemolytic activities of Mimosa tenuiflora (Willd) Poir.(Mimosoidea). Afr. J. Microbiol. Res. 2015, 9, 2166-2171. [CrossRef]

137. Silva, S.A.d.N.M.; Barros, A.B.; Souza, J.M.T.; Moura, A.F.; Araújo, A.R.d.; Mendes, M.G.A.; Daboit, T.C.; Silva, D.A.d.; Araújo, A.J.; Marinho Filho, J.D.B. Phytochemical and biological prospection of Mimosa genus plants extracts from Brazilian northeast. Phytochem. Lett. 2020, 39, 173-181. [CrossRef]

138. Nagarajan, K.; Saravanararaja, M.; Aruna Devi, S.P. Antibacterial Efficiency of Fabaceae Plants of a Tropical Freshwater Lake. Int. J. Res. Sci. 2015, 2, 13-17. [CrossRef]

139. Abirami, S.G.; Mani, K.S.; Devi, M.N.; Devi, P.N. The antimicrobial activity of Mimosa pudica L. Int. J. Ayur. Pharma Res. 2014, 2, 105-108.

140. Sheeba, D.G.; Gomathi, K.S.; Citarasu, D. Anti-mycobacterial and phytochemical investigation of methanol extracts of few medicinal plants. J. Chem. Pharm. Sci. 2015, 8, 480-486.

141. Kakad, S.L.; Tungikar, V.V.; Dhembare, A.J. Evaluation of antibacterial activity of plant extracts against bacterial pathogen. Der Pharm. Sin. 2015, 6, 1-5. [CrossRef]

142. Thakur, A.; Pradhan, P.; Sharma, Y.; Bhateja, P. Pharmacognostical, physiochemical and antimicrobial action of mimosa pudica leaves. J. Pharma. Res. 2016, 5, 52-55.

143. Le Thoa, N.T.; Nam, P.C.; Nhat, D.M. Antibacterial activities of the extracts of Mimosa pudica L. an in-vitro study. Int. J. Adv. Sci. Eng. Inf. Technol. 2015, 5, 358-361. [CrossRef]

144. Dhanya, K.; Thangavel, M. Analysis of Phytochemicals and Mimosine from Mimosa Pudica. Int. J. 2015, 3, $672-676$.

145. Ahuchaogu, A.; Chukwu, J.; Obike, A.; Ugonna Oha, T.; Bull, J.; Echeme, O. Quantitative determination of secondary metabolites and antibacterial activity of Mimosa Pudica. Int. J. Med. Plants Nat. Prod. 2017, 3, 1-5. [CrossRef]

146. Chukwu, O.J.; Ahuchaogu, A.A.; Ukaogo, P.; Obike, A.; Echeme, J.B.O. Antifungal activity of Mimosa pudica, isolation and NMR characterization of bioactive components. Asian J. Chem. Sci. 2017, 2, 1-5. [CrossRef]

147. De Morais, C.B.; Scopel, M.; Pedrazza, G.P.R.; da Silva, F.K.; Dalla Lana, D.F.; Tonello, M.L.; Miotto, S.T.S.; Machado, M.M.; de Oliveira, L.F.S.; Fuentefria, A.M.; et al. Anti-dermatophyte activity of Leguminosae plants from Southern Brazil with emphasis on Mimosa pigra (Leguminosae). J. Mycol. Med. 2017, 27, 530-538. [CrossRef]

148. Ali, M.; Azhar, I.; Ahmad, F.; Ahmad, V.; Usmanghani, K. Antimicrobial screening of Mimoaceous plants. Pharm. Biol. 2001, 39 , 43-46. [CrossRef]

149. Magalhães, F.E.A.; Batista, F.L.A.; Serpa, O.F.; Moura, L.F.W.G.; Lima, M.d.C.L.; da Silva, A.R.A.; Guedes, M.I.F.; Santos, S.A.A.R.; de Oliveira, B.A.; Nogueira, A.B.; et al. Orofacial antinociceptive effect of Mimosa tenuiflora (Willd.) Poiret. Biomed. Pharmacother. 2018, 97, 1575-1585. [CrossRef] [PubMed]

150. Zia-Ul-Haq, M. Historical and introductory aspects of carotenoids. In Carotenoids: Structure and Function in the Human Body; Zia-Ul-Haq, M., Dewanjee, S., Riaz, M., Eds.; Springer: Cham, Switzerland, 2021; pp. 1-42.

151. Das, K.; Yasin, M.; Mahbub, N.U.; Islam, M.S.; Mahbuba, N. Evaluation of antioxidant and cytotoxic activity of methanolic extract of Mimosa pudica leaves. Pharm. Innov. 2014, 3, 32.

152. Chimsook, T. Bioactivities of Mimosa pudica and Phyllanthus niruri crude extracts collected from the locality of Chaiyaphum, Thailand. Adv. Mat. Res. 2014, 12-15. [CrossRef]

153. Jose, J.; Sudheesh, S.; Dhanya, A.; Kumar, T.S.; Sony, J.; Variyar, E.J. In vitro studies of immunomodulatory and free radical scavenging activities of flavonoid isolated from Mimosa pudica. Int. J. Pharm. Sci. Res. 2014, 5, 4254-4261. [CrossRef]

154. Ittiyavirah, S.P.; Pullochal, I. Adaptogenic and nootropic activity of Mimosa pudica in albino wistar rats. Int. J. Nutr. Pharmacol. Neurol. Dis. 2014, 4, 231. [CrossRef]

155. Rakotomalala, G.; Agard, C.; Tonnerre, P.; Tesse, A.; Derbré, S.; Michalet, S.; Hamzaoui, J.; Rio, M.; Cario-Toumaniantz, C.; Richomme, P. Extract from Mimosa pigra attenuates chronic experimental pulmonary hypertension. J. Ethnopharmacol. 2013, 148, 106-116. [CrossRef] 
156. Singh, R.; Jain, S.C.; Jasrai, Y. Antioxidant activity and total phenolic content of various extracts from Mimosa hamata Willd., Mimosaceae. Int. J. Phytomed. 2012, 4, 314.

157. Jiménez, N.; Carrillo-Hormaza, L.; Pujol, A.; Álzate, F.; Osorio, E.; Lara-Guzman, O. Antioxidant capacity and phenolic content of commonly used anti-inflammatory medicinal plants in Colombia. Ind. Crop. Prod. 2015, 70, 272-279. [CrossRef]

158. Silva, M.; Carvalho, A.; Rocha, C.; Vilegas, W.; Silva, M.; Gouvêa, C. Ethanolic extract of Mimosa caesalpiniifolia leaves: Chemical characterization and cytotoxic effect on human breast cancer MCF-7 cell line. S. Afr. J. Bot. 2014, 93, 64-69. [CrossRef]

159. Piyapong, Y.; Ampa, K. Hypoglycemic and hypolipidemic activities of ethanolic extract from Mimosa pudica L. in normal and streptozotocin-induced diabetic rats. Pharmacogn. J. 2017, 9, 834-837. [CrossRef]

160. Konsue, A.; Picheansoonthon, C.; Talubmook, C. Fasting Blood Glucose Levels and Hematological Values in Normal and Streptozotocin-Induced Diabetic Rats of Mimosa pudica L. Extracts. Pharmacogn. J. 2017, 9, 315-322. [CrossRef]

161. Ao, S.; Kc, O.; Ukwueze, S. Evaluation of the antidiabetic potential of ethanol root extract of Mimosa pigra Linn (Fabaceae) in alloxan-induced diabetic albino rats. Int. J. Curr. Res. 2015, 7, 15577-15581.

162. Choi, J.; Park, Y.-G.; Yun, M.-S.; Seol, J.-W. Effect of herbal mixture composed of Alchemilla vulgaris and Mimosa on wound healing process. Biomed. Pharmacother. 2018, 106, 326-332. [CrossRef]

163. Liu, G.; Ren, G.; Zhao, L.; Cheng, L.; Wang, C.; Baoguo, S. Antibacterial activity and mechanism of bifidocin A against Listeria monocytogenes. Food Cont. 2017, 73, 854-861. [CrossRef]

164. Emanuella Sales da Silva-Leite, K.; Silva Queiroz, C.; Da Costa Madeira, J.; Marcos Gomes Soares, P.; Pereira, M.; Assreuy, A.M. Polysaccharide extract of Mimosa tenuiflora stem barks stimulates acute inflammatory response via nitric oxide. Acta Sci. Biol. Sci. 2016, 38, 473. [CrossRef]

165. Liu, L.; Li, J.; Yue, F.; Yan, X.; Wang, F.; Bloszies, S.; Wang, Y. Effects of arbuscular mycorrhizal inoculation and biochar amendment on maize growth, cadmium uptake and soil cadmium speciation in Cd-contaminated soil. Chemosphere 2018, 194, 495-503. [CrossRef]

166. Silva, M.; Vilegas, W.; Aparecido da Silva, M.; Paula Ribeiro Paiotti, A.; Mercaldi Pastrelo, M.; Luiz Menin Ruiz, P.; de Moura, C.; Tizuko Fujiyama Oshima, C.; Araki Ribeiro, D. The anti-inflammatory potential of Mimosa caesalpiniifolia Following experimental colitis: Role of COX-2 and TNF-Alpha expression. Drug Res. 2017, 68, 196-204. [CrossRef]

167. Patro, G.; Bhattamisra, S.K.; Mohanty, B.K. Analgesic, antiepileptic, and behavioral study of Mimosa pudica (Linn.) on experimental rodents. Int. J. Nutr. Pharmacol. Neurol. Dis. 2015, 5, 144. [CrossRef]

168. Zhu, Y.; Zhang, S. Antibacterial activity and mechanism of lacidophilin from Lactobacillus pentosus against Staphylococcus aureus and Escherichia coli. Front. Microbiol. 2016, 34, 71-79. [CrossRef]

169. Kishore, R.N.; Sri, A.T.; Anjaneyulu, N.; Ramanikanth, C.; Divya, A.; Sainath, K.; Suri, L.S. Study of the CNS Activities of Mimosa Pudica Linn. in animals model. Indo Am. J. Pharm. Sci. 2017, 4, 760-764. [CrossRef]

170. Mahadevan, M.V.; Ramaswamy, R.S.; Banumathi, V. Mimosa pudica exerts Neuroprotection against MPP+ induced neurotoxicity in SHSY5Y cell lines-An in vitro model of anti-parkinsonism. Int. J. Pharm. Pharm. Sci. 2016, 9, 21-26. [CrossRef]

171. Sumiwi, S.A.; Abdassah, M.; Muthiarani, R.; Krishnan, K.G.; Akhsanitami, R.; Zuhrotun, A.; Levita, J. Inhibition of Uric Acid Formation By Mimosa pudica L. Herb Extract Tablets. Res. J. Pharm. Biol. Chem. Sci. 2017, 8, 236-242.

172. Oliveira, L.M.B.; Macedo, I.T.F.; Vieira, L.S.; Camurça-Vasconcelos, A.L.F.; Tomé, A.R.; Sampaio, R.A.; Louvandini, H.; Bevilaqua, C.M.L. Effects of Mimosa tenuiflora on larval establishment of Haemonchus contortus in sheep. Vet. Parasitol. 2013, 196, 341-346. [CrossRef]

173. Bautista, E.; Calzada, F.; Ortega, A.; Yépez-Mulia, L. Antiprotozoal activity of flavonoids isolated from Mimosa tenuiflora (Fabaceae-Mimosoideae). J. Mex. Chem. Soc. 2011, 55, 251-253.

174. Santos, E.A.d.; Carvalho, C.M.d.; Costa, A.L.S.; Conceicao, A.S.; Moura, F.P.; Santana, A.E.G. Bioactivity evaluation of plant extracts used in indigenous medicine against the snail, Biomphalaria glabrata, and the larvae of Aedes aegypti. Evid. Based Complement. Alternat. Med. 2012, 9, 846583. [CrossRef]

175. Shamsuddini, S.; Rajab Alian, S.; Mirzayi, M.; Boroufiei, M. Efficacy of Mimosa tenuiflora extract on growth of Leishmania protozoa in vitro. Iran. J. Dermatol. 2006, 9, 173-178.

176. Surendra Kumar, M.; Akshaya, M.; Irfana, C.P.; Rajpriya, U.; Shabeerali, A.; Babu, G. Evaluation of Mimosa Pudica Linn and Discorea alata Linn for its larvicidal activity. World J. Pharm. Pharm. Sci. 2016, 5, 1967-1970.

177. Brito, D.R.B.; Costa-Júnior, L.M.; Garcia, J.L.; Torres-Acosta, J.F.J.; Louvandini, H.; Cutrim-Júnior, J.A.A.; Araújo, J.F.M.; Soares, E.D.S. Supplementation with dry Mimosa caesalpiniifolia leaves can reduce the Haemonchus contortus worm burden of goats. Vet. Parasitol. 2018, 252, 47-51. [CrossRef] [PubMed]

178. Edem Ekpenyong, E.; Linus Anderson, E.; Adewale Abdullateef, T.; Adebanji Modupe, A.; Kunlere, O. The impact of Mimosa Pudica on the Histoarchitecture -pituitary-testicular axis cadium treated rats. World J. Pharm. Pharm. Sci. 2015, 4, 169-179.

179. Shorinwa Olusayo, A.; Nnamdi, E.; Afieroho Ozadheoghene, E. Evaluation of Mimosa Pigra roots on Haematological and biochemical parameters of Albino rats. Int. J. Curr. Res. 2016, 7, 15577-15581. [CrossRef]

180. Monçao, N.B.N.; Costa, L.M.; Arcanjo, D.D.R.; Araújo, B.Q.; Lustosa, M.C.G.; da França Rodrigues, K.A.; de Amorim Carvalho, F.A.; Costa, A.P.R.; Citó, A.M.d.G.L. Chemical constituents and toxicological studies of leaves from Mimosa caesalpiniifolia Benth., a Brazilian honey plant. Pharmacogn. Mag. 2014, 10, S456. [CrossRef]

181. Silva, V.A.; Gonçalves, G.F.; Pereira, M.S.; Gomes, I.F.; Freitas, A.F.; Diniz, M.F.; Pessôa, H.L. Assessment of mutagenic, antimutagenic and genotoxicity effects of Mimosa tenuiflora. Rev. Bras. Farmacogn. 2013, 23, 329-334. [CrossRef] 
182. Medeiros, R.M.T.; de Figueiredo, A.P.M.; Benício, T.M.A.; Dantas, F.P.M.; Riet-Correa, F. Teratogenicity of Mimosa tenuiflora seeds to pregnant rats. Toxicon 2008, 51, 316-319. [CrossRef] [PubMed]

183. Pimentel, L.E.A.; Correa, F.R.; Gardner, D.; Panter, K.E.; Dantas, A.F.M.; Medeiros, R.M.T.; Mota, R.A.; Araújo, J.A.S. Mimosa tenuiflora as a cause of malformations in ruminants in the Northeastern Brazilian semiarid rangelands. Vet. Pathol. 2007, 44, 928-931. [CrossRef] [PubMed]

184. Correa, F.; Medeiros, R.; Tokarnia, C.; Döbereiner, J. Toxic Plants for Livestock in Brazil: Economic Impact, Toxic Species, Control Measures and Public Health Implications; Poisonous Plants: Global Research and Solutions; CAB International: Wallingford, UK, 2007; pp. 2-14. [CrossRef]

185. Dantas, A.F.M.; Riet-Correa, F.; Medeiros, R.M.T.; Lopes, J.R.; Gardner, D.R.; Panter, K.; Mota, R.A. Embryonic death in goats caused by the ingestion of Mimosa tenuiflora. Taxicon 2012, 59, 555-557. [CrossRef]

186. Gardner, D.; Riet-Correa, F.; Lemos, D.; Welch, K.; Pfister, J.; Panter, K. Teratogenic effects of Mimosa tenuiflora in a rat model and possible role of N-methyl-and N, N-dimethyltryptamine. J. Agric. Food Chem. 2014, 62, 7398-7401. [CrossRef] [PubMed] 